OPEN ACCESS

Edited by:

Balázs Pál,

University of Debrecen, Hungary

Reviewed by:

Yuriy Pankratov,

University of Warwick,

United Kingdom

Mario Valentino,

University of Malta, Malta

${ }^{*}$ Correspondence:

Miroslava Anderova

miroslava.anderova@iem.cas.cz

Received: 29 November 2019

Accepted: 21 February 2020

Published: 19 March 2020

Citation:

Belov Kirdajova D, Kriska J,

Tureckova $J$ and Anderova M (2020) Ischemia-Triggered Glutamate Excitotoxicity From the Perspective of

Glial Cells.

Front. Cell. Neurosci. 14:51. doi: 10.3389/fncel.2020.00051

\section{Ischemia-Triggered Glutamate Excitotoxicity From the Perspective of Glial Cells}

\author{
Denisa Belov Kirdajova ${ }^{1,2}$, Jan Kriska ${ }^{1,2}$, Jana Tureckova ${ }^{1}$ and Miroslava Anderova ${ }^{1,2 *}$ \\ ${ }^{1}$ Department of Cellular Neurophysiology, Institute of Experimental Medicine, Academy of Sciences of the Czech Republic \\ (ASCR), Prague, Czechia, ${ }^{2}$ Second Faculty of Medicine, Charles University, Prague, Czechia
}

A plethora of neurological disorders shares a final common deadly pathway known as excitotoxicity. Among these disorders, ischemic injury is a prominent cause of death and disability worldwide. Brain ischemia stems from cardiac arrest or stroke, both responsible for insufficient blood supply to the brain parenchyma. Glucose and oxygen deficiency disrupts oxidative phosphorylation, which results in energy depletion and ionic imbalance, followed by cell membrane depolarization, calcium $\left(\mathrm{Ca}^{2+}\right)$ overload, and extracellular accumulation of excitatory amino acid glutamate. If tight physiological regulation fails to clear the surplus of this neurotransmitter, subsequent prolonged activation of glutamate receptors forms a vicious circle between elevated concentrations of intracellular $\mathrm{Ca}^{2+}$ ions and aberrant glutamate release, aggravating the effect of this ischemic pathway. The activation of downstream $\mathrm{Ca}^{2+}$-dependent enzymes has a catastrophic impact on nervous tissue leading to cell death, accompanied by the formation of free radicals, edema, and inflammation. After decades of "neuron-centric" approaches, recent research has also finally shed some light on the role of glial cells in neurological diseases. It is becoming more and more evident that neurons and glia depend on each other. Neuronal cells, astrocytes, microglia, NG2 glia, and oligodendrocytes all have their roles in what is known as glutamate excitotoxicity. However, who is the main contributor to the ischemic pathway, and who is the unsuspecting victim? In this review article, we summarize the so-far-revealed roles of cells in the central nervous system, with particular attention to glial cells in ischemiainduced glutamate excitotoxicity, its origins, and consequences.

Keywords: ischemic pathway, glutamate excitotoxicity, glutamate uptake/release, cell death, astrocytes, oligodendrocytes, NG2 glia, glutamate receptors and transporters

\section{INTRODUCTION}

Glutamate excitotoxicity is a cell death mechanism triggered by excessive glutamate release from neurons as well as glial cells. It was described almost 50 years ago as "a certain kind of regionally specific neuropathology" in the hypothalamus of infant mice (Olney, 1971). Glutamate excitotoxicity may develop during numerous events; as a secondary injury after traumatic injury (Park et al., 2008), during various brain pathologies, such as Alzheimer's (Tannenberg et al., 2004), Parkinson's (Verma et al., 2018), or Huntington's disease (Warby et al., 2008; Girling et al., 2018) or during ischemia, which is the main topic of this review article. Despite the different etiology of brain 
damage, strikingly similar consequent events are triggered (Bramlett and Dietrich, 2004; Amani et al., 2019), which could possibly lead to the development of a common treatment for a number of disorders in the central nervous system (CNS). Under physiological conditions, neuronal cells heavily depend on glia. Astrocytes, the most abundant glial cell type in the brain, have many functions, as they scavenge neurotransmitters, shuttle metabolites and maintain homeostasis in the CNS. However, during ischemia, they fail to carry out these functions and become a threat to the adjacent neurons. Thus, glial cells can act as defenders of the CNS as well as initiators and propagators of ischemic injury (Takano et al., 2009).

\section{ISCHEMIA}

Ischemia is a medical condition in which poor blood flow to the tissue causes oxygen and glucose deprivation (OGD), both leading to cell death (Puig et al., 2018). A fall in the number of neurons, followed by a decrease in the counts of glia is apparent especially in the brain parenchyma, due to its high demand for aerobic metabolism. The adult human brain represents a relatively small proportion of the body weight ( $\sim 2 \%$ ), but it accounts for more than $20 \%$ of the whole body energy budget (Doyle et al., 2008). Normal cerebral blood flow (CBF) is approximately $50 \mathrm{ml} / 100 \mathrm{~g} / \mathrm{min}$ and ischemia occurs when the $\mathrm{CBF}$ drops under $40 \%$ of its physiological values (Baron, 2001; Heiss et al., 2004). When below a CBF of $10 \mathrm{ml} / 100 \mathrm{~g} / \mathrm{min}$, rapid irreversible damage to neurons and oligodendrocytes ensues (Matsumoto et al., 1990; Baltan, 2016). The typical symptoms of brain ischemia range from mild to severe and may encompass dizziness, impairments in vision and body movement, difficulty speaking, coordination issues, and unconsciousness (Nadarajan et al., 2014). Ischemic stroke is one of the leading causes of mortality worldwide, surpassed only by cancer and cardiovascular diseases (Doyle et al., 2008). It is estimated that the lifetime risk of cerebral stroke is at 1 in 6 middle-aged (55-75-year-old) adults (Seshadri et al., 2006) and the death rates are lower in more developed countries, with $\sim 15 \%$ mortality (Marini et al., 1999). According to the location and extent of the injury, ischemia can be divided into two subtypes: focal and global. Focal cerebral ischemia (FCI) is caused by the occlusion of specific arteries of the brain, while global cerebral ischemia (GCI) stems from an overall decrease in blood flow (Yao et al., 2018).

\section{Focal Cerebral Ischemia}

As the name suggests, FCI (or stroke) is confined to a locally defined region of the brain. and is caused by thrombosis, or embolism (VanGilder et al., 2012). In the affected area of nervous tissue close to the occluded vessel, two distinct zones can be distinguished: infarction core (a zone of severe ischemia) and penumbra (a zone of moderate ischemia; Rossi et al., 2007), and the size of both of these zones is almost equivalent (Ginsberg, 2003); however, as the ischemic injury progresses, the penumbra becomes "devoured" by the ischemic core (Zhao et al., 1997). The infarction core is characterized by a lack of adenosine triphosphate (ATP), pathological concentrations of ions, high concentrations of glutamate and tissue acidosis. Cell death occurs within the first minutes after the onset of ischemic injury (Wetterling et al., 2016), partially due to the inability of compromised astrocytes to deliver nutrients to neurons (Chisholm and Sohrabji, 2016). Nevertheless, it is necessary to mention that in the ischemic core, also surviving and even newly formed viable neurons have been detected (Zhang et al., 2017). On the contrary, there is a residual blood flow in the penumbra due to the presence of collateral arteries (Harukuni and Bhardwaj, 2006; Jung et al., 2017), with only lowered concentrations of ATP, to some extent maintained ionic concentrations, recurrent episodes of cortical spreading depression (or peri-infarct depolarization; Hinzman et al., 2015; Oliveira-Ferreira et al., 2019), and apoptosis as typical cellular death (Rossi et al., 2007; Doyle et al., 2008; Figure 1). Moreover, glial elements, astrocytes and NG2 glia, in this area form the so-called glial scar that prevents detrimental compounds from entering the spared nervous tissue (Adams and Gallo, 2018), while NG2 cells also display a multipotent differentiation potential (Honsa et al., 2012). Despite the substantial cessation of the $\mathrm{CBF}$ in the penumbra, the levels of glucose metabolism remain constant due to elevated glucose utilization; however, a normal rate of glucose production is maintained for only $\sim 1 \mathrm{~h}$ from the onset of FCI (Belayev et al., 1997).

\section{Global Cerebral Ischemia}

GCI results from transient cardiac arrest causing a systemic and complete cessation of blood flow in the whole parenchyma of the brain (Harukuni and Bhardwaj, 2006), which then diminishes the number of neuronal and glial cells and reduces the integrity of the blood-brain barrier (BBB; Sanganalmath et al., 2017). This type of ischemic injury is characterized by delayed neuronal death (Guo et al., 2019) in specific brain regions of the brain (Kirino and Sano, 1984; Anderova et al., 2011) and by the proliferation and activation of glial cells (Anderova et al., 2011). Moreover, GCI increases the expression of calcium-permeable ion channels in astrocytes, which may influence the output of the ischemic insult (Butenko et al., 2012). The events occurring during GCI are very similar to those found in the core of FCI. While the restoration of CBF is essential for the protection of spared brain tissue (DuránLaforet et al., 2019), reperfusion may also bring more $\mathrm{Ca}^{2+}$, causing further damage (Unal-Cevik et al., 2004; Harukuni and Bhardwaj, 2006; Kauppinen and Swanson, 2007). The disruption of the $\mathrm{BBB}$, caused partly by astrocyte dysfunction, may also complicate the situation (Kahles et al., 2007), causing vasogenic edema and extensive compression of the brain (Thompson and Ronaldson, 2014).

\section{Phases of Ischemia}

Ischemic injury may be manifested to various extents, depending on the duration of blood flow cessation (Heiss et al., 2004). Mild ischemia (CBF greater than $30 \mathrm{ml} / 100 \mathrm{~g} / \mathrm{min}$ ) does not normally cause cell death during the first $6 \mathrm{~h}$ after injury, moderate ischemia (CBF between 12 and $30 \mathrm{ml} / 100 \mathrm{~g} / \mathrm{min}$ ) 


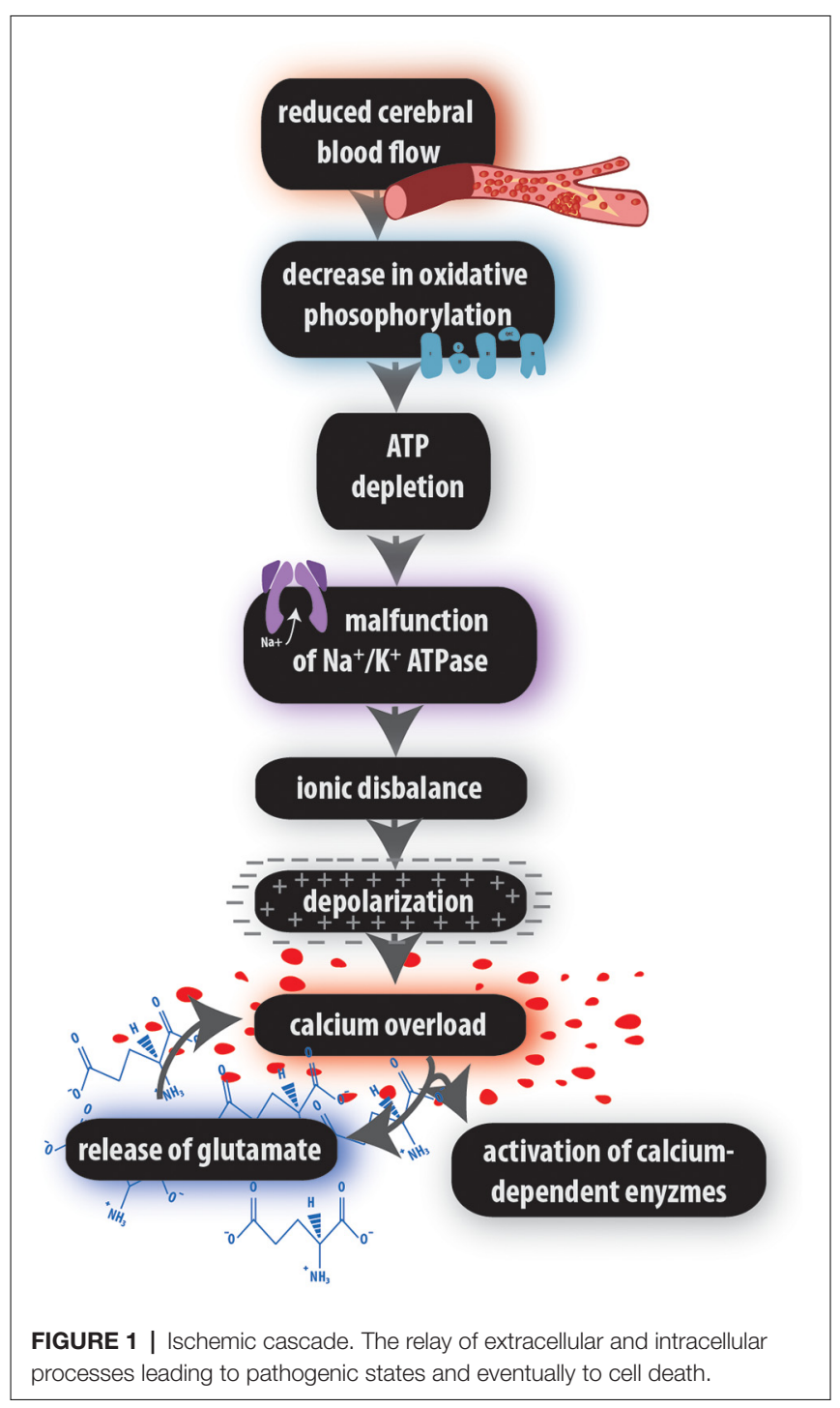

reaches the threshold of viability in $3 \mathrm{~h}$, and severe ischemia (CBF lower than $12 \mathrm{ml} / 100 \mathrm{~g} / \mathrm{min}$ ) causes cell death in less than an hour (Sakoh et al., 2000). As ischemia progresses, it can be further divided into three phases according to the events occurring in the affected tissue: acute (or initial), subacute (intermediate), and chronic (late) phase (Andreeva et al., 2014). In the acute ischemic phase, the tissue is affected by a sequence of molecular and cellular events due to a decrease in the CBF. This sequence of events is called the ischemic pathway, which begins with energy depletion and glutamate excitotoxicity, and ends in cell death (Lai et al., 2014; Cuartero et al., 2016; Figure 1). According to the changes in membrane potential, the most vulnerable cells to 30 -min OGD are neurons, followed by astrocytes, while NG2 glia showed no significant pathological alterations (Du et al., 2018). Moreover, microglial cells are least vulnerable to ischemia because they express glutamate receptors only after the onset of pathological conditions when they become reactive (Gottlieb and Matute, 1997). During the subacute phase (24-72 h after the stroke onset), vasogenic edema begins (Wetterling et al., 2016). However, weeks after the onset of ischemia, the chronic phase leads to additional tissue damage and may be the result of delayed neurodegeneration triggered by oxidative stress and immune activation. All three phases of ischemic injury are characterized by specific patterns of gene expression (Andreeva et al., 2014), and whereas neuronal necrosis occurs early in the ischemic pathway and negatively affects neighboring neurons and glia, delayed neuronal death emerges several days or even weeks after primary damage due to apoptosis (Du et al., 1996; Zhang J. et al., 2012).

\section{Ischemic Pathway}

Ischemic injury is usually studied in the adult mammalian brain at the cellular as well as the molecular level (Rossi et al., 2007). Morphological changes, occurring during the activation of microglia and astrocytes, or higher proliferation of NG2 glia, microglia and astrocytes are all hallmarks of ischemia (Davalos et al., 2005; Pforte et al., 2005; Burns et al., 2009; Anderova et al., 2011). Another set of pathogenic events, the aforementioned ischemic pathway (Figure 1), takes place in the nervous tissue affected by ischemia (Amantea et al., 2018). Such a series of biochemical processes is a typical consequence of cardiac arrest or stroke. From minutes up to days after ischemic injury, neurons and glia in the affected area die due to the presence of detrimental chemical compounds activated over time. This mostly linear relay of cellular events starts with a low supply of oxygen and glucose, while oxygen insufficiency completely disrupts mitochondrial oxidative phosphorylation (Erecińska and Silver, 2001). As most of the energy formed in the brain is due to glucose oxidation to carbon dioxide and water (Rama and García, 2016), its absence causes ATP depletion within only a few minutes, which is the result of no long-term energy stores in the brain (Doyle et al., 2008). The lack of ATP hampers the physiological function of ion pumps and, as the cells fail to maintain electrochemical gradients, it results in depolarization due to the aberrant influx of sodium ions $\left(\mathrm{Na}^{+}\right)$and $\mathrm{Ca}^{2+}$ into the cell, accompanied by potassium ion $\left(\mathrm{K}^{+}\right)$efflux. The elevated extracellular concentration of $\mathrm{K}^{+}$causes the opening of L-type voltage-gated $\mathrm{Ca}^{2+}$ channels (Luoma et al., 2011). Ion pumps and exchangers are unable to keep up with the increasing concentrations of $\mathrm{Ca}^{2+}$, which is not pumped out of the cell, and high $\mathrm{Ca}^{2+}$ levels trigger the release of glutamate, a major contributor to ischemia-induced excitotoxicity in neurons and glial cells (Papazian et al., 2018; Verma et al., 2018; Figure 1). This excitatory amino acid acts as a neurotransmitter and binds to glutamate receptors, of which opening leads to additional $\mathrm{Ca}^{2+}$ entry into the lumen of the cell. A sustained activation of $\mathrm{Ca}^{2+}$-permeable channels due to an impaired glutamate uptake by astrocytes (Mori et al., 2004) leads to a pathological increase in intracellular $\mathrm{Ca}^{2+}$ $\left(\left[\mathrm{Ca}^{2+}\right]_{\mathrm{i}}\right)$ and overexcites the cells which in turn release harmful substances, such as reactive oxygen species (ROS; Sattler et al., 1999) or ATPases, endonucleases, proteases, and phospholipases that belong to a group of $\mathrm{Ca}^{2+}$-dependent degradative enzymes. Once the cellular membrane is disrupted by phospholipases, more detrimental chemicals enter the cell, eventually causing the 
release of apoptotic signals from mitochondria and triggering the caspase-dependent cascade, which leads to the death of cells (Rebai and Amri, 2018; Figure 2). Moreover, another type of detrimental signals spreads from dying cells to viable glia and neurons. The so-called peri-infarct depolarizations are probably triggered by neuronal and glial release of glutamate, which increases inward currents and thus depolarizes cells (Hossmann, 1996; Somjen, 2001; Hartings et al., 2017), and occur in the surroundings of the lesions caused by FCI, beginning in the ischemic core and propagating to the spared regions of nervous tissue (Hossmann, 1996). These recurrent waves of increased concentrations of $\mathrm{K}^{+}$and astrocytic $\mathrm{Ca}^{2+}$ cause cytotoxic edema (Hartings et al., 2017) and may potentially result in terminal depolarizations and falls in perfusion, causing secondary expansion of the infarct core at the expense of the penumbral region (Strong et al., 2007; Hinzman et al., 2015; Rakers and Petzold, 2017).

\section{GLUTAMATE}

As already mentioned, glutamate is the driving force of ischemiainduced excitotoxicity. It is the most abundant free amino acid in the CNS, acting as an excitatory neurotransmitter (Pinky et al., 2018). Additionally, under physiological conditions, it plays an important role in learning and memory (Marmiroli and Cavaletti, 2012) and glutamate released from astrocytes synchronizes the activity of hippocampal neurons (Angulo et al., 2004). A large proportion of glutamate in the body comes from the diet; however, it is unable to cross the $\mathrm{BBB}$ and must be generated by the resident cells in the CNS. For this reason, this compound is synthesized from its precursor alpha-ketoglutarate, a key molecule in the Krebs cycle (Mark et al., 2001; Rowley et al., 2012). Glutamate is also recycled from glutamine, produced by glial cells in the glutamate-glutamine cycle (Diaz-Ruiz et al., 2016; Hu et al., 2018). In normal synaptic communication, neuronal cells release glutamate from the presynaptic terminals of the axon into the synaptic cleft. The quanta of glutamate accumulated in the extracellular space (ECS) activate glutamate receptors on the surface of postsynaptic terminals (Rowley et al., 2012). Nevertheless, the extracellular levels of glutamate require a tight physiological regulation in order to maintain optimal neuronal excitation and, at the same time, to restrain its excitotoxic effect. The maintenance of glutamate homeostasis largely relies on the activity of astrocytic transporters that under physiological conditions clear glutamate from the synaptic

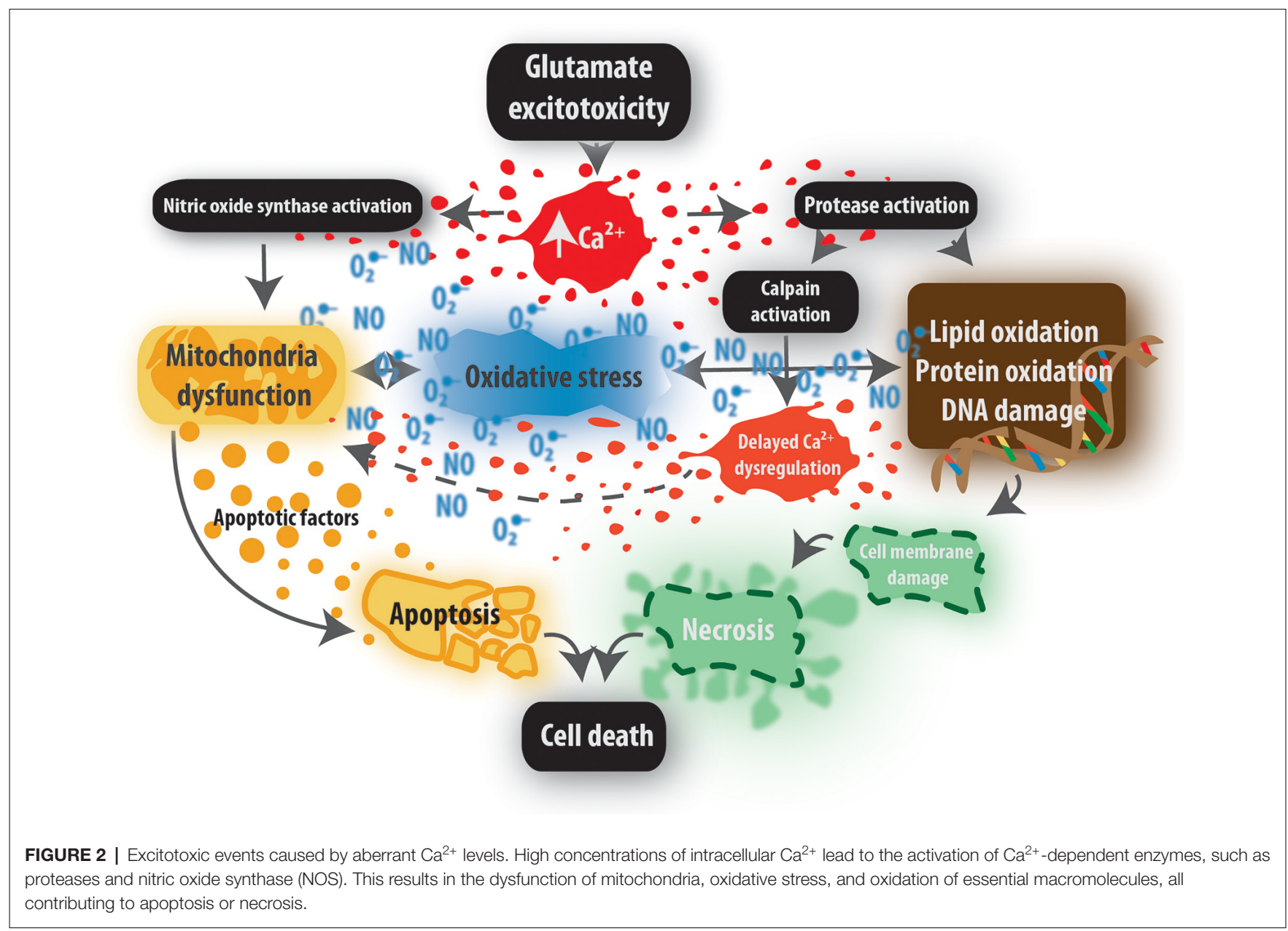


cleft (Bylicky et al., 2018). However, in pathological conditions such as ischemia/reperfusion injury (Volterra et al., 1994; Harvey et al., 2011; Zhang et al., 2019), or during aging (Lewis et al., 2012), the activity of glial glutamate transporters ceases and the abundance of glutamate may damage the surrounding nervous tissue and hamper normal brain functions. Moreover, proinflammatory cytokine tumor necrosis factor $\alpha$ $(\mathrm{TNF} \alpha)$ increases the astrocytic expression of glutaminase, which converts glutamine back to glutamate. Since astrocytes are the principal glutamine factory in the CNS, the effect of TNF $\alpha$ counteracts their main mission and serves as a mediator in excitotoxicity-promoting events during inflammation (Milewski et al., 2019). The dysfunction of glutamatergic neurotransmission results in neuronal excitotoxicity, meaning that glutamate excites cells to their death.

\section{GLUTAMATE RECEPTORS}

The release of glutamate is followed by the activation of its postsynaptic receptors. These receptors are of two kinds: ionotropic or metabotropic (mGluRs). Ionotropic, or ligandgated, receptors are divided into two groups: N-methylD-aspartate (NMDA) receptors and non-NMDA receptors, and further classified into three classes, depending on the specific agonist (Atoji and Sarkar, 2019) that binds to the particular receptor: NMDA receptors, $\alpha$-amino-3-hydroxy5-methyl-4-isoxazolepropionic acid (AMPA) receptors, and kainate receptors. The excitotoxic injury is mediated mainly via glutamate receptors of the NMDA class (Gupta et al., 2013; Girling et al., 2018). Metabotropic receptors are coupled to heterotrimeric guanine nucleotide-binding $(G)$ proteins that relay the signal to its effector channels or intracellular enzymes. These receptors are also divided into three categories, depending on the G proteins they utilize; group I is excitatory (Feng et al., 2019), while groups II and III are inhibitory (Price et al., 2005; Blackshaw et al., 2011). Group-I receptors signal through protein kinase $\mathrm{C}$ and phospholipase $\mathrm{C}$, while the latter produces inositol triphosphate. This molecule binds to receptors located on the endoplasmic reticulum, resulting in the $\mathrm{Ca}^{2+}$ release into the lumen of the cell (Ribeiro et al., 2010). The inhibitory mGluRs influence adenylyl cyclase that converts ATP to its cyclic form, $3^{\prime}, 5^{\prime}$-cyclic adenosine monophosphate (cAMP), which normally activates protein kinase A (Pin and Duvoisin, 1995). Ionotropic receptors form an ion channel pore and, after the ligand binds to their extracellular domain, the ion channel opens and thus allows the influx of positively charged ions $\left(\mathrm{Na}^{+}\right.$, $\left.\mathrm{Ca}^{2+}\right)$. This causes depolarization of the cell membrane, action potential progression, and the release of neurotransmitters from the presynaptic terminals (Mark et al., 2001). Under normal conditions, NMDA receptors are blocked by $\mathrm{Mg}^{2+}$ ions. These ions are expelled only after depolarization of the cell, which is achieved by the activation of the non-NMDA receptors that do not possess the $\mathrm{Mg}^{2+}$ block. After the ligand binds to its non-NMDA receptor, the channel opens immediately, allowing positive ions (mainly $\mathrm{Na}^{+}$) to flow into the cell. Once the $\mathrm{Mg}^{2+}$ block is removed from the NMDA receptor, glutamate is able to open the channel and large quantities of $\mathrm{Ca}^{2+}$ flow into the cell (Dzamba et al., 2013). Ionotropic receptors of the NMDA type have also been identified on the membranes of astrocytes and oligodendrocytes. Interestingly, these receptors are devoid of $\mathrm{Mg}^{2+}$ block and can be thus activated without antecedent depolarization (Salter and Fern, 2005; Lalo et al., 2006). Moreover, glial NMDARs contain GluN3A receptor subunit, which lowers $\mathrm{Ca}^{2+}$ permeability (Burzomato et al., 2010; Palygin et al., 2011); however, their permeability to $\mathrm{Na}^{+}$ is substantial (Pachernegg et al., 2012) and causes swelling of glial cells, which may aggravate ongoing excitotoxicity during ischemia. Glial cells also possess non-NMDA ionotropic glutamate receptors that were found mainly in oligodendrocytes and astrocytes (Matute et al., 2002). AMPA receptors are composed of 4 subunits, of which the GluR2 subunit determines the $\mathrm{Ca}^{2+}$ permeability (Park et al., 2008). Interestingly, TNF $\alpha$, present at the site of injury (Crespo et al., 2007), increases the synaptic levels of GluR2-lacking receptors and therefore exacerbates the excitotoxic damage (Stellwagen et al., 2005). Moreover, dysfunctional signaling via group I mGluRs is thought to lead to defective internalization of GluR2-containing AMPA receptors, which may also influence the permeability of the cellular membrane to $\mathrm{Ca}^{2+}$ (Feng et al., 2019). Hyperactivation of glutamate receptors, caused by the surplus of glutamate in the ECS, leads to a massive $\mathrm{Ca}^{2+}$ influx. If the energy supply is sufficient, ion pumps take care of the ion equilibrium in the cells and remove some of the positive ions after they have entered the cell (Piccolini et al., 2013). However, if the energy in the cell is low, the ion pumps do not work properly, which leads to a significant increase in the $\left[\mathrm{Ca}^{2+}\right]_{\mathrm{i}}$ (Kumagai et al., 2019). Such $\left[\mathrm{Ca}^{2+}\right]_{\mathrm{i}}$ increase results in the activation of protein kinases and other downstream $\mathrm{Ca}^{2+}$-dependent enzymes that destroy important molecules and disintegrate the cell membrane, causing further $\mathrm{Ca}^{2+}$ influx to the cells, release of free radicals from damaged mitochondria, and subsequent cell death (Chan, 2001; Kumagai et al., 2019; Figure 2). Additionally, after glutamate exposure, the concentration of the neurotransmitter ATP in the ECS increases, aggravating the NMDA receptor-mediated cell death (Simões et al., 2018). However, ATP also acts as a modulator, since glutamate released during neuronal activity can activate non-NMDA receptors on astrocytes, which triggers the release of ATP (Zhang et al., 2003). This molecule is released from astrocytes predominantly through connexin 43 hemichannels (Cx43; Kang et al., 2008) and suppresses glutamatergic synapses through presynaptic P2Y receptors (Zhang et al., 2003) or synaptic P2X receptors (Lalo et al., 2016). Here, astrocytes and astrocytic ATP perform as saviors of the CNS, while a similar function has been attributed also to adenosine, which is a product of ATP, released also by glial cells (Zhang et al., 2003). Neurotransmitter receptors for ATP and glutamate are necessary also for oligodendrocyte differentiation and myelination; however, their overactivation during ischemia results in $\mathrm{Ca}^{2+}$ overload and mitochondrial dysfunction, which leads to white matter injury. In the view of the fact that white matter is more susceptible to ischemiainduced excitotoxicity (Doyle et al., 2018), especially in striatal white matter of adult individuals (Ahrendsen et al., 2016), oligodendrocytes and NG2 glia should be considered as primary 
therapeutic targets under hypoxic conditions (Mifsud et al., 2014; Dai et al., 2020).

\section{GLUTAMATE TRANSPORTERS}

Glutamate uptake via EAATs serves as a major mechanism for regulating the extracellular concentration of glutamate and preventing glutamate excitotoxicity. Glutamate uptake is mainly accomplished by astrocytes which either convert glutamate to glutamine or feed it into their own metabolism. Normally, the astrocytic glutamate transporters are indirectly involved in the synaptic transmission termination by regulating the availability of glutamate for postsynaptic neuronal receptors. Moreover, they regulate the neurotransmitter release by controlling the amount of glutamate that reaches the presynaptic receptors. Finally, the astrocytic glutamate uptake protects neurons from hyperexcitability and subsequent excitotoxic damage by maintaining extracellular glutamate concentration under neurotoxic levels.

Although there are several membrane proteins capable of transporting glutamate, only members of EAAT are usually named as "glutamate transporters." This name suggests that EAATs transport not only glutamate but also other excitatory amino acids. Five members of the family have been cloned and classified in the mammalian brain tissue-EAAT1-5. According to the solute carrier (SLC) terminology, EAAT1 corresponds to Slc1a3, EAAT2 corresponds to Slcla2, EAAT3 to Slcla1, EAAT4 to Slcla6, and EAAT5 to Slcla7 (Kanai and Hediger, 2004). In rodents, the EAAT1 analog has been termed as GLAST, EAAT2 as GLT-1 and EAAT3 as EAAC1.

The EAATs have been categorized as glial and neuronal, where the glial subfamily includes EAAT1 and EAAT2 and the neuronal subfamily consists of EAAT3-5. Nevertheless, the neuronal EAAT2 expression at the mRNA level was demonstrated quite a long time ago (Torp et al., 1997). The question of whether the neuronal expression has any functional relevance was partially answered by Petr and co-authors (Petr et al., 2015) who studied the function of EAAT2 expressed in excitatory synapses, employing conditional knockouts. Moreover, the contribution of presynaptic EAAT2 to the glutamate uptake has been acknowledged in hippocampal neurons (Furness et al., 2008).

The expression pattern of EAATs significantly differs in various brain regions. EAAT1 is preferably expressed in the cerebellum (Lehre and Danbolt, 1998) and a number of smaller regions, such as the inner ear (Takumi et al., 1997; Furness et al., 2008) the retina (Rauen et al., 1996; Lehre et al., 1997), and circumventricular organs (Berger and Hediger, 2000). In other CNS regions, EAAT2 prevails and is thus the major transporter responsible for glutamate uptake (Lehre and Danbolt, 1998). EAAT1 is often co-expressed with EAAT2, but they do not form hetero-oligomeric complexes. A higher density of EAAT1 and EAAT2 has been detected in membranes facing nerve terminals, axons and spines rather than in membranes facing capillaries, pia and stem dendrites (Chaudhry et al., 1995). Moreover, the expression pattern of EAATs changes during development. While EAAT1 predominates during the early development in radial glia and immature astrocytes, EAAT2 predominates in adulthood (Shibata et al., 1997; Kugler and Schleyer, 2004).

Similarly, neuronal transporters EAAT3 dominate in the hippocampus, while EAAT4s are abundantly expressed in cerebellar Purkinje cells (Furuta et al., 1997; Shashidharan et al., 1997; Dehnes et al., 1998; Massie et al., 2008). Both EAAT3 and EAAT4 are typically localized on the neuronal somas and dendrites and are not present on axonal terminals. EAAT5 is thought to be a retinal glutamate transporter and has not been identified in the brain so far (Eliasof et al., 1998).

The uptake of glutamate via EAATs is driven by the cotransport of $3 \mathrm{Na}^{+}$and $1 \mathrm{H}^{+}$, followed by the counter-transport of $\mathrm{K}^{+}$. This stoichiometry provides enough energy for active glutamate transport into the cell against the steep concentration gradient. Positive charge entering the cell is compensated by an uncoupled flux of chloride ions $\left(\mathrm{Cl}^{-}\right)$, thus the transporters also function as chloride channels (Fairman et al., 1995; Wadiche et al., 1995). Through this mechanism, L-glutamate, L- and Daspartate, but not D-glutamate, can be transported (Drejer et al., 1982; Bender et al., 1998). Additionally, transmembrane domains of EAATs may form a water-permeable pore and thus they also contribute to water transport (MacAulay et al., 2001).

Since, EAATs play an essential role in regulating glutamatergic synapses, there are many neurological disorders that are related to the impaired activity of glutamate transport. During ischemia, insufficient energy supply results in decreased activity of $\mathrm{Na}^{+} / \mathrm{K}^{+}$ATPase, which in turn causes a disruption of $\mathrm{Na}^{+}$and $\mathrm{K}^{+}$transmembrane gradients. Since glutamate transport via EAATs is coupled to the cotransport of $\mathrm{Na}^{+}$ and $\mathrm{K}^{+}$, the impairment of ion gradient leads to a reduced capacity of the EAATs and elevated extracellular glutamate concentrations. Finally, the ion gradient disruption may cause a reversal of transporter functioning, which contributes to an additional increase of glutamate levels in the ECS (Allen et al., 2004). The impairment of glutamate transport after ischemic injury contributes to the accumulation of extracellular glutamate and the neuronal damage associated with excitotoxicity. Therefore, the enhanced expression levels of astroglial glutamate transporters following brain ischemia may underlie the protective reaction triggered by high glutamate levels. Nevertheless, the results of studies analyzing changes in EAAT expression following an ischemic brain injury are inconsistent. The upregulation of EAAT1 and EAAT2 in the early phases of ischemia and its correlation with neuroprotection have been approved by many (Ganel et al., 2006; Weller et al., 2008; Arranz et al., 2010). On the contrary, other groups observed the downregulation of EAATs in different models of ischemic injury (Fukamachi et al., 2001; Rao et al., 2001; Chen et al., 2005; Moretto et al., 2005).

Although it is generally accepted that astrocytes are the key players in glutamate uptake, which at synapses accounts for about $90 \%$ of total clearance, the contribution of other cell types cannot be overlooked. EAAT1 and EAAT2 are functionally expressed in microglia where they are involved in synaptic glutamate clearance (Noda et al., 1999; Morioka et al., 2008). Their expression enhances in the activated form of microglia following neuronal injuries (López-Redondo et al., 2000) 
and also in brain ischemia (Beschorner et al., 2007). Some studies show that under selected pathological conditions, the expression of astrocytic EAATs is decreased and conversely it increases in activated microglia (Xin et al., 2009). These findings suggest that under such conditions, or in restricted areas, microglia can adopt the role of astrocytes in glutamate uptake. In addition, oligodendrocytes express functional glutamate transporters with properties similar to those observed in astrocytes (Matute et al., 2006). Endothelial cells are another cell type, which significantly contributes to the regulation of extracellular glutamate concentration. These cells form one of the $\mathrm{BBB}$ layers and thus participate in the communication between brain tissue and the vascular system. Three members of the EAAT family, excitatory amino acid transporters 1-3 (EAAT1-3), have been detected in the abluminal membrane of the BBB (O'Kane et al., 1999). In brain pathologies such as ischemia, the increased concentration of extracellular glutamate activates the glutamate uptake via endothelial EAATs. Subsequently, the glutamate may be extruded across the luminal membrane into the bloodstream through another type of glutamate carrier, referred to as facilitative glutamate transporters (Hawkins and Viña, 2016). Finally, at least one study, performed in the retina, described an EAAT-mediated glutamate uptake by another brain cell type-pericytes (Akanuma et al., 2015). A scheme summarizing the mechanism of glutamate uptake in the ischemic CNS is shown in Figure 3.

\section{ISCHEMIC PRECONDITIONING}

Alterations in the expression of glutamate transporters also appear to play a key role in the so-called ischemic preconditioning. This term refers to the cell/tissue adaptation to ischemic conditions after being exposed to "subtoxic" doses of stressors, such as hypo-/hyperoxic preconditioning, hypo/hyperthermia, OGD or pharmacological preconditioning. Preconditioning results in a transient protective phenotype called ischemic tolerance, in which the tissue is more resistant to a subsequent more severe ischemic event. In the neural tissue, this phenomenon was first described in 1990 by Kitagawa and co-authors in several different areas of the gerbil brain (Kitagawa et al., 1990, 1991). Since then, many investigators have been engaged in finding molecular mechanisms that lie beneath the minimization of neuronal damage and the facilitation of regenerative processes. These mechanisms include complex biological cascades that are specific to the applied stimulus and employ both neuronal as well as glial pathways (for review, see Thushara Vijayakumar et al., 2016). These are mainly the immune response that involves the microglial activation of the pro-inflammatory cytokines, such as interleukins $1 \beta$ and 6 (IL-1 $\beta$, IL-6), and TNF $\alpha$ (Karikó et al., 2004), the nitric oxide synthase (NOS) cascade (Gidday et al., 1999) or the activation of certain enzymes, such as stress-activated kinases, cyclooxygenase-2 (COX-2; Iadecola et al., 2001; Colangelo et al., 2004) or sphingosine kinase 2 (SPK-2; Yung et al., 2012). Recent studies have shown that preconditioning can also activate changes at the gene level, which involves activation of molecules, such as transcription factors, transducers, sensors, and effectors, as well as numerous post-translational modifications. Genomic and proteomic analysis of the adult rat brain, following preconditioning induced by a 10 -min transient middle cerebral artery occlusion (MCAO), showed for example upregulation of heat shock proteins or transforming growth factor- $\alpha$ (TGF- $\alpha$; Dhodda et al., 2004).

In addition to these mechanisms, processes activated by increased glutamate concentration also play an important role (for review, see Krzyzanowska et al., 2014). This role includes the activation of NMDA receptors on the one hand and the regulation of EAATs on the other. NMDA activation was reported to mediate neuroprotection by inhibition of stress-activated c-Jun $\mathrm{N}$ terminal kinase (JNK), activation of extracellular signal-regulated kinase (ERK1/2) and protein kinase $B$ (Akt1), and regulation of normal cAMP-responsive elementbinding (CREB) activity (Miao et al., 2005; Soriano et al., 2006). In neuronal cortical cultures, tolerance was achieved with glutamate preconditioning and blocked by NMDA and AMPA receptor antagonists (Lin et al., 2008). Other studies have documented the decreased expression of glutamate receptors, in particular NMDA and AMPA, which reduced the excitotoxicity after ischemic preconditioning (Aizenman et al., 2000; Tanaka et al., 2002; Dave et al., 2005). Similarly, changes in the expression of glial GLT-1 have been also proposed as key mechanisms of ischemic preconditioning (Romera et al., 2007; Zhang et al., 2007; Gong et al., 2012). Moreover, OGD preconditioning performed in neuron/astrocyte co-culture revealed that the reversed operation of astrocytic GLT-1 was crucial to the development of neuronal ischemic tolerance (Kawahara et al., 2005). Recent studies show that GLT-1 expression and function of glutamine synthetase during preconditioning can be maintained via mechanisms including upregulation of $\mathrm{Cx} 43$ and inhibition of cellular kinase Src (Li et al., 2018). Another study suggests that p38 mitogen-activated protein kinase (MAPK) participates in the mediation of astrocytic GLT-1 upregulation during the induction of brain ischemic tolerance after ischemic preconditioning (Zhang et al., 2017).

\section{MECHANISMS OF GLUTAMATE RELEASE-THE CONTRIBUTION OF NEURONS AND GLIAL CELLS}

In the CNS, glutamate is primarily released by excitatory neurons. The major pathway for its release from neurons comprises $\mathrm{Ca}^{2+}$-dependent exocytosis, which underlies fast synaptic transmission and, under physiological conditions, excitatory neurons represent a prime source of glutamate rises in the ECS. As already described above, the clearance of synaptically-released glutamate is one of the most important functions of astrocytes, which impedes glutamate excitotoxicity. Nevertheless, recent studies also point toward astrocytic function in releasing glutamate to the nearby neurons. Therefore, both the uptake and release of glutamate represent a precise mechanism for the fine-tuning of neuronal excitability, synaptic transmission, and plasticity under physiological conditions 


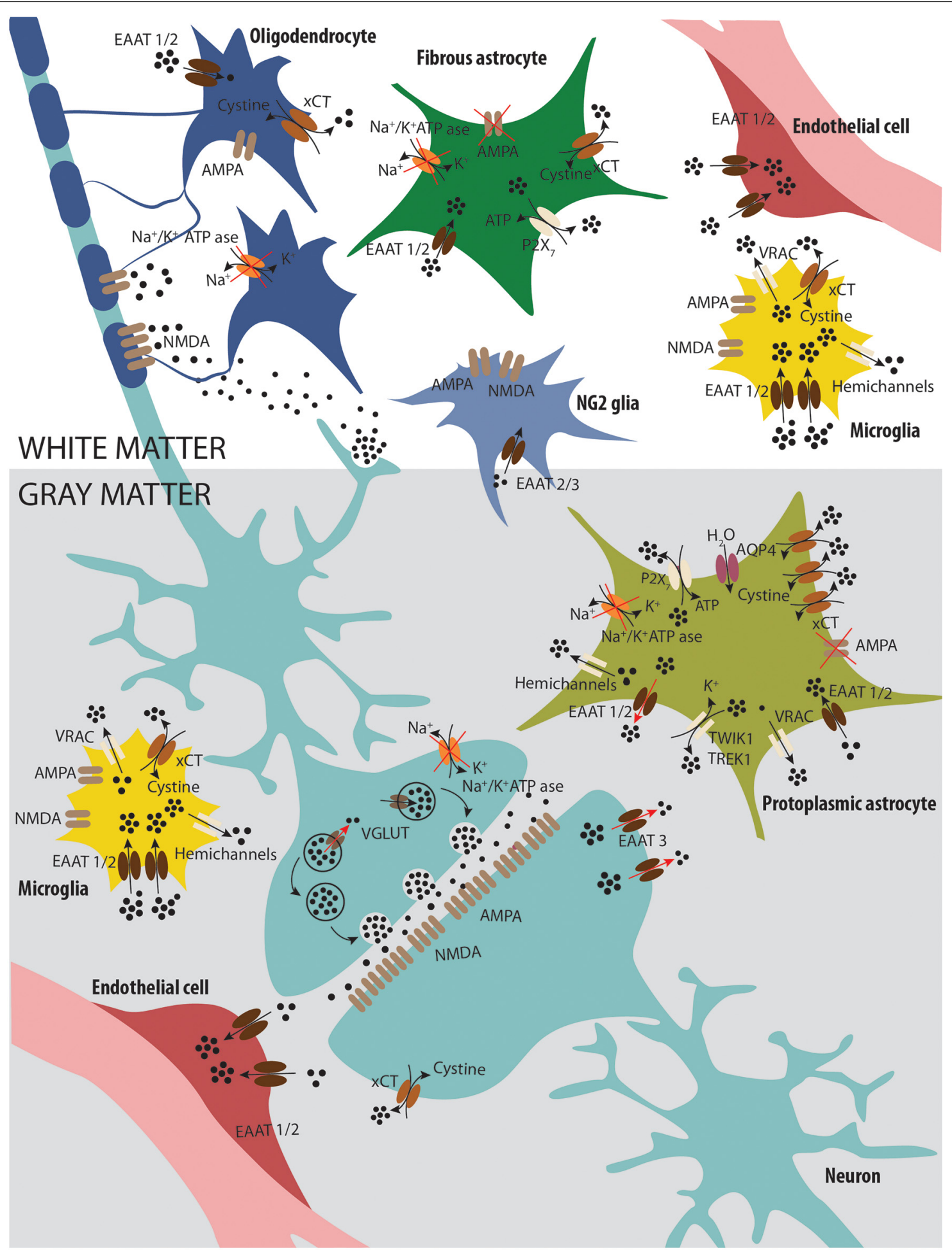

FIGURE 3 | Various cell types in white and gray matter are hives of activity during ischemia-induced glutamate excitotoxicity. The scheme shows the main mechanisms that maintain or disrupt the homeostasis of glutamate (black dots) under ischemic conditions in white and gray matter. The location of individual receptors and transporters, as well as the direction of glutamate fluxes (arrows) in ischemia, are also depicted. In gray matter, glutamate is mainly released either from vesicles or via the reversal of glutamate transporters of neurons and astrocytes. The efflux through transporters is a result of $\mathrm{Na}^{+} / \mathrm{K}^{+} \mathrm{ATPase}$ inhibition and subsequent collapse of the ion gradients. Since the operation of vesicular glutamate transporters (VGLUTs) depends on $\mathrm{H}^{+}$ATPase activity, vesicles lose their glutamate upon adenosine triphosphate (ATP) depletion. The compromised astrocytic uptake of glutamate may be partially compensated by the activity of microglial 
FIGURE 3 | Continued

and endothelial EAATs. Astrocytes and microglia also contribute to the excess of extracellular glutamate by overexpressing cystine/glutamate antiporters.

Other contributors to the glutamate release were identified on the astrocytes, and comprise hemichannels, and TREK and TWIK channels. Swelling of astrocytes due to the activity of AQP4 channels, resulting in brain edema, opens VRACs that release glutamate to the extracellular space (ECS). The means of glutamate release in white matter differ from those identified in gray matter. Excitotoxicity is not enhanced by the reversal glutamate uptake, but via vesicular release from axons, which results in cytotoxic overactivation of myelinic N-methyl-D-aspartate (NMDA) receptors. Higher vulnerability/susceptibility of white matter to ischemia is a consequence of higher expression of AMPA and NMDA receptors on the cells of the oligodendrocytic lineage. Abbreviations: AMPA,

$\alpha$-amino-3-hydroxy-5-methyl-4-isoxazolepropionic acid; AQP4, aquaporin 4; EAAT1-3, excitatory amino acid transporters 1-3; NMDA,

$\mathrm{N}$-methyl-D-aspartic acid or $\mathrm{N}$-methyl-D-aspartate; $\mathrm{P} 2 \mathrm{X}_{7}$, ionotropic purinergic receptor 7; TREK1, two-pore-domain background $\mathrm{K}^{+}$channel; TWIK 1, two-pore-domain $\mathrm{K}^{+}$channel; VGLUT, vesicular glutamate transporter; VRAC, volume-regulated anion channels; $\mathrm{xCT}$, cystine/glutamate antiporter.

(Hamilton and Attwell, 2010; Araque et al., 2014; Gundersen et al., 2015; Allen and Eroglu, 2017). In CNS disorders, such as ischemia, trauma or neurodegeneration, the effective maintenance of glutamate homeostasis usually fails, while the glutamate release from different cellular types wins through, and results in detrimental glutamate excitotoxicity. Considering ischemic injury in the CNS, one should be conscious of the maturity of nervous tissue (perinatal, adult or aged), severity and type of ischemia (global vs. focal), region specificity (gray or white matter; cortex, hippocampus or corpus callosum) and phase of ischemia (acute or late), in which participation of cellular elements in glutamate release may differ. Two main phases were identified in severe cerebral ischemia in vivo (Astrup et al., 1977; Hansen and Nedergaard, 1988; Rossi et al., 2007). The first phase, taking a few minutes, is characterized by a gradual elevation of extracellular $\mathrm{K}^{+}$concentration $\left(\left[\mathrm{K}^{+}\right]_{\mathrm{o}}\right)$, with small changes in the concentration of other principal ions. The second phase is characterized by anoxic depolarization, loss of principal ionic gradients, and glutamate accumulation in the ECS. Furthermore, oxidative stress during post-ischemic reperfusion was proposed as an additional trigger of glutamate release (Tretter and Adam-Vizi, 2002).

\section{Neuronal Part in Glutamate Excitotoxicity}

The main route by which mature axons release glutamate during acute ischemia primarily comprises vesicular release (Figure 3), which has been shown in white matter (Doyle et al., 2018), in cerebral ischemia in vivo (Katayama et al., 1991; Jabaudon et al., 2000), in a slice model of hippocampal ischemia (Andrade and Rossi, 2010), and in an in vitro model of ischemia (Fujimoto et al., 2004; Lee and Kim, 2015). The second route of glutamate release from neurons was described in severe brain ischemic injury by Rossi et al. (2000) who demonstrated that a reversed operation of neuronal glutamate transporters (Figure 3) plays a key role in generating the anoxic depolarization, that eliminates information processing in the CNS a few minutes after the onset of ischemia. However, several events that take place prior to glutamate release were described in the early phase of ischemia. In a slice model of hippocampal ischemia, Andrade and Rossi (2010) identified several early cellular cascades triggered by ischemia, such as $\mathrm{Ca}^{2+}$ entry and release from intracellular stores, actin filament depolymerization, and vesicular release of glutamate, which is dependent on actin dynamics but independent of $\left[\mathrm{Ca}^{2+}\right]_{\mathrm{i}}$ rise. Lee and Kim (2015) showed that the $\mathrm{Ca}^{2+}$ uptake via plasma membrane $\mathrm{Na}^{+} / \mathrm{Ca}^{2+}$ exchanger (NCX) underlies the ischemia-induced $\mathrm{Ca}^{2+}$ rises and the consequent increase in vesicular glutamate release from presynaptic terminals in the early phase of brain ischemia. All of these processes precede the anoxic depolarization by a few minutes.

In the acute phase of ischemia, which is characterized by anoxic depolarization and a massive increase in $\left[\mathrm{Ca}^{2+}\right]_{i}$ mediated by both $\mathrm{Ca}^{2+}$ influx and $\mathrm{Ca}^{2+}$-induced $\mathrm{Ca}^{2+}$ release from intracellular stores, the vesicular release from presynaptic terminals further adds to the glutamate elevation. The importance of vesicular glutamate release from axons and its involvement in ischemia-induced myelin damage was recently documented by Doyle et al. (2018). Their findings contrast with previous reports describing reversal of glutamate uptake as a main contributor to glutamate excitotoxicity under ischemic conditions in the CA1 region of the neonatal hippocampus (Rossi et al., 2000), adult spinal cord (Li et al., 1999) or mouse optic nerve (Baltan et al., 2008). Their direct measurement of extracellular glutamate in white matter gave no evidence for significant ischemia-induced release via reversal of glutamate uptake. Ischemia-induced glutamate release pathways in the white matter of the brain thus clearly differ from those functioning in gray matter regions, such as the hippocampal CA1 or cortex. Doyle et al. (2018) showed that acute ischemic myelin injury is initiated by vesicular release from axons, which results in cytotoxic overactivation of myelinic NMDA receptors comprising GluN2C/D subunits, which are primarily incorporated into extra-synaptic NMDA receptors (Brickley et al., 2003).

We should also mention the cysteine-glutamate exchanger $(\mathrm{xCT})$, which promotes glutathione synthesis by taking up cysteine and releasing glutamate, and which could possibly add to glutamate excitotoxicity evoked by ischemia and, consequently, to the overactivation of extrasynaptic NMDA receptors and neuronal death. In response to OGD, Soria et al. (2014) detected currents in pyramidal cortical neurons of rodent brain slices. These currents were sensitive to the pharmacological inhibition of the xCT but insensitive to the blockade of EAATs or vesicular glutamate release. Furthermore, xCT inhibition significantly attenuated neuronal damage (Soria et al., 2014). Since, xCTs were reported in neurons, but they were also found in astrocytes, oligodendrocytes, and microglia, it needs to be clarified whether $\mathrm{xCT}$-released glutamate is of neuronal or glial origin (Figure 3).

\section{Astrocytes add Significantly to Glutamate Excitotoxicity}

The mechanisms of glutamate release from astrocytes are still a matter of debate, especially in the field studying its role as gliotransmitter, and in conjunction with glutamate 
excitotoxicity in CNS disorders such as ischemia. Several studies suggest that astrocytes release glutamate via $\mathrm{Ca}^{2+}$-dependent vesicular release, by a mechanism analogous to that described in neurons, as reviewed recently by Savtchouk and Volterra (2018). Nevertheless, it is disputed by others, who emphasize that an increase in the astrocyte $\mathrm{Ca}^{2+}$ levels and the resulting glutamate release are non-specific and that astrocytes lack any vesicular release machinery (Barres, 2008; Fiacco and McCarthy, 2018). Furthermore, several non-vesicular release mechanisms have also been described (Nedergaard et al., 2002; Hamilton and Attwell, 2010; Gundersen et al., 2015).

The release of glutamate from vesicles can either be dependent on external $\mathrm{Ca}^{2+}$ or on $\mathrm{Ca}^{2+}$ release from intracellular stores (Bezzi et al., 2001, 2004). The presence of intracellular vesicles containing glutamate, VGLUTs 1 and 2 as well as specific vesicular proteins ( $\mathrm{v}$-SNAREs), were described in astrocytes by several research teams (Bezzi et al., 2004; Montana et al., 2004; Ni and Parpura, 2009; Bergersen et al., 2012). Recently, using single and double v-SNARE knockout mice, Schwarz et al. (2017) have proven that astrocytes express synaptobrevin II and cellubrevin on distinct vesicle populations and mediate glutamate and neuropeptide $\mathrm{Y}$ release through distinct, previously unrecognized, secretion pathways which may be essential in neuron-astrocyte communication. Different experimental strategies that demonstrate a functional role of vesicular release from astrocytes were summarized by Bohmbach et al. (2018).

In cerebral ischemia, the non-vesicular glutamate release in astrocytes is primarily represented by a reversed operation of glutamate transporters, which occurs under the conditions upon intracellular ATP depletion. Since the energy requirements for glutamate uptake are extremely high, the reversal of glutamate transport is preceded by a decline in astrocytic glutamate uptake, which signifies the earliest astrocytic contribution to the development of glutamate excitotoxicity, together with the already reversed glutamate uptake in neurons (Rossi et al., 2000). It was shown that the expression of both glutamate transporters (EAAT1 and EAAT2) in astrocytes is rapidly reduced following hypoxia and ischemia, which leads to further extrasynaptic glutamate accumulation (Sheldon and Robinson, 2007; Ketheeswaranathan et al., 2011). Furthermore, the ATP-dependent conversion of glutamate into glutamine by astrocytic glutamine synthetase turns out to have been impaired during energy failure, thus elevating the intracellular glutamate concentrations in astrocytes, which subsequently leads to reduced glutamate uptake or even enhanced glutamate release by reversed uptake (Lipton and Rosenberg, 1994). As reviewed in detail by Pajarillo et al. (2019), the expression and function of glutamate transporters during ischemia may be dysregulated at different levels, ranging from either positive or negative transcriptional regulation, RNA splicing, epigenetic modulation, such as DNA methylation or histone modification, to post-translational glycosylation and phosphorylation.

Apart from glutamate transporters, several ion channels that may release glutamate from astrocytes were already proposed. Interestingly, under ischemic stress, Liu et al.
(2006) demonstrated the participation of maxi-anion channels and volume-sensitive outwardly rectifying anion channels (VRACs) in glutamate release from mouse astrocytes, with the predominant contribution of maxi-anion channels. They also found that the contribution of gap junction hemichannels, vesicle-mediated exocytosis, and reversed operation of the $\mathrm{Na}^{+}$dependent glutamate transporters, was none or minor (Liu et al., 2006). Employing transient MCAO, together with the microdialysis and pharmacological inhibition of GLT-1 and VRACs, Feustel et al. (2004) demonstrated that VRACs are the predominant contributors to glutamate release in the ischemic cortical penumbra; this contrasts with severely affected ischemic regions, in which the reversal of glutamate transport plays a major role. Such evidence supporting VRACs as astrocytic glutamate-releasing channels were indirect and based on pharmacological inhibitors, which may affect the function of other membrane proteins, including those directly involved in the glutamate transport (Bowens et al., 2013). Nevertheless, the latest work of Yang et al. (2019) revealed astrocytic VRACs as major candidates mediating glutamate release in FCI. They took advantage of recent findings, which revealed that the leucine-rich repeat-containing protein $8 \mathrm{~A}$ (LRRC8A, also named SWELL1) and its four other associated homologs (LRRC8B-E) form heteromeric VRACs (Voss et al., 2014; Schober et al., 2017; Osei-Owusu et al., 2018). In a well-designed approach, which employed a conditional knockout of Swell1 in astrocytes in an experimental model of stroke, Yang et al. (2019) proved that the $\mathrm{Swell}^{-/-}$mice had significantly smaller infarct volumes and better scores for overall neurological function than the control mice. In contrast to the role of VRACs in astrocytic glutamate release, their activation in neurons was shown to mediate $\mathrm{Cl}^{-}$influx and further contribute to cell damage by promoting neuronal swelling (Inoue and Okada, 2007; Zhang et al., 2011).

Upon $\mathrm{G}$ protein-coupled receptor activation, $\mathrm{Ca}^{2+}$-dependent anion channel Bestrophin 1 and two-pore domain $\mathrm{K}^{+}$channels TWIK1 and TREK1 were also suggested to participate in glutamate release (Woo et al., 2012; Ryoo and Park, 2016). Nevertheless, a markedly increased TREK1 expression in the hippocampal CA1 region and cerebral cortex after FCI was rather attributed to their neuroprotective function (Pivonkova et al., 2010; Wang et al., 2012; Pivonkova and Anderova, 2017). Clarification of the role of these channels in glutamate release will require the generation of conditional knockout mice, in which TREK1 or TWIK1 channels are removed specifically in astrocytes, thus providing a suitable system to assess their participation in neuroprotection or glutamate excitotoxicity (Heurteaux et al., 2004; Wu et al., 2013).

In response to extracellular ATP, the $\mathrm{P}_{2} \mathrm{X}_{7}$ purinergic receptors may shift from rapid-gating channels selective for small cations to more slowly developing "dilated pore" conformations permeable to molecules up to $900 \mathrm{Da}$ (North, 2002) and thus facilitate glutamate release under pathological conditions (Duan et al., 2003). In the CNS, these receptors were described in astrocytes, microglia, oligodendrocytes, and neurons (Hamilton et al., 2008; Grygorowicz et al., 2010; Burnstock, 2017); however, their precise role in glutamate excitotoxicity is not yet fully elucidated. 
Astrocytes and neurons also express several large pore hemichannels that may open in response to various stimuli, allowing cytoplasmic molecules such as ATP and glutamate permeate (Hansen et al., 2014). Several studies revealed that the expression of astrocytic $\mathrm{Cx} 43$ is increased after hypoxia/ischemia and that $\mathrm{Cx} 43$ may play an important role in cell death and neuronal damage (Davidson et al., 2013; Ma et al., 2018). The astrocytic hemichannels are activated via increased $\mathrm{Ca}^{2+}$ levels and inflammatory factors, such as IL-1 $\beta$, epidermal growth factor (Morita et al., 2007), or TNF $\alpha$ (Giaume et al., 2013). Their activation then results in the uncontrolled release of ATP and glutamate. Key membrane proteins participating in astrocytic glutamate release are summarized in Figure 3. Nevertheless, their exact role in astrocytic and neuronal (patho-) physiology is still not well defined.

There is no doubt about the importance of astrocytes in maintaining CNS health, while their role in CNS disorders seems to be ambiguous. The failure of their crucial functions has emerged to be one of the important contributing factors of the several CNS disorders situating them to the position of "foes." On the other hand, they are able to protect or support neighboring cells, especially during the early phases of ischemia, which marks them as "good guys." Thus, defining astrocyte heterogeneity in the healthy, but also ischemic, CNS may enable us to better understand their roles and to support "beneficial" astrocytes and suppress those damaging the CNS.

\section{Oligodendrocytes}

Oligodendrocytes and axons are the main targets of ischemic white matter injury. Myelinating oligodendrocytes and their precursor cells are particularly vulnerable to energy deprivation (Fern and Moller, 2000). In the conditions of OGD, the earliest changes are visible on oligodendrocytes, especially the swelling of their soma, which extends to myelin processes and subsequently results in axonal beading (Baltan, 2014). Oligodendrocytes express functional glutamate transporters with properties similar to those observed in astrocytes and may also operate in the reverse mode, releasing glutamate into the ECS under conditions of energy deprivation (Matute et al., 2006). The main transporter expressed by oligodendrocytes is GLAST (EAAT1; Figure 3), while a subpopulation of adult oligodendrocyte progenitors expresses the EAAC1 (EAAT3), which is also present in neurons (Domercq et al., 1999).

\section{Microglia and Glutamate Release}

Upon activation, microglia may release high amounts of the neurotransmitter glutamate, thus also contributing to excitotoxic injury during brain hypoxia-ischemia. It has been shown that microglia possess two main systems for glutamate transport, GLT-1 for transport into the cells and the xCT system for transport out of the cells. Glutamate taken up through GLT-1 is used for direct incorporation into glutathione and to supply the intracellular glutamate pool to allow cystine uptake through xCT (Bridges et al., 2012; Persson and Rönnbäck, 2012). The presence of VRACs and their contribution to glutamate release in microglia (Figure 3) was demonstrated by exposing rat microglia to hypoosmotic stress, $\mathrm{H}_{2} \mathrm{O}_{2}$, or ROS-triggering zymosan; this potently increased the swelling-activated glutamate release in these cells and was sensitive to VRAC blocker, DCPIB (Harrigan et al., 2008). Similarly to astrocytes, activated microglia release excessive glutamate through gap junction hemichannels (Takeuchi et al., 2006) and their importance in glutamate excitotoxicity were described by Umebayashi and co-authors, as the blockade of these channels by INI-0602 was protective in secondary spinal cord injury (Umebayashi et al., 2014). Recently, a signaling pathway controlling glutamate release from human microglia during hypoxia was revealed by Socodato et al. (2018). They showed that a hypoxia-mediated redox imbalance promotes the release of $\mathrm{Ca}^{2+}$ from the endoplasmic reticulum and activates the non-receptor protein tyrosine kinase Src at the plasma membrane; this enhances the glutamate permeability of microglial gap junctions. Microglia can influence glutamate homeostasis also indirectly by releasing factors such as ROS, $\mathrm{TNF} \alpha$, and IL-1 $\beta$, which impairs the function of glutamate transporters in other glial cells (Domercq et al., 2007).

\section{ATP Release}

Impact similar to the elevation of glutamate in the ECS was observed in the uncontrolled increase of extracellular ATP. Anoxic depolarization, which occurs during ischemia, triggers ATP release from neurons and glial cells leading to a marked elevation of extracellular ATP concentration (Dale and Frenguelli, 2009), which leads to $\mathrm{Ca}^{2+}$ overload, tissue excitotoxicity, and amplification of the inflammation (Domercq et al., 2010; Kim Y. et al., 2018). During ischemia, ATP release originates from multiple sources, such as vesicular release from neurons (Orlando et al., 2014), exocytosis from microglia (Imura et al., 2013) and astrocytes (Hamilton and Attwell, 2010), hemichannels that can release ATP from glial cells (Montero and Orellana, 2015), or by opening of $\mathrm{P}_{2} \mathrm{X}_{7}$ ionotropic receptors that form a large pore allowing the ATP release from astrocytes (North, 2002; Yan et al., 2010). Additionally, cell death and membrane damage cause an additional massive release of glutamate and ATP, aggravating the initial ischemia-induced damage (Matute and Ransom, 2012). ATP acts on purinergic receptors and exerts a cytotoxic role in the CNS. Among $\mathrm{P} 2 \mathrm{X}$ receptors, most evidence indicates that $\mathrm{P} 2 \mathrm{X}_{7}$ receptors contribute to ischemia-induced damage via marked $\mathrm{Ca}^{2+}$ entry into the neurons and glia and facilitation of glutamate release (Arbeloa et al., 2012; Zeng et al., 2012; Eyo et al., 2013). In oligodendrocytes, the sustained $\mathrm{P} 2 \mathrm{X}_{7}$ receptor activation induces cell death, myelin damage, and white matter injury (Matute et al., 2007; Matute, 2008; Domercq et al., 2010). For a detailed review covering purinergic signaling in brain ischemia, see Pedata et al. (2016).

\section{GLUTAMATE-INDUCED BRAIN EDEMA}

Increases in the extracellular glutamate concentration have been put into context with cerebral edema, namely the so-called cytotoxic edema of astrocytes. Brain edema may be defined as an increase in the brain tissue volume resulting from the abnormal accumulation of water. Usually, three types of edema are distinguished according to the mechanisms responsible for 
the water accumulation in tissue-cytotoxic, ionic and vasogenic edema. In the early phases of ischemia, cytotoxic edema occurs as a result of the accumulation of osmotically active ions within the cell, followed by the entry of water from the ECS. This is followed by the formation of ionic edema as a result of an extracellular ionic and water level decrease, creating new gradients between plasma and interstitial fluid and driving trans-capillary fluxes of ions and osmotically obligated water. Vasogenic edema is a consequence of the BBB disruption, which leads to the water/macromolecules flux from the bloodstream to the brain ECS and it usually accompanies progressed stages of brain ischemia or other pathologies. This issue is discussed in detail in the excellent reviews by Pasantes-Morales and VázquezJuarez (2012) and Thrane et al. (2014). Here, we only focus on the mechanisms of cytotoxic stadium of the brain edema, which is related to the increased glutamate levels and the impaired glutamate uptake.

Cytotoxic (cellular) edema accompanies pathological states that are related to the ionic disbalance, such as hyponatremia, ischemia, brain trauma or hepatic encephalopathy. Astrocytes are key contributors to the generation of cellular edema due to their relationship with the cerebral vasculature and their prominent homeostatic functions. Nevertheless, the ability of cytotoxic swelling has also been described in other cell types, namely neurons and endothelial cells (Panickar et al., 2015; Jayakumar et al., 2018) For review, see the work of Jha et al. (2019). The swelling of astrocytes is the result of a number of mechanisms that, however, depend on specific pathological conditions and may also vary locally. In general, astrocytic swelling is triggered by the uptake of osmotically active substances, so-called primary drivers, which are normally more concentrated outside the cell and extruded from the cell by active transport. Their movement results in the creation of chemical gradients for other molecules further termed secondary participants, for which no pre-existing electrochemical gradients normally exist, and which move in order to maintain electrical and osmotic neutrality (Simard et al., 2006). For example, increases in intracellular $\mathrm{Na}^{+}$concentration $\left(\left[\mathrm{Na}^{+}\right]_{\mathrm{i}}\right)$ lead to the entry of $\mathrm{Cl}^{-}$and water, where $\mathrm{Na}^{+}$is a primary driver and $\mathrm{Cl}^{-}$and water are secondary participants. In ischemia, the key mechanisms include the water channel, aquaporin-4 (AQP4; Manley et al., 2000), the $\mathrm{Na}^{+}-\mathrm{K}^{+}-\mathrm{Cl}^{-}$cotransporter 1 (NKCC1; Su et al., 2002a,b), the sulfonylurea receptor 1 (SUR1)-regulated non-selective cation channels (NCCa-ATP; Simard et al., 2006; Stokum et al., 2018), the $\mathrm{Na}^{+}$-dependent EAATs (Schneider et al., 1992), and finally, Donnan cell swelling including $\mathrm{Cl}^{-}$and $\mathrm{K}^{+}$channels (Kimelberg, 2005). The specific mechanisms depend on the distance from the ischemic core. In the ischemic core, rapid depletion of energy substrates leads to the inhibition of $\mathrm{Na}^{+} / \mathrm{K}^{+}$ATPase and subsequent collapse of the ion gradient-a marked increase in the $\left[\mathrm{Na}^{+}\right]_{i}$ and $\left[\mathrm{Ca}^{2+}\right]_{\mathrm{i}}$ and extracellular $\mathrm{K}^{+}$concentrations. The resulting membrane depolarization then creates an inwardly directed driving force for $\mathrm{Cl}^{-}$via anion channels, which in turn causes the additional influx of $\mathrm{Na}^{+}$and $\mathrm{K}^{+}$in order to achieve charge neutralization. This mechanism of cell swelling has been coined in the literature as Donnan cell swelling (Kimelberg,
2005; Wilson and Mongin, 2018). Moreover, the ATP sensitive SUR1-transient receptor potential melastatin 4 channels, which can operate without energy supply, play a significant role in the astrocytic swelling located in the ATP-depleted areas (Chen and Simard, 2001; Chen et al., 2003). In the penumbra, where the energy supply persists and a gradual increase in $\mathrm{K}^{+}$ and glutamate concentrations occurs, the NKCC1 and $\mathrm{Na}^{+}$dependent glutamate transporters are the main mechanisms involved in astrocytic swelling.

Considering the topic of this review, we only focus therein on mechanisms that are activated by increased glutamate levels or, conversely, contribute to the release of glutamate into the ECS (Figure 3). Glutamate may affect the astrocytic swelling indirectly through the stimulation of neuronal activity, or directly via astrocytic glutamate receptors and transporters. In the latter case, astrocyte swelling is either caused by the accumulation of glutamate alone or by ions, whose transport is activated by the binding of glutamate to mGluRs.

\section{Glutamate Transporters}

The activation of $\mathrm{Na}^{+}$-dependent glutamate transporters results in the influx of glutamate molecules together with $3 \mathrm{Na}^{+}$. These both act as primary drivers and are followed by water movement into the cell (Chan and Chu, 1990; Schneider et al., 1992). As we already mentioned, the glutamate uptake via EAATs is a process dependent on the electrochemical gradient of $\mathrm{Na}^{+}$and hence on the activity of $\mathrm{Na}^{+} / \mathrm{K}^{+}$ATPase. Therefore, this mechanism occurs in areas where energy substrates are not completely depleted. In addition, in the case of energy depletion, these transporters can function in the reversed mode and thus contribute to glutamate release as also mentioned above.

\section{Metabotropic Glutamate Receptors}

The idea of astrocytic swelling induced by the activation of mGluRs was supported by studies that showed that swelling of cultured astrocytes was induced by mGluR agonists trans-ACPD and L-AP4 (Hansson, 1994; Yuan and Wang, 1996). Alternatively, other mGluR agonists, e.g., ibotenic acid, did not induce any swelling and, moreover, mGluR antagonists MCPG and MAP4 did not prevent the swelling (Bender et al., 1998). The activation of mGluRs leads to the $\left[\mathrm{Ca}^{2+}\right]_{i}$ increase and finally, to the opening of $\mathrm{K}^{+}$channels (Hansson, 1994; Bender et al., 1998). Moreover, it has been shown, that one of the astrocytic glutamate receptors, mGluR5, forms a functional tripartite complex together with AQP4 and $\mathrm{Na}^{+} / \mathrm{K}^{+}$ ATPase, which has an important function in the regulation of water and $\mathrm{K}^{+}$homeostasis in the brain (Illarionova et al., 2010). As all components of this system are involved in the glutamate-induced swelling (Bender et al., 1998), it is possible that the whole system plays a role in astrocyte swelling (Stokum et al., 2015).

\section{Ionotropic Glutamate Receptors}

Since NMDA receptors mediate the transfer of $\mathrm{Na}^{+}$into cells, there is a possibility that they represent, in addition to glutamate transporters and metabotropic receptors, another mechanism responsible for the cytotoxic swelling activated by increased 
glutamate concentrations (Winkler et al., 2016). In astrocytic cultures, this possibility has been confirmed using specific NMDA receptor inhibitors such as ketamine or dizocilpine (MK801; Chan and Chu, 1990; Chan et al., 1990; Hansson, 1994).

\section{Glutamate-Induced $\mathrm{K}^{+}$Uptake by $\mathrm{K}^{+}$ Channels}

The uptake of $\mathrm{K}^{+}$is most likely triggered by the activation of $\mathrm{Na}^{+} / \mathrm{K}^{+}$ATPase as a result of glutamate cotransport together with $\mathrm{Na}^{+}$. As the glutamate-induced swelling is sensitive to the specific $\mathrm{K}^{+}$channel blockers, namely $\mathrm{Ba}^{2+}$ and tetraethylammonium (TEA), it is likely that delayed outwardly and inwardly rectifying $\mathrm{K}^{+}$channels are involved (Bender et al., 1998).

\section{Regulatory Volume Decrease (RVD)}

As uncontrolled volume changes are harmful to cells and may eventually lead to cell death, mechanisms controlling the cell volume are essential for physiological cell functioning. The majority of cells possess regulatory volume mechanisms, which involve specific membrane transport and/or metabolic processes leading to compensatory changes in the intracellular osmolyte concentrations and thus returning cell volume to the normal resting state. The generated osmotic gradients subsequently drive water across the membrane by diffusion through the bilayer or through AQPs. The recovery of cell volume after swelling is accomplished by the extrusion of the major intracellular ions $\left(\mathrm{K}^{+}\right.$ and $\mathrm{Cl}^{-}$) and organic osmolytes, such as taurine and amino acids (Sanchez-Olea et al., 1993a,b; Vitarella et al., 1994). The efflux of $\mathrm{Cl}^{-}$and also the organic osmolytes during regulatory volume decrease (RVD) are mainly mediated by VRACs (Abdullaev et al., 2006). The conductivity of VRACs for small organic molecules is important in this context, mainly because these substances (e.g., glutamate, aspartate) are also major CNS neurotransmitters. Thus, the release of these molecules affects brain functions, and in the case of glutamate, it dramatically contributes to the glutamate toxicity as suggested by Kimelberg et al. (1990). For more details on this subject, see Kimelberg (2005) and Mongin (2016).

\section{PATHOLOGICAL CONSEQUENCES OF GLUTAMATE EXCITOTOXICITY}

In general, an excess or prolonged exposure of neurons and glia to high levels of extracellular glutamate during ischemia both lead to a massive $\mathrm{Ca}^{2+}$ entry into the cells of both gray and white matter (Danysz and Parsons, 2003; Van Damme et al., 2007). Such excessive $\left[\mathrm{Ca}^{2+}\right]_{\mathrm{i}}$ initiates a series of molecular neurotoxic cascades, including the activation and overstimulation of proteases, lipases, phosphatases, and endonucleases (Orrenius et al., 2003). This leads to the activation of several signaling pathways, mainly causing an overproduction of free radicals, mitochondrial damage, cell membrane disruption, and DNA fragmentation, which all culminate in apoptotic or necrotic cell death (Figure 2; Rama and García, 2016).

\section{Overactivation of Glial Glutamate Receptors}

Glutamatergic signaling through glutamate receptors forms a major component of excitatory synaptic transmission in the CNS. However, glutamate release in the CNS is not exclusive to synaptic terminals but also arises from unmyelinated axons and glial cells under both physiological and pathophysiological conditions (Ceprian and Fulton, 2019). Glial cells express both types of glutamate receptors-ionotropic (NMDA, AMPA, and kainate) and metabotropic in gray and white matter. For reviews, see D’Antoni et al. (2008), Dzamba et al. (2013), Ceprian and Fulton (2019) and Fern and Matute (2019).

In astrocytes, the most probable composition of NMDA receptors seems to be tri-heteromeric, containing GluN1, GluN2C/D and GluN3 subunits (Palygin et al., 2011); however, the subunit composition varies regionally as well as in different developmental stages of nervous tissue and in various pathological states. Functional studies (Shelton and McCarthy, 1999; Lalo et al., 2006; Serrano et al., 2008) suggest that astrocytic NMDA receptors are primarily involved in neuron-astrocyte communication. It has been shown that brain ischemia results in the increased expression of NMDA receptors in astrocytes (Gottlieb and Matute, 1997; Krebs et al., 2003). Functional AMPA receptors of astrocytes are present in the majority of the CNS regions except for the hippocampus. The subunit composition of astrocytic AMPA receptors differs from region to region, leading to the variability in their permeability to $\mathrm{Ca}^{2+}$ (Matthias et al., 2003). Astrocytic AMPA receptors do not appear to be vulnerable to pathological conditions associated with glutamate-mediated excitotoxicity because of their low $\mathrm{Ca}^{2+}$ permeability (Li and Stys, 2000). These findings, and similar observations of excitotoxic resistance in astrocytes (Rothman, 1984), are supported by RNA-seq data, showing the dominance of GluA2 (inhibits permeability of $\mathrm{Ca}^{2+}$ ) in both cortical and hippocampal astrocytes in situ (Mölders et al., 2018). This excitotoxic resistance of astrocytes is weakened in white matter fibrous astrocytes, but there is currently no evidence that this is related to the expression of glutamate receptors (Fern and Matute, 2019).

Oligodendrocytes are known to be extremely sensitive to OGD and their vulnerability changes during development and aging. Similarly to neurons, the enormous $\mathrm{Ca}^{2+}$ entry induced by glutamate excitotoxicity occurs via activation of different glutamate receptors. This process is involved in the death of oligodendrocytes in ischemic damage of gray as well as white matter (Ransom and Baltan, 2009; Matute, 2011). The subunit composition of glutamate receptors and their localization in oligodendrocytes (soma, processes, myelin) predispose them to the susceptibility to ischemic injury as their AMPA receptors are especially permeable to $\mathrm{Ca}^{2+}$ (Káradóttir and Attwell, 2007) and their NMDA receptors are only weakly blocked by $\mathrm{Mg}^{2+}$, allowing them to produce considerable currents at resting membrane potential (Káradóttir et al., 2005). Moreover, oligodendrocytes also express receptors of all three groups of metabotropic glutamate receptors, but their levels are developmentally regulated and are very low in mature cells of 
this lineage (Deng et al., 2004). The overactivation of AMPA and kainate receptors leads to the demise of oligodendrocytes and primary and/or secondary myelin destruction as a consequence of massive influx of $\mathrm{Ca}^{2+}$ (McDonald et al., 1998; Alberdi et al., 2002; Sánchez-Gómez et al., 2011). Also, it has been shown that ischemia modeled in vitro leads to the NMDA receptor activation, resulting in $\mathrm{Ca}^{2+}$ increases in oligodendrocytes that are abolished by NMDA antagonists, such as memantine, D-AP5, or MK-801 (Salter and Fern, 2005; Micu et al., 2006, 2007). Salter and Fern (2005) have also reported that the activation of NMDA receptors results in the fast $\mathrm{Ca}^{2+}$-dependent morphological changes, which are manifested by detachment and disintegration of oligodendroglial processes and formation of swellings, and that blocking the NMDA receptors prevents injury to oligodendrocytic processes.

Oligodendrocyte precursor cells (NG2 glia) and immature oligodendrocytes are very sensitive to transient OGD (Fern and Moller, 2000). Thus, simulated ischemia in young animals induces an inward current in oligodendrocytes that are partly mediated by NMDA and AMPA/kainate receptors (Káradóttir et al., 2005). The sensitivity to hypoxia-ischemia damage has been correlated to the maturation of oligodendrocytes in several species (Riddle et al., 2006; Segovia et al., 2008; Buser et al., 2010) including human (Back et al., 2002), with pre-oligodendrocytes being identified as particularly vulnerable. Importantly, within the oligodendrocyte lineage, pre-oligodendrocytes in developing white matter exhibit the greatest abundance of GluA4 (Talos et al., 2006), a $\mathrm{Ca}^{2+}$-permeable subunit, highly expressed in neural cells exhibiting vulnerability to excitotoxic death (Page and Everitt, 1995).

Microglia express members of all ionotropic and metabotropic glutamate receptors. Activation of ionotropic receptors leads to enhanced release of $\mathrm{TNF} \alpha, \mathrm{IL}-1$ and $\mathrm{NO}$ (Noda et al., 2000; Murugan et al., 2011). Specifically, increased expression of AMPA receptors in hypoxic white matter sensitizes microglia to glutamate, leading to a regulatory response that reduces protective IGF-1 release, while increasing the release of inflammatory mediators (Sivakumar et al., 2010). Regarding metabotropic glutamate receptors, different subunits of metabotropic groups I (mGluR5), II (mGluR2 and 3), and III (mGluR4, 6, and 8, but not mGluR7) are expressed by microglia and regulate microglial transformation into neuroprotective (via group III mGluRs) or neurotoxic (via group II mGluRs) phenotypes (Pocock and Kettenmann, 2007).

\section{Periventricular Leukomalacia}

The specific case of overactivation of glial glutamate receptors occurs in premature white matter injury. The premature brain undergoes critical developmental events as neuronal migration, growth of axons and dendrites, synaptogenesis, development of the vascular system, and myelination. The abundance of glutamate receptors in the white matter is a key element for these processes, but also a reason for increased vulnerability to possible excitotoxic conditions (Pregnolato et al., 2019). The presence of glutamate receptors is developmentally regulated. In the case of pre-oligodendrocytes, AMPA receptors are expressed, while in mature oligodendrocytes, NMDA receptors prevail. The overstimulation of non-NMDA receptors results in the rapid cell death, while overstimulation of NMDA receptors leads to a loss of cellular processes (Deng and Poretz, 2003; Deng et al., 2004, 2006). Due to this fact, hypoxia in the premature brain leads to white matter injury termed periventricular leukomalacia (PVL), which manifests as cerebral palsy and cognitive/behavioral deficits (Wilson-Costello et al., 2007). The injury of white matter is characterized by focal periventricular necrosis, with axonal damage and macrophages along with diffuse inflammation, with reactive astrocytes and activated microglia in the surrounding white matter. Pre-oligodendrocytes, which are more vulnerable than immature neurons or mature oligodendrocytes, are most affected (Haynes et al., 2003). The unique feature of the PVL is an arrest in the development of oligodendrocytes at the pre-oligodendrocyte stage, leading to the abnormal myelination (Volpe et al., 2011). Damage to pre-oligodendrocytes and hypomyelination is unlikely to be solely due to autonomous cell-intrinsic vulnerability. Numerous studies have demonstrated that microglial activation and astrogliosis play important roles in triggering white matter injury in PVL (Liu et al., 2013). Activated microglia mediate the death of pre-oligodendrocytes by two distinct mechanisms in a time-dependent manner. The early phase of cell damage occurs within $24 \mathrm{~h}$ and is mediated by NO-dependent oxidative damage. The delayed cell death, mediated by cytokines, is evident at $48 \mathrm{~h}$ (Pang et al., 2010; Falahati et al., 2013). Similarly, astrocytes induce apoptosis of oligodendrocytes by producing inflammatory cytokines such as TNF $\alpha$ and IL-1 $\beta$ (Deng et al., 2014). Currently, there is no specific treatment for PVL, but many studies try to find specific agents to attenuate white matter damage by preventing cell death of pre-oligodendrocytes. Pre-treatment with $\mathrm{MgSO}_{4}$ attenuated the loss of oligodendrocyte markers, such as myelin basic protein (MBP) and oligodendrocyte transcription factor (Olig2), in ipsilateral white matter and decreased the number of microglia, preventing thus cell death of pre-oligodendrocytes (Seyama et al., 2018). Another studied approach to ameliorate PVL was to transplant human oligodendrocyte progenitors. The results indicate that the transplanted cells restored neurobehavioral functions by preventing axonal demyelination and that human oligodendrocyte progenitor cells could be a suitable candidate for cell therapy of PVL (Kim T. K. et al., 2018).

\section{Oxidative Stress}

Free radicals are the result of normal cellular function and metabolic activity of the cell. They could be any chemical species (atoms, molecules) capable of independent existence, and having one or more unpaired electrons. The most common free radicals induced by excitotoxicity are molecules derived from oxygen and NO, called ROS (superoxide radicals and hydroxyl radicals) and reactive nitrogen species (RNS; NO, peroxynitrite), respectively. Free radicals are highly reactive and can directly oxidize and damage macromolecules, such as proteins, lipids, and DNA (Sugawara et al., 2002; Kalogeris et al., 2014). Oxidative stress represents a condition, in which the production of free radicals exceeds the capacity of the antioxidant defenses to keep the levels below the toxic threshold. The cell uses 
different antioxidant defenses, including superoxide dismutase, catalase, glutathione detoxification pathways, and thioredoxin detoxification pathways (Kudin et al., 2012).

In general, neurons and glial cells possess the ability to defend against oxidative stress, but astrocytes display the highest basal levels of glutathione in the CNS, which predetermines their ability to remove high amounts of ROS and RNS (Sun et al., 2006). Furthermore, the glutathione system is regulated by the inducible nuclear factor erythroid-2-related factor 2 (Nrf2; Bell et al., 2015). Astrocytes, compared to neurons, have enhanced Nrf2 that upregulates antioxidant genes (NQO1, glutathione reductase, TXNRD1, glucose-6-phosphate dehydrogenase, malic enzyme, transketolase, and transaldolase) to protect astrocytes and also neurons (Lee et al., 2003; Shih et al., 2003). They are also capable of modulating the microglial inflammatory response, providing negative regulation by releasing an astrocytebased factor that induces the microglial Nrf2 activity and increases the expression of antioxidant heme oxygenase-1. These antioxidant products suppress ROS/RNS and return microglia to the resting state (Min et al., 2006). Astrocytes also protect the brain against ischemia-associated oxidative stress by producing ROS scavenger metallothionein-II (Trendelenburg et al., 2002; Waller et al., 2018).

Oligodendrocytes are less vulnerable to oxidative stress than neurons but much more than other glial cells (Husain and Juurlink, 1995). Such vulnerability could originate from the highest levels of immobilized, protein-bound iron, which can be a potent cytotoxin by catalyzing the conversion of hydrogen peroxide to hydroxyl radicals via the Fenton reaction (Connor and Menzies, 1996). Moreover, when compared to astrocytes, oligodendrocytes possess less than half of the glutathione content, which leads to less effective peroxide scavenging due to the lower activity of glutathione peroxidase (Juurlink et al., 1998). They also have a high metabolic activity that requires a high consumption of oxygen and ATP, which generates more ROS (Mifsud et al., 2014). Oxidative stress is the leading cause of hypomyelination and mature oligodendrocyte deficiency because it increases the expression of genes known to inhibit oligodendroglial differentiation (French et al., 2009). Oligodendrocyte precursor cells are even more susceptible to oxidative stress than oligodendrocytes. The higher vulnerability is due to an upregulation of AMPA receptors (Itoh et al., 2002) and transiently increased expression of the glutamate transporter EAAT2 (Desilva et al., 2007). A recent study showed that the antioxidant signaling of OPCs is regulated by miR146b-5p, enhancing the activation of Nrf2 signaling, which attenuates apoptosis and ROS production (Li et al., 2019). Catalpol, a potent antioxidant and free radical scavenger acting through the ERK1/2 signaling pathway, has also been shown to positively affect NG2 glia (pre-myelinating oligodendrocytes) after oxidative stress (Cai et al., 2016).

\section{Mitochondrial Dysfunction}

The ischemia-induced excitotoxicity results in mitochondrial malfunctioning due to the damage to mitochondrial proteins, membranes, and DNA, thus impairing the ability of mitochondria to synthesize ATP and carry out their wide range of metabolic functions (Rama and García, 2016). The permeability transition pore (mPTP) in the mitochondrial membrane develops in response to $\mathrm{Ca}^{2+}$ overload and enables the release of pro-apoptotic factors. Such factors include cytochrome C, apoptosis-inducing factor (AIF) and Smac/Diablo, which participate in the activation of intrinsic apoptotic signaling (Yang et al., 2018). Ischemia also triggers the depolarization of the mitochondrial membrane, resulting in excessive ROS production, decreased ATP generation and PTEN-induced putative kinase 1 accumulation (Lazarou et al., 2015). As a consequence of ATP reduction, damaged mitochondria are repaired through the fusion with healthy mitochondria, or mitochondrial fission enables the segregation of damaged mitochondria and subsequent elimination via mitophagy (Liu et al., 2018). Stressed or dying cells with dysfunctional mitochondria might acquire healthy mitochondria through tunneling nanotubes to another cell type (Torralba et al., 2016). A recent study also showed that neurons already under physiological conditions release mitochondria that are internalized and degraded by adjacent astrocytes (Davis et al., 2014). Moreover, after stroke, astrocytes can release functional mitochondria towards neurons by a $\mathrm{Ca}^{2+}$. dependent mechanism. This neuroglial crosstalk contributes to neuroprotective mechanisms after stroke, since the suppression of this mitochondrial transfer worsens the neurological outcome (Hayakawa et al., 2016). Interestingly, a subset of mitochondria (35\%) faces extreme $\mathrm{Ca}^{2+}$ overload, which acts as a "point of no return" and causes delayed excitotoxic cell death despite the fact that the majority of undamaged mitochondria still maintain normal functions (Pivovarova et al., 2004).

\section{Calpain Excitotoxicity}

Additionally, the $\mathrm{Ca}^{2+}$ overload triggers the hyperactivation of calpains, $\mathrm{Ca}^{2+}$-dependent proteases that under pathological conditions add to the ischemia-induced excitotoxic damage. Calpains cleave the NCX3, which further leads to extra $\mathrm{Ca}^{2+}$ accumulation in neurons (Pignataro et al., 2004; Bano et al., 2005). Subsequently, $\mathrm{Ca}^{2+}$ activates a protease that transforms xanthine dehydrogenase into xanthine oxidase, an important enzyme in the production of free radicals (Gagliardi, 2000).

\section{Cell Death}

Cell death is induced by many mechanisms: necrosis, apoptosis, autophagy, oncosis, necroptosis, etc., depending on the onset and the severity of ischemia (Fricker et al., 2018). Necrosis occurs mainly in the ischemic core as a result of a severe deficit or absence of oxygen and glucose. On the contrary, apoptosis takes place in the ischemic penumbra, where certain levels of oxygen and glucose remain, still maintaining the functional activity of cells (Rama and García, 2016). The difference is also in the time window when these mechanisms occur. Necrosis is mainly detected during the first post-ischemic minutes, whereas apoptosis develops hours or days later. Apoptosis, unlike necrosis, requires the integrity of the plasma membrane and a sufficient amount of ATP (Radak et al., 2017). The dichotomy between necrosis in the ischemic core and apoptosis in the ischemic penumbra is not strict as apoptotic death 
has been also shown in the ischemic core and vice versa (Onténiente et al., 2003).

\section{APOPTOSIS}

Apoptosis can be activated by two general pathways: the extrinsic pathway is initiated by the death receptors, such as TNF receptors, CD95/Fas or TRAIL expressed on the cell surface. These ligand-activated receptors can, via the formation of death-inducing signaling complexes, trigger caspase- 8 activation. This may trigger caspase-dependent apoptosis either directly via caspase-3 processing and/or indirectly, through $\mathrm{BH} 3$-only protein Bid cleavage and the mitochondria-dependent signaling (Gupta, 2003).

On the other hand, the intrinsic apoptotic pathway is triggered by all the mechanisms that we have mentioned above, including oxidative stress, mitochondria dysfunction and high levels of $\mathrm{Ca}^{2+}$. An important role in this type of apoptosis is played by cytochrome $\mathrm{C}$ which is released due to ionic imbalance, mitochondrial swelling, or the formation of a pore in the mitochondrial outer membrane (MOM; Uzdensky, 2019). The Bcl-2 family proteins are known as major inducers and regulators of the MOM pore formation. These proteins can be divided into two groups: anti-apoptotic proteins, including Bcl-2, Bcl-XL, Mcl-1 and pro-apoptotic proteins, such as Bax, Bak, and a group of BH3-only sentinels, such as Bim, Bid, p53-upregulated modulator of apoptosis (PUMA), or Bad. In cerebral ischemia, the pro-apoptotic stimuli (Bax and/or Bak) activate apoptosis by disturbing the anti-apoptotic/pro-apoptotic balance (Doyle et al., 2008). Once released from the intermembrane space, cytochrome $\mathrm{C}$ binds to the apoptotic protease activating factor-1 (Apaf-1), which oligomerizes and thus induces the binding and autoactivation/processing of pro-caspase 9 in a multimeric complex named apoptosome. The activated caspase- 9 then activates the effector caspases 3 and 7 that subsequently cleave homeostatic, cytoskeletal-, repair-, metabolic-, and cell signaling proteins, driving cells to apoptotic death (Niizuma et al., 2010).

In addition to cytochrome-C/caspase-3-mediated apoptosis, there is growing evidence for caspase-independent pathways in programmed cell death. This mechanism is activated via other pro-apoptotic proteins released from the $\mathrm{MPTP}$, such as AIF or endonuclease G. AIF is not dependent on functional caspases and could, therefore, serve as an alternative death pathway after cellular energy depletion (Broughton et al., 2009).

\section{Glial Cells and Apoptosis}

Neurons and cells of the oligodendroglial lineage are the most sensitive cellular elements and are damaged on the front line of ischemia or later they undergo delayed cell death. On the contrary, glial cells, namely microglia, and astrocytes are less vulnerable to hypoxia or hypoglycemia (Lyons and Kettenmann, 1998). The early hypotheses suggested that stroke elicits mainly the caspase-dependent apoptosis in neurons. However, the recent findings revealed that apoptosis is widespread in non-neuronal cells and that caspase-independent mechanisms play the main role in their death (Uzdensky, 2019). Such neuronal death in a caspase-independent manner was described in stroke, in which NG2 glia produce Bcl-2/E1B$19 \mathrm{~K}$-interacting protein 3 (BNIP3), a proapoptotic member of the Bcl-2 family proteins ( $\mathrm{Li}$ et al., 2013). BNIP3 induces excessive mitophagy and autosis-like cell death. NG2 glia is eliminated during the early post-ischemic reperfusion, $3 \mathrm{~h}$ after MCAO in the adult rat brain. Compared to the other glial cell populations (astrocytes, microglia, and myelinating oligodendrocytes), the immunoreactivity of the NG2 proteinexpressing glial cells, showed a rapid decrease. NG2 glia are possibly more vulnerable to severe ischemia and might be a crucial factor for axon demyelination and consequent neuronal loss (Li et al., 2013). Neuregulin-1 $\beta$ was proposed as a protector of NG2 glia against apoptosis, of which activity might be associated with the anti-apoptotic PI3K-Akt signaling pathway (Linying et al., 2014).

In astrocytic apoptosis, it has been shown that PUMA, a $\mathrm{BH} 3$-only member of the $\mathrm{Bcl}-2$ protein family, is upregulated during ischemia. This protein is involved in the onset and progression of several diseases and is required for $\mathrm{p} 53$-dependent and p53-independent forms of apoptosis. The downregulation of PUMA by siRNA transfection significantly decreases the apoptosis of astrocytes (Chen et al., 2015). PUMA could be also downregulated by the overexpression of astrocytic micro-RNA (miR-29a), thus reducing neuronal vulnerability to ischemia (Ouyang et al., 2013). On the contrary, inhibition of miR-30d increases cell autophagy but decreases cell apoptosis in astrocytes exposed to ischemia (Zhao F. et al., 2017) Interestingly, the inhibition of apoptosis in astrocytes was detected in transient receptor potential channels TRPC3/6/7 knockout mice subjected to ischemia. The deletion of these channels can reduce the nuclear factor $\kappa \mathrm{B}(\mathrm{NF} \kappa \mathrm{B})$ phosphorylation (pro-apoptotic) and downregulate the expression of pro-apoptotic Bcl-2 family protein Bax (Chen et al., 2017).

The activated microglia release Toll-like receptor 4, which is a pro-inflammatory protein activating the $\mathrm{NF} \kappa \mathrm{B}$ pathway. It leads to the expression and release of the pro-inflammatory cytokines TNF $\alpha$ and IL-6, thus exacerbating neuronal damage and apoptosis (Zhao S. C. et al., 2017). Similarly, extracellular heat shock protein 70 (Hsp70) activates pro-inflammatory cytokines, while its intracellular localization results in a decrease in this signaling. Hsp70 is upregulated after stroke and it is not found only in microglia, but also in other cell types. Increased expression of Hsp70 causes the downregulation of dynamin, which transfers the death receptor Fas to the cell surface, inducing apoptosis, and thus Hsp70 acts neuroprotectively (Gülke et al., 2018). There are many studies regarding micro-RNA and microglia-mediated neuronal apoptosis, suggesting potential novel therapeutic interventions for ischemia. A recent study showed that miR-21 in microglia may suppress FasL production; however, in ischemic conditions, this micro-RNA is downregulated (Zhang L. et al., 2012). Another study showed that intravenously injected microgliaderived exosomes with miR-124 attenuated neuronal apoptosis after OGD (Song et al., 2019).

The caspase-dependent pathway may contribute to oligodendrocyte apoptosis in ischemia. In models of permanent FCI, oligodendrocyte injury is attenuated in cells with eliminated 


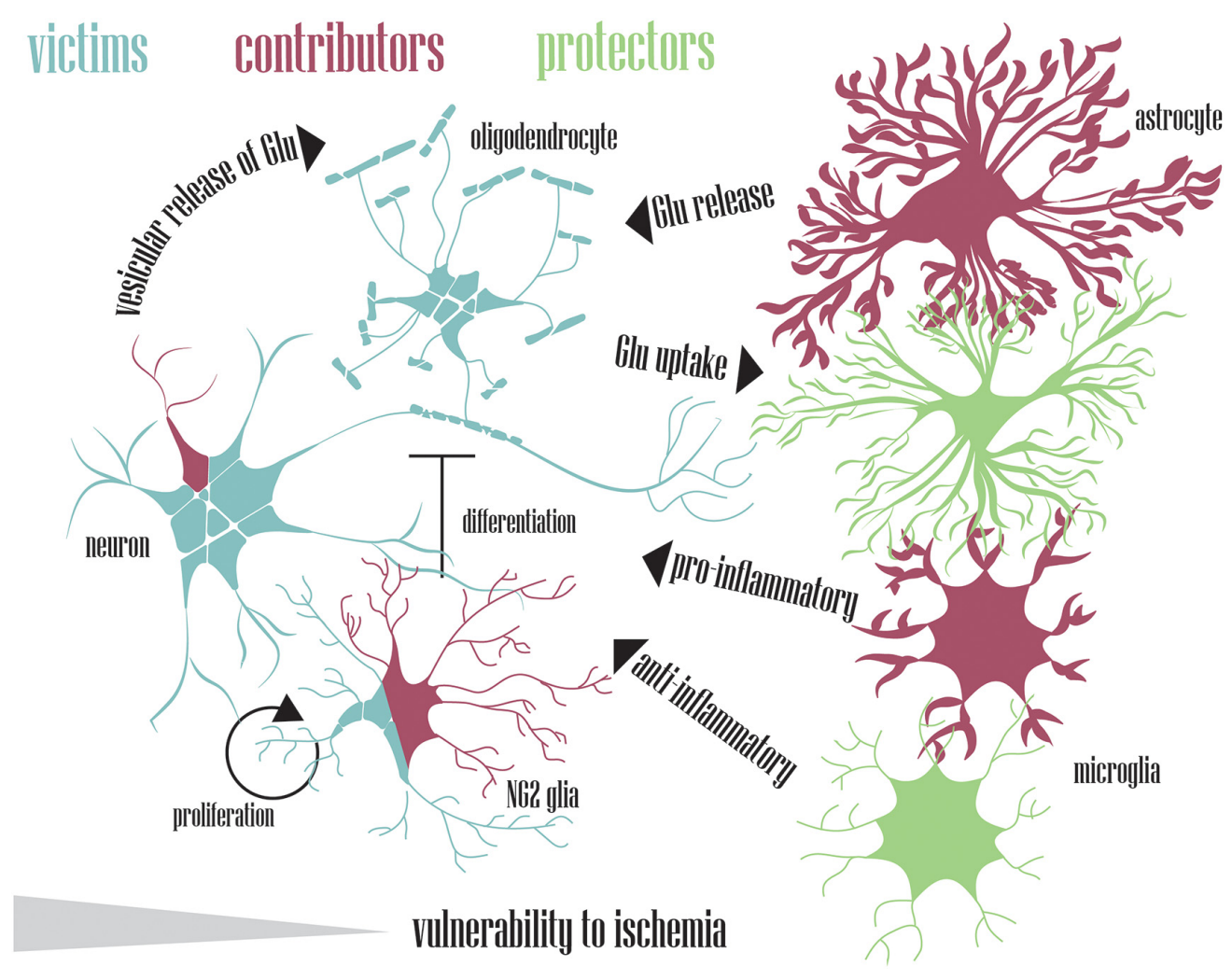

FIGURE 4 | Who is the main contributor to the ischemic pathway, and who is the unsuspecting victim? The simplistic scheme shows the generalized role of individual cells and their vulnerability to ischemia.

Bax expression or in oligodendrocytes overexpressing caspase inhibitor p35 (Shibata et al., 2000; Sánchez-Gómez et al., 2011). Oligodendrocytes could be robustly protected against ischemiainduced loss by butyrate and trichostatin A via histone deacetylases (HDAC) inhibition. The HDAC inhibitors downregulate caspase 3, mitigating white matter injury (Kim and Chuang, 2014). Like in previous cases of glia apoptosis, there is also evidence for the micro-RNA function in oligodendrocyte apoptosis. Here, apoptosis is suppressed through exosomal miR134 by negatively regulating the caspase- 8 -dependent apoptosis pathway (Xiao et al., 2018). Excitotoxicity itself may not only act detrimentally on oligodendrocytes, but it can also cause the death of other cell types. A recent study proposed a mechanism in which oligodendrocyte injury induced by ischemia is associated with molecules released from activated microglia. According to this study, oligodendrocyte apoptosis is caused by TNF $\alpha$ and IL-1 $\beta$, released due to the fractalkine receptor chemokine receptor 1 (CX3CR1) and its ligand (CX3CL1) axis and the p38MAPK pathway (for more detail, see Wu et al., 2016).

\section{CONCLUSION}

In the present review article, we summarized available pieces of information regarding ischemia-triggered glutamate excitotoxity, its causes, and its consequences. This pathological process stems from excessive activation of glutamate receptors in neural cells and is considered a principal mechanism of neuronal death in various CNS disorders. Unfortunately, the intravenous administration of plasminogen activators remains the best and the only treatment for ischemic stroke, while timing is the key to success. The last decades have broadened our horizons, as many roles of glial cells in glutamate excitotoxicity have emerged, documenting once and for all the importance of these non-neuronal dwellers of the CNS. Recent research showed that some of them are as susceptible to overactivated glutamate signaling as neurons, some try to resist and fight against the inevitable fate. A graphical representation of such a struggle of various resident cell types is depicted in Figure 4. Addressing the question "Who is the main contributor to the ischemic pathway, and who is the unsuspecting victim?" is a heroic deed since astrocytes and microglia have both positive and negative functions in the contribution to excitotoxicity. Also, NG2 glia and neurons are not as innocent victims as they seem, because neurons participate in myelin/oligodendrocyte damage and NG2 glia lose their ability to replace dying oligodendrocytes. Therefore, all the CNS cells probably share the blame in this process. The ischemic pathway consists of many steps and seems to be so complex that targeting only its single part might not be sufficient. Nevertheless, there are more stops during the journey starting at the onset of ischemic injury, with its final destination at cell death that could serve as prospective therapeutic targets. To list some of them, the modulation of the activity 
of cysteine-glutamate exchangers, glutamate transporters, or apoptotic pathway appears to be one of the most promising for the development of new drugs. Additionally, a comprehensive understanding of the roles of glial cells in glutamate excitotoxicity may pave the way for new therapeutic approaches and strategies to treat many brain pathologies, such as ischemia or Alzheimer's and Parkinson's disease, amyotrophic lateral sclerosis or even psychiatric disorders, for example, schizophrenia.

\section{AUTHOR CONTRIBUTIONS}

MA, DB, JK, and JT wrote and edited the manuscript. DB worked on the figures realization. MA supervised the study.

\section{REFERENCES}

Abdullaev, I. F., Rudkouskaya, A., Schools, G. P., Kimelberg, H. K., and Mongin, A. A. (2006). Pharmacological comparison of swelling-activated excitatory amino acid release and $\mathrm{Cl}^{-}$currents in cultured rat astrocytes. J. Physiol. 572, 677-689. doi: 10.1113/jphysiol.2005.103820

Adams, K. L., and Gallo, V. (2018). The diversity and disparity of the glial scar. Nat. Neurosci. 21, 9-15. doi: 10.1038/s41593-017-0033-9

Ahrendsen, J. T., Grewal, H. S., Hickey, S. P., Culp, C. M., Gould, E. A., Shimizu, T., et al. (2016). Juvenile striatal white matter is resistant to ischemia-induced damage. Glia 64, 1972-1986. doi: 10.1002/glia.23036

Aizenman, E., Sinor, J. D., Brimecombe, J. C., and Herin, G. A. (2000). Alterations of N-methyl-D-aspartate receptor properties after chemical ischemia. J. Pharmacol. Exp. Ther. 295, 572-577.

Akanuma, S., Zakoji, N., Kubo, Y., and Hosoya, K. (2015). In vitro study of L-glutamate and l-glutamine transport in retinal pericytes: involvement of excitatory amino acid transporter 1 and alanine-serine-cysteine transporter 2. Biol. Pharm. Bull. 38, 901-908. doi: 10.1248/bpb.b15-00133

Alberdi, E., Sánchez-Gómez, M. V., Marino, A., and Matute, C. (2002). Ca ${ }^{2+}$ influx through AMPA or kainate receptors alone is sufficient to initiate excitotoxicity in cultured oligodendrocytes. Neurobiol. Dis. 9, 234-243. doi: 10.1006/nbdi. 2001.0457

Allen, N. J., and Eroglu, C. (2017). Cell biology of astrocyte-synapse interactions. Neuron 96, 697-708. doi: 10.1016/j.neuron.2017.09.056

Allen, N. J., Káradóttir, R., and Attwell, D. (2004). Reversal or reduction of glutamate and GABA transport in CNS pathology and therapy. Pflugers Arch. 449, 132-142. doi: 10.1007/s00424-004-1318-x

Amani, M., Zolghadrnasab, M., and Salari, A. A. (2019). NMDA receptor in the hippocampus alters neurobehavioral phenotypes through inflammatory cytokines in rats with sporadic Alzheimer-like disease. Physiol. Behav. 202, 52-61. doi: 10.1016/j.physbeh.2019.01.005

Amantea, D., Greco, R., Micieli, G., and Bagetta, G. (2018). Paradigm shift to neuroimmunomodulation for translational neuroprotection in stroke. Front. Neurosci. 12:241. doi: 10.3389/fnins.2018.00241

Anderova, M., Vorisek, I., Pivonkova, H., Benesova, J., Vargova, L., Cicanic, M., et al. (2011). Cell death/proliferation and alterations in glial morphology contribute to changes in diffusivity in the rat hippocampus after hypoxiaischemia. J. Cereb. Blood Flow Metab. 31, 894-907. doi: 10.1038/jcbfm. 2010.168

Andrade, A. L., and Rossi, D. J. (2010). Simulated ischaemia induces $\mathrm{Ca}^{2+}$-independent glutamatergic vesicle release through actin filament depolymerization in area CA1 of the hippocampus. J. Physiol. 588, 1499-1514. doi: 10.1113/jphysiol.2010.187609

Andreeva, K., Zhang, M., Fan, W., Li, X., Chen, Y., Rebolledo-Mendez, J. D., et al. (2014). Time-dependent gene profiling indicates the presence of different phases for ischemia/reperfusion injury in retina. Ophthalmol. Eye Dis. 6, 43-54. doi: 10.4137/oed.s17671

Angulo, M. C., Kozlov, A. S., Charpak, S., and Audinat, E. (2004). Glutamate released from glial cells synchronizes neuronal activity in the hippocampus. J. Neurosci. 24, 6920-6927. doi: 10.1523/JNEUROSCI.047304.2004

\section{FUNDING}

This study was supported by the Czech Science Foundation (Grantová Agentura České Republiky; GACR: 19-02046S, 1903016S). As both projects focus on two CNS disorders, amyotrophic lateral sclerosis and schizophrenia, glutamateinduced neurotoxicity is their main focus.

\section{ACKNOWLEDGMENTS}

We would like to thank Frances Zatrepalkova for proofreading the manuscript.

Araque, A., Carmignoto, G., Haydon, P. G., Oliet, S. H., Robitaille, R., and Volterra, A. (2014). Gliotransmitters travel in time and space. Neuron 81, 728-739. doi: 10.1016/j.neuron.2014.02.007

Arbeloa, J., Pérez-Samartín, A., Gottlieb, M., and Matute, C. (2012). P2X7 receptor blockade prevents ATP excitotoxicity in neurons and reduces brain damage after ischemia. Neurobiol. Dis. 45, 954-961. doi: 10.1016/j.nbd.2011.12.014

Arranz, A. M., Gottlieb, M., Pérez-Cerdá, F., and Matute, C. (2010). Increased expression of glutamate transporters in subcortical white matter after transient focal cerebral ischemia. Neurobiol. Dis. 37, 156-165. doi: 10.1016/j.nbd.2009. 09.019

Astrup, J., Symon, L., Branston, N. M., and Lassen, N. A. (1977). Cortical evoked potential and extracellular $\mathrm{K}^{+}$and $\mathrm{H}^{+}$at critical levels of brain ischemia. Stroke 8, 51-57. doi: 10.1161/01.str.8.1.51

Atoji, Y., and Sarkar, S. (2019). Localization of AMPA, kainate, and NMDA receptor mRNAs in the pigeon cerebellum. J. Chem. Neuroanat. 98, 71-79. doi: 10.1016/j.jchemneu.2019.04.004

Back, S. A., Han, B. H., Luo, N. L., Chricton, C. A., Xanthoudakis, S., Tam, J., et al. (2002). Selective vulnerability of late oligodendrocyte progenitors to hypoxia-ischemia. J. Neurosci. 22, 455-463. doi: 10.1523/JNEUROSCI.22-0200455.2002

Baltan, S. (2014). Excitotoxicity and mitochondrial dysfunction underlie age-dependent ischemic white matter injury. Adv. Neurobiol. 11, 151-170. doi: 10.1007/978-3-319-08894-5_8

Baltan, S. (2016). Age-specific localization of NMDA receptors on oligodendrocytes dictates axon function recovery after ischemia. Neuropharmacology 110, 626-632. doi: 10.1016/j.neuropharm.2015. 09.015

Baltan, S., Besancon, E. F., Mbow, B., Ye, Z., Hamner, M. A., and Ransom, B. R. (2008). White matter vulnerability to ischemic injury increases with age because of enhanced excitotoxicity. J. Neurosci. 28, 1479-1489. doi: 10.1523/JNEUROSCI.5137-07.2008

Bano, D., Young, K. W., Guerin, C. J., Lefeuvre, R., Rothwell, N. J., Naldini, L., et al. (2005). Cleavage of the plasma membrane $\mathrm{Na}^{+} / \mathrm{Ca}^{2+}$ exchanger in excitotoxicity. Cell 120, 275-285. doi: 10.1016/j.cell.2004.11.049

Baron, J. C. (2001). Perfusion thresholds in human cerebral ischemia: historical perspective and therapeutic implications. Cerebrovasc. Dis. 11, 2-8. doi: 10.1159/000049119

Barres, B. A. (2008). The mystery and magic of glia: a perspective on their roles in health and disease. Neuron 60, 430-440. doi: 10.1016/j.neuron.2008. 10.013

Belayev, L., Zhao, W., Busto, R., and Ginsberg, M. D. (1997). Transient middle cerebral artery occlusion by intraluminal suture: I. Three-dimensional autoradiographic image-analysis of local cerebral glucose metabolism-blood flow interrelationships during ischemia and early recirculation. J. Cereb. Blood Flow Metab. 17, 1266-1280. doi: 10.1097/00004647-199712000-00002

Bell, K. F., Al-Mubarak, B., Martel, M. A., McKay, S., Wheelan, N., Hasel, P., et al. (2015). Neuronal development is promoted by weakened intrinsic antioxidant defences due to epigenetic repression of Nrf2. Nat. Commun. 6:7066. doi: 10.1038/ncomms8066

Bender, A. S., Schousboe, A., Reichelt, W., and Norenberg, M. D. (1998). Ionic mechanisms in glutamate-induced astrocyte swelling: role of 
$\mathrm{K}^{+}$influx. J. Neurosci. Res. 52, 307-321. doi: 10.1002/(sici)10974547(19980501)52:3<307::aid-jnr7>3.0.co;2-h

Berger, U. V., and Hediger, M. A. (2000). Distribution of the glutamate transporters GLAST and GLT-1 in rat circumventricular organs, meninges, and dorsal root ganglia. J. Comp. Neurol. 421, 385-399. doi: 10.1002/(sici)10969861(20000605)421:3<385::aid-cne7>3.0.co;2-s

Bergersen, L. H., Morland, C., Ormel, L., Rinholm, J. E., Larsson, M., Wold, J. F., et al. (2012). Immunogold detection of L-glutamate and D-serine in small synaptic-like microvesicles in adult hippocampal astrocytes. Cereb. Cortex 22, 1690-1697. doi: 10.1093/cercor/bhr254

Beschorner, R., Simon, P., Schauer, N., Mittelbronn, M., Schluesener, H. J., Trautmann, K., et al. (2007). Reactive astrocytes and activated microglial cells express EAAT1, but not EAAT2, reflecting a neuroprotective potential following ischaemia. Histopathology 50, 897-910. doi: 10.1111/j.1365-2559. 2007.02703.x

Bezzi, P., Domercq, M., Vesce, S., and Volterra, A. (2001). Neuron-astrocyte cross-talk during synaptic transmission: physiological and neuropathological implications. Prog. Brain Res. 132, 255-265. doi: 10.1016/s00796123(01)32081-2

Bezzi, P., Gundersen, V., Galbete, J. L., Seifert, G., Steinhauser, C., Pilati, E., et al. (2004). Astrocytes contain a vesicular compartment that is competent for regulated exocytosis of glutamate. Nat. Neurosci. 7, 613-620. doi: $10.1038 / \mathrm{nn} 1246$

Blackshaw, L. A., Page, A. J., and Young, R. L. (2011). Metabotropic glutamate receptors as novel therapeutic targets on visceral sensory pathways. Front. Neurosci. 5:40. doi: 10.3389/fnins.2011.00040

Bohmbach, K., Schwarz, M. K., Schoch, S., and Henneberger, C. (2018). The structural and functional evidence for vesicular release from astrocytes in situ. Brain Res. Bull. 136, 65-75. doi: 10.1016/j.brainresbull.2017.01.015

Bowens, N. H., Dohare, P., Kuo, Y. H., and Mongin, A. A. (2013). DCPIB, the proposed selective blocker of volume-regulated anion channels, inhibits several glutamate transport pathways in glial cells. Mol. Pharmacol. 83, 22-32. doi: 10.1124/mol.112.080457

Bramlett, H. M., and Dietrich, W. D. (2004). Pathophysiology of cerebral ischemia and brain trauma: similarities and differences. J. Cereb. Blood Flow Metab. 24, 133-150. doi: 10.1097/01.wcb.0000111614.19196.04

Brickley, S. G., Misra, C., Mok, M. H., Mishina, M., and Cull-Candy, S. G. (2003). NR2B and NR2D subunits coassemble in cerebellar Golgi cells to form a distinct NMDA receptor subtype restricted to extrasynaptic sites. J. Neurosci. 23, 4958-4966. doi: 10.1523/JNEUROSCI.23-1204958.2003

Bridges, R., Lutgen, V., Lobner, D., and Baker, D. A. (2012). Thinking outside the cleft to understand synaptic activity: contribution of the cystine-glutamate antiporter (System $\mathrm{x}_{c}^{-}$) to normal and pathological glutamatergic signaling. Pharmacol. Rev. 64, 780-802. doi: 10.1124/pr.110. 003889

Broughton, B. R., Reutens, D. C., and Sobey, C. G. (2009). Apoptotic mechanisms after cerebral ischemia. Stroke 40, e331-e339. doi: 10.1161/strokeaha.108. 531632

Burns, K. A., Murphy, B., Danzer, S. C., and Kuan, C. Y. (2009). Developmental and post-injury cortical gliogenesis: a genetic fate-mapping study with NestinCreER mice. Glia 57, 1115-1129. doi: 10.1002/glia.20835

Burnstock, G. (2017). Purinergic signalling and neurological diseases: an update. CNS Neurol. Disord. Drug Targets 16, 257-265. doi: $10.2174 / 1871527315666160922104848$

Burzomato, V., Frugier, G., Pérez-Otaño, I., Kittler, J. T., and Attwell, D. (2010). The receptor subunits generating NMDA receptor mediated currents in oligodendrocytes. J. Physiol. 588, 3403-3414. doi: 10.1113/jphysiol.2010. 195503

Buser, J. R., Segovia, K. N., Dean, J. M., Nelson, K., Beardsley, D., Gong, X., et al. (2010). Timing of appearance of late oligodendrocyte progenitors coincides with enhanced susceptibility of preterm rabbit cerebral white matter to hypoxia-ischemia. J. Cereb. Blood Flow Metab. 30, 1053-1065. doi: $10.1038 /$ jcbfm.2009.286

Butenko, O., Dzamba, D., Benesova, J., Honsa, P., Benfenati, V., Rusnakova, V., et al. (2012). The increased activity of TRPV4 channel in the astrocytes of the adult rat hippocampus after cerebral hypoxia/ischemia. PLoS One 7:e39959. doi: 10.1371/journal.pone.0039959
Bylicky, M. A., Mueller, G. P., and Day, R. M. (2018). Mechanisms of endogenous neuroprotective effects of astrocytes in brain injury. Oxid. Med. Cell. Longev. 2018:6501031. doi: 10.1155/2018/6501031

Cai, Q., Ma, T., Li, C., Tian, Y., and Li, H. (2016). Catalpol protects pre-myelinating oligodendrocytes against ischemia-induced oxidative injury through ERK1/2 signaling pathway. Int. J. Biol. Sci. 12, 1415-1426. doi: $10.7150 /$ ijbs. 16823

Ceprian, M., and Fulton, D. (2019). Glial cell AMPA receptors in nervous system health, injury and disease. Int. J. Mol. Sci. 20:E2450. doi: 10.3390/ijms20102450

Chan, P. H. (2001). Reactive oxygen radicals in signaling and damage in the ischemic brain. J. Cereb. Blood Flow Metab. 21, 2-14. doi: 10.1097/00004647200101000-00002

Chan, P. H., and Chu, L. (1990). Mechanisms underlying glutamate-induced swelling of astrocytes in primary culture. Acta Neurochir. Suppl. 51, 7-10. doi: 10.1007/978-3-7091-9115-6_3

Chan, P. H., Chu, L., and Chen, S. (1990). Effects of MK-801 on glutamateinduced swelling of astrocytes in primary cell culture. J. Neurosci. Res. 25, 87-93. doi: 10.1002/jnr.490250111

Chaudhry, F. A., Lehre, K. P., van Lookeren Campagne, M., Ottersen, O. P., Danbolt, N. C., and Storm-Mathisen, J. (1995). Glutamate transporters in glial plasma membranes: highly differentiated localizations revealed by quantitative ultrastructural immunocytochemistry. Neuron 15, 711-720. doi: 10.1016/08966273(95)90158-2

Chen, M., Dong, Y., and Simard, J. M. (2003). Functional coupling between sulfonylurea receptor type 1 and a nonselective cation channel in reactive astrocytes from adult rat brain. J. Neurosci. 23, 8568-8577. doi: 10.1523/JNEUROSCI.23-24-08568.2003

Chen, J. C., Hsu-Chou, H., Lu, J. L., Chiang, Y. C., Huang, H. M., Wang, H. L., et al. (2005). Down-regulation of the glial glutamate transporter GLT-1 in rat hippocampus and striatum and its modulation by a group III metabotropic glutamate receptor antagonist following transient global forebrain ischemia. Neuropharmacology 49, 703-714. doi: 10.1016/j.neuropharm.2005. 05.002

Chen, X., Lu, M., He, X., Ma, L., Birnbaumer, L., and Liao, Y. (2017). TRPC3/6/7 knockdown protects the brain from cerebral ischemia injury via astrocyte apoptosis inhibition and effects on NF-кB translocation. Mol. Neurobiol. 54, 7555-7566. doi: 10.1007/s12035-016-0227-2

Chen, M., and Simard, J. M. (2001). Cell swelling and a nonselective cation channel regulated by internal $\mathrm{Ca}^{2+}$ and $\mathrm{ATP}$ in native reactive astrocytes from adult rat brain. J. Neurosci. 21, 6512-6521. doi: 10.1523/JNEUROSCI.21-17-06512.2001

Chen, H., Tian, M., Jin, L., Jia, H., and Jin, Y. (2015). PUMA is invovled in ischemia/reperfusion-induced apoptosis of mouse cerebral astrocytes. Neuroscience 284, 824-832. doi: 10.1016/j.neuroscience.2014.10.059

Chisholm, N. C., and Sohrabji, F. (2016). Astrocytic response to cerebral ischemia is influenced by sex differences and impaired by aging. Neurobiol. Dis. 85 , 245-253. doi: 10.1016/j.nbd.2015.03.028

Colangelo, V., Gordon, W. C., Mukherjee, P. K., Trivedi, P., and Ottino, P. (2004) Downregulation of COX-2 and JNK expression after induction of ischemic tolerance in the gerbil brain. Brain Res. 1016, 195-200. doi: 10.1016/j.brainres. 2004.05.017

Connor, J. R., and Menzies, S. L. (1996). Relationship of iron to oligodendrocytes and myelination. Glia 17, 83-93. doi: 10.1002/(SICI)10981136(199606)17:2<83::AID-GLIA1>3.0.CO;2-7

Crespo, A. R., Da Rocha, A. B., Jotz, G. P., Schneider, R. F., Grivicich, I. Pinheiro, K., et al. (2007). Increased serum sFas and TNF $\alpha$ following isolated severe head injury in males. Brain Inj. 21, 441-447. doi: 10.1080/02699050701311125

Cuartero, M. I., de la Parra, J., Garcia-Culebras, A., Ballesteros, I., Lizasoain, I., and Moro, M. A. (2016). The kynurenine pathway in the acute and chronic phases of cerebral ischemia. Curr. Pharm. Des. 22, 1060-1073. doi: $10.2174 / 1381612822666151214125950$

Dai, X., Chen, J., Xu, F., Zhao, J., Cai, W., Sun, Z., et al. (2020). TGF $\alpha$ preserves oligodendrocyte lineage cells and improves white matter integrity after cerebral ischemia. J. Cereb. Blood Flow Metab. 40, 639-655. doi: $10.1177 / 0271678 X 19830791$

Dale, N., and Frenguelli, B. G. (2009). Release of adenosine and ATP during ischemia and epilepsy. Curr. Neuropharmacol. 7, 160-179. doi: $10.2174 / 157015909789152146$ 
D’Antoni, S., Berretta, A., Bonaccorso, C. M., Bruno, V., Aronica, E., Nicoletti, F., et al. (2008). Metabotropic glutamate receptors in glial cells. Neurochem. Res. 33, 2436-2443. doi: 10.1007/s11064-008-9694-9

Danysz, W., and Parsons, C. G. (2003). The NMDA receptor antagonist memantine as a symptomatological and neuroprotective treatment for Alzheimer's disease: preclinical evidence. Int. J. Geriatr. Psychiatry 18, S23-S32. doi: 10.1002 /gps.938

Davalos, D., Grutzendler, J., Yang, G., Kim, J. V., Zuo, Y., Jung, S., et al. (2005). ATP mediates rapid microglial response to local brain injury in vivo. Nat. Neurosci. 8, 752-758. doi: 10.1038/nn1472

Dave, K. R., Lange-Asschenfeldt, C., Raval, A. P., Prado, R., Busto, R., Saul, I., et al. (2005). Ischemic preconditioning ameliorates excitotoxicity by shifting glutamate $/ \gamma$-aminobutyric acid release and biosynthesis. J. Neurosci. Res. 82, 665-673. doi: 10.1002/jnr.20674

Davidson, J. O., Green, C. R., Bennet, L., Nicholson, L. F., DaneshMeyer, H., O'Carroll, S. J., et al. (2013). A key role for connexin hemichannels in spreading ischemic brain injury. Curr. Drug Targets 14, 36-46. doi: $10.2174 / 138945013804806479$

Davis, C. H., Kim, K. Y., Bushong, E. A., Mills, E. A., Boassa, D., Shih, T., et al. (2014). Transcellular degradation of axonal mitochondria. Proc. Natl. Acad. Sci. U S A 111, 9633-9638. doi: 10.1073/pnas.1404651111

Dehnes, Y., Chaudhry, F. A., Ullensvang, K., Lehre, K. P., Storm-Mathisen, J., and Danbolt, N. C. (1998). The glutamate transporter EAAT4 in rat cerebellar Purkinje cells: a glutamate-gated chloride channel concentrated near the synapse in parts of the dendritic membrane facing astroglia. J. Neurosci. 18, 3606-3619. doi: 10.1523/JNEUROSCI.18-10-03606.1998

Deng, W., Neve, R. L., Rosenberg, P. A., Volpe, J. J., and Jensen, F. E. (2006). $\alpha$-amino-3-hydroxy-5-methyl-4-isoxazole propionate receptor subunit composition and cAMP-response element-binding protein regulate oligodendrocyte excitotoxicity. J. Biol. Chem. 281, 36004-36011. doi: 10.1074/jbc.M606459200

Deng, W., and Poretz, R. D. (2003). Oligodendroglia in developmental neurotoxicity. Neurotoxicology 24, 161-178. doi: 10.1016/s0161813x(02)00196-1

Deng, W., Wang, H., Rosenberg, P. A., Volpe, J. J., and Jensen, F. E. (2004). Role of metabotropic glutamate receptors in oligodendrocyte excitotoxicity and oxidative stress. Proc. Natl. Acad. Sci. U S A 101, 7751-7756. doi: 10.1073/pnas. 0307850101

Deng, Y., Xie, D., Fang, M., Zhu, G., Chen, C., Zeng, H., et al. (2014). Astrocyte-derived proinflammatory cytokines induce hypomyelination in the periventricular white matter in the hypoxic neonatal brain. PLoS One 9:e87420. doi: 10.1371/journal.pone.0087420

Desilva, T. M., Kinney, H. C., Borenstein, N. S., Trachtenberg, F. L., Irwin, N., Volpe, J. J., et al. (2007). The glutamate transporter EAAT2 is transiently expressed in developing human cerebral white matter. J. Comp. Neurol. 501, 879-890. doi: 10.1002/cne.21289

Dhodda, V. K., Sailor, K. A., Bowen, K. K., and Vemuganti, R. (2004). Putative endogenous mediators of preconditioning-induced ischemic tolerance in rat brain identified by genomic and proteomic analysis. J. Neurochem. 89, 73-89. doi: 10.1111/j.1471-4159.2004.02316.x

Diaz-Ruiz, A., Montes, S., Salgado-Ceballos, H., Maldonado, V., RiveraEspinosa, L., and Ríos, C. (2016). Enzyme activities involved in the glutamate-glutamine cycle are altered to reduce glutamate after spinal cord injury in rats. Neuroreport 27, 1317-1322. doi: 10.1097/wnr.0000000000 000700

Domercq, M., Perez-Samartin, A., Aparicio, D., Alberdi, E., Pampliega, O., and Matute, C. (2010). P2X7 receptors mediate ischemic damage to oligodendrocytes. Glia 58, 730-740. doi: 10.1002/glia.20958

Domercq, M., Sánchez-Gómez, M. V., Areso, P., and Matute, C. (1999). Expression of glutamate transporters in rat optic nerve oligodendrocytes. Eur. J. Neurosci. 11, 2226-2236. doi: 10.1046/j.1460-9568.1999.00639.x

Domercq, M., Sánchez-Gómez, M. V., Sherwin, C., Etxebarria, E., Fern, R., and Matute, C. (2007). System xc- and glutamate transporter inhibition mediates microglial toxicity to oligodendrocytes. J. Immunol. 178, 6549-6556. doi: 10.4049/jimmunol.178.10.6549

Doyle, S., Hansen, D. B., Vella, J., Bond, P., Harper, G., Zammit, C., et al. (2018). Vesicular glutamate release from central axons contributes to myelin damage. Nat. Commun. 9:1032. doi: 10.1038/s41467-018-03427-1
Doyle, K. P., Simon, R. P., and Stenzel-Poore, M. P. (2008). Mechanisms of ischemic brain damage. Neuropharmacology 55, 310-318. doi: 10.1016/j. neuropharm.2008.01.005

Drejer, J., Larsson, O. M., and Schousboe, A. (1982). Characterization of L-glutamate uptake into and release from astrocytes and neurons cultured from different brain regions. Exp. Brain Res. 47, 259-269. doi: 10.1007/bf002 39385

Du, C., Hu, R., Csernansky, C. A., Hsu, C. Y., and Choi, D. W. (1996). Very delayed infarction after mild focal cerebral ischemia: a role for apoptosis? J. Cereb. Blood Flow Metab. 16, 195-201. doi: 10.1097/00004647-199603000-00003

Du, Y., Wang, W., Lutton, A. D., Kiyoshi, C. M., Ma, B., Taylor, A. T., et al. (2018). Dissipation of transmembrane potassium gradient is the main cause of cerebral ischemia-induced depolarization in astrocytes and neurons. Exp. Neurol. 303, 1-11. doi: 10.1016/j.expneurol.2018.01.019

Duan, S., Anderson, C. M., Keung, E. C., Chen, Y., and Swanson, R. A. (2003). $\mathrm{P} 2 \mathrm{X} 7$ receptor-mediated release of excitatory amino acids from astrocytes. J. Neurosci. 23, 1320-1328. doi: 10.1523/JNEUROSCI.23-04-01320.2003

Durán-Laforet, V., Fernández-López, D., García-Culebras, A., González-Hijón, J., Moraga, A., Palma-Tortosa, S., et al. (2019). Delayed effects of acute reperfusion on vascular remodeling and late-phase functional recovery after stroke. Front. Neurosci. 13:767. doi: 10.3389/fnins.2019.00767

Dzamba, D., Honsa, P., and Anderova, M. (2013). NMDA receptors in glial cells: pending questions. Curr. Neuropharmacol. 11, 250-262. doi: $10.2174 / 1570159 \times 11311030002$

Eliasof, S., Arriza, J. L., Leighton, B. H., Kavanaugh, M. P., and Amara, S. G. (1998), Excitatory amino acid transporters of the salamander retina: identification, localization and function. J. Neurosci. 18, 698-712. doi: 10.1523/JNEUROSCI. 18-02-00698.1998

Erecińska, M., and Silver, I. A. (2001). Tissue oxygen tension and brain sensitivity to hypoxia. Respir. Physiol. 128, 263-276. doi: 10.1016/s0034-5687(01)00306-1

Eyo, U. B., Miner, S. A., Ahlers, K. E., Wu, L. J., and Dailey, M. E. (2013). $\mathrm{P} 2 \mathrm{X} 7$ receptor activation regulates microglial cell death during oxygen-glucose deprivation. Neuropharmacology 73, 311-319. doi: 10.1016/j.neuropharm. 2013.05.032

Fairman, W. A., Vandenberg, R. J., Arriza, J. L., Kavanaugh, M. P., and Amara, S. G. (1995). An excitatory amino-acid transporter with properties of a ligand-gated chloride channel. Nature 375, 599-603. doi: 10.1038/375 $599 \mathrm{a} 0$

Falahati, S., Breu, M., Waickman, A. T., Phillips, A. W., Arauz, E. J., Snyder, S., et al. (2013). Ischemia-induced neuroinflammation is associated with disrupted development of oligodendrocyte progenitors in a model of periventricular leukomalacia. Dev. Neurosci. 35, 182-196. doi: 10.1159/000346682

Feng, X., Yang, F., Rabenstein, M., Wang, Z., Frech, M. J., Wree, A., et al. (2019). Stimulation of mGluR1/5 improves defective internalization of AMPA receptors in NPC1 mutant mouse. Cereb. Cortex doi: 10.1093/cercor/bhz179 [Epub ahead of print].

Fern, R., and Matute, C. (2019). Glutamate receptors and white matter stroke. Neurosci. Lett. 694, 86-92. doi: 10.1016/j.neulet.2018.11.031

Fern, R., and Moller, T. (2000). Rapid ischemic cell death in immature oligodendrocytes: a fatal glutamate release feedback loop. J. Neurosci. 20, 34-42. doi: 10.1523/JNEUROSCI.20-01-00034.2000

Feustel, P. J., Jin, Y., and Kimelberg, H. K. (2004). Volume-regulated anion channels are the predominant contributors to release of excitatory amino acids in the ischemic cortical penumbra. Stroke 35, 1164-1168. doi: 10.1161/01.str. 0000124127.57946.a1

Fiacco, T. A., and McCarthy, K. D. (2018). Multiple lines of evidence indicate that gliotransmission does not occur under physiological conditions. J. Neurosci. 38, 3-13. doi: 10.1523/JNEUROSCI.0016-17.2017

French, H. M., Reid, M., Mamontov, P., Simmons, R. A., and Grinspan, J. B. (2009). Oxidative stress disrupts oligodendrocyte maturation. J. Neurosci. Res. 87, 3076-3087. doi: 10.1002/jnr.22139

Fricker, M., Tolkovsky, A. M., Borutaite, V., Coleman, M., and Brown, G. C. (2018). Neuronal cell death. Physiol. Rev. 98, 813-880. doi: 10.1152/physrev. 00011.2017

Fujimoto, S., Katsuki, H., Kume, T., Kaneko, S., and Akaike, A. (2004). Mechanisms of oxygen glucose deprivation-induced glutamate release from cerebrocortical slice cultures. Neurosci. Res. 50, 179-187. doi: 10.1016/j.neures. 2004.06.013 
Fukamachi, S., Furuta, A., Ikeda, T., Ikenoue, T., Kaneoka, T., Rothstein, J. D., et al. (2001). Altered expressions of glutamate transporter subtypes in rat model of neonatal cerebral hypoxia-ischemia. Dev. Brain Res. 132, 131-139. doi: 10.1016/s0165-3806(01)00303-0

Furness, D. N., Dehnes, Y., Akhtar, A. Q., Rossi, D. J., Hamann, M., Grutle, N. J., et al. (2008). A quantitative assessment of glutamate uptake into hippocampal synaptic terminals and astrocytes: new insights into a neuronal role for excitatory amino acid transporter 2 (EAAT2). Neuroscience 157, 80-94. doi: 10.1016/j.neuroscience.2008.08.043

Furuta, A., Rothstein, J. D., and Martin, L. J. (1997). Glutamate transporter protein subtypes are expressed differentially during rat CNS development. J. Neurosci. 17, 8363-8375. doi: 10.1523/JNEUROSCI.17-21-08363.1997

Gagliardi, R. J. (2000). Neuroprotection, excitotoxicity and NMDA antagonists. Arq. Neuropsiquiatr. 58, 583-588. doi: 10.1590/s0004-282x2000000300030

Ganel, R., Ho, T., Maragakis, N. J., Jackson, M., Steiner, J. P., and Rothstein, J. D. (2006). Selective up-regulation of the glial $\mathrm{Na}^{+}$-dependent glutamate transporter GLT1 by a neuroimmunophilin ligand results in neuroprotection. Neurobiol. Dis. 21, 556-567. doi: 10.1016/j.nbd.2005.08.014

Giaume, C., Leybaert, L., Naus, C. C., and Sáez, J. C. (2013). Connexin and pannexin hemichannels in brain glial cells: properties, pharmacology, and roles. Front. Pharmacol. 4:88. doi: 10.3389/fphar.2013.00088

Gidday, J. M., Shah, A. R., Maceren, R. G., Wang, Q., Pelligrino, D. A., Holtzman, D. M., et al. (1999). Nitric oxide mediates cerebral ischemic tolerance in a neonatal rat model of hypoxic preconditioning. J. Cereb. Blood Flow Metab. 19, 331-340. doi: 10.1097/00004647-199903000-00011

Ginsberg, M. D. (2003). Adventures in the pathophysiology of brain ischemia: penumbra, gene expression, neuroprotection: the 2002 Thomas Willis Lecture. Stroke 34, 214-223. doi: 10.1161/01.str.0000048846.09677.62

Girling, K. D., Demers, M. J., Laine, J., Zhang, S., Wang, Y. T., and Graham, R. K. (2018). Activation of caspase- 6 and cleavage of caspase- 6 substrates is an early event in NMDA receptor-mediated excitotoxicity. J. Neurosci. Res. 96, 391-406. doi: 10.1002/jnr.24153

Gong, S. J., Chen, L. Y., Zhang, M., Gong, J. X., Ma, Y. X., Zhang, J. M., et al. (2012). Intermittent hypobaric hypoxia preconditioning induced brain ischemic tolerance by up-regulating glial glutamate transporter-1 in rats. Neurochem. Res. 37, 527-537. doi: 10.1007/s11064-011-0639-3

Gottlieb, M., and Matute, C. (1997). Expression of ionotropic glutamate receptor subunits in glial cells of the hippocampal CA1 area following transient forebrain ischemia. J. Cereb. Blood Flow Metab. 17, 290-300. doi: 10.1097/00004647-199703000-00006

Grygorowicz, T., Struzyńska, L., Sulkowski, G., Chalimoniuk, M., and Sulejczak, D. (2010). Temporal expression of P2X7 purinergic receptor during the course of experimental autoimmune encephalomyelitis. Neurochem. Int. 57, 823-829. doi: 10.1016/j.neuint.2010.08.021

Gülke, E., Gelderblom, M., and Magnus, T. (2018). Danger signals in stroke and their role on microglia activation after ischemia. Ther. Adv. Neurol. Disord. 11:1756286418774254. doi: 10.1177/1756286418774254

Gundersen, V., Storm-Mathisen, J., and Bergersen, L. H. (2015). Neuroglial transmission. Physiol. Rev. 95, 695-726. doi: 10.1152/physrev.00024.2014

Guo, C. Y., Xiong, T. Q., Tan, B. H., Gui, Y., Ye, N., Li, S. L., et al. (2019). The temporal and spatial changes of actin cytoskeleton in the hippocampal CA1 neurons following transient global ischemia. Brain Res. 1720:146297. doi: 10.1016/j.brainres.2019.06.016

Gupta, S. (2003). Molecular signaling in death receptor and mitochondrial pathways of apoptosis (Review). Int. J. Oncol. 22, 15-20. doi: 10.3892/ijo. 22.1.15

Gupta, K., Hardingham, G. E., and Chandran, S. (2013). NMDA receptordependent glutamate excitotoxicity in human embryonic stem cell-derived neurons. Neurosci. Lett. 543, 95-100. doi: 10.1016/j.neulet.2013.03.010

Hamilton, N. B., and Attwell, D. (2010). Do astrocytes really exocytose neurotransmitters? Nat. Rev. Neurosci. 11, 227-238. doi: 10.1038/nrn2803

Hamilton, N., Vayro, S., Kirchhoff, F., Verkhratsky, A., Robbins, J., Gorecki, D. C., et al. (2008). Mechanisms of ATP- and glutamate-mediated calcium signaling in white matter astrocytes. Glia 56, 734-749. doi: 10.1002/glia.20649

Hansen, A. J., and Nedergaard, M. (1988). Brain ion homeostasis in cerebral ischemia. Neurochem. Pathol. 9, 195-209. doi: 10.1007/bf03160362

Hansen, D. B., Ye, Z. C., Calloe, K., Braunstein, T. H., Hofgaard, J. P., Ransom, B. R., et al. (2014). Activation, permeability, and inhibition of astrocytic and neuronal large pore (hemi)channels. J. Biol. Chem. 289, 26058-26073. doi: 10.1074/jbc.M114.582155

Hansson, E. (1994). Metabotropic glutamate receptor activation induces astroglial swelling. J. Biol. Chem. 269, 21955-21961.

Harrigan, T. J., Abdullaev, I. F., Jourd'heuil, D., and Mongin, A. A. (2008). Activation of microglia with zymosan promotes excitatory amino acid release via volume-regulated anion channels: the role of NADPH oxidases. J. Neurochem. 106, 2449-2462. doi: 10.1111/j.1471-4159.2008.05553.x

Hartings, J. A., Shuttleworth, C. W., Kirov, S. A., Ayata, C., Hinzman, J. M., Foreman, B., et al. (2017). The continuum of spreading depolarizations in acute cortical lesion development: examining Leao's legacy. J. Cereb. Blood Flow Metab. 37, 1571-1594. doi: 10.1177/0271678X16654495

Harukuni, I., and Bhardwaj, A. (2006). Mechanisms of brain injury after global cerebral ischemia. Neurol. Clin. 24, 1-21. doi: 10.1016/j.ncl.2005.10.004

Harvey, B. K., Airavaara, M., Hinzman, J., Wires, E. M., Chiocco, M. J., Howard, D. B., et al. (2011). Targeted over-expression of glutamate transporter 1 (GLT-1) reduces ischemic brain injury in a rat model of stroke. PLoS One 6:e22135. doi: 10.1371/journal.pone.0022135

Hawkins, R. A., and Viña, J. R. (2016). How glutamate is managed by the bloodbrain barrier. Biology 5:E37. doi: 10.3390/biology5040037

Hayakawa, K., Esposito, E., Wang, X., Terasaki, Y., Liu, Y., Xing, C., et al. (2016). Transfer of mitochondria from astrocytes to neurons after stroke. Nature 535, 551-555. doi: 10.1038/nature 18928

Haynes, R. L., Folkerth, R. D., Keefe, R. J., Sung, I., Swzeda, L. I., Rosenberg, P. A., et al. (2003). Nitrosative and oxidative injury to premyelinating oligodendrocytes in periventricular leukomalacia. J. Neuropathol. Exp. Neurol. 62, 441-450. doi: 10.1093/jnen/62.5.441

Heiss, W. D., Sobesky, J., and Hesselmann, V. (2004). Identifying thresholds for penumbra and irreversible tissue damage. Stroke 35, 2671-2674. doi: 10.1161/01.str.0000143329.81997.8a

Heurteaux, C., Guy, N., Laigle, C., Blondeau, N., Duprat, F., Mazzuca, M., et al. (2004). TREK-1, a $\mathrm{K}^{+}$channel involved in neuroprotection and general anesthesia. EMBO J. 23, 2684-2695. doi: 10.1038/sj.emboj.7600234

Hinzman, J. M., DiNapoli, V. A., Mahoney, E. J., Gerhardt, G. A., and Hartings, J. A. (2015). Spreading depolarizations mediate excitotoxicity in the development of acute cortical lesions. Exp. Neurol. 267, 243-253. doi: 10.1016/j. expneurol.2015.03.014

Honsa, P., Pivonkova, H., Dzamba, D., Filipova, M., and Anderova, M. (2012). Polydendrocytes display large lineage plasticity following focal cerebral ischemia. PLoS One 7:e36816. doi: 10.1371/journal.pone.0036816

Hossmann, K. A. (1996). Periinfarct depolarizations. Cerebrovasc. Brain Metab. Rev. 8, 195-208.

Hu, X., Yang, J., Sun, Y., Gao, X., Zhang, L., Li, Y., et al. (2018). Lanthanum chloride impairs memory in rats by disturbing the glutamate-glutamine cycle and over-activating NMDA receptors. Food Chem. Toxicol. 113, 1-13. doi: 10.1016/j.fct.2018.01.023

Husain, J., and Juurlink, B. H. J. (1995). Oligodendroglial precursor cell susceptibility to hypoxia is related to poor ability to cope with reactive oxygen species. Brain Res. 698, 86-94. doi: 10.1016/0006-8993(95)00832-b

Iadecola, C., Sugimoto, K., Niwa, K., Kazama, K., and Ross, M. E. (2001). Increased susceptibility to ischemic brain injury in cyclooxygenase-1-deficient mice. J. Cereb. Blood Flow Metab. 21, 1436-1441. doi: 10.1097/00004647-20011200000008

Illarionova, N. B., Gunnarson, E., Li, Y., Brismar, H., Bondar, A., Zelenin, S., et al. (2010). Functional and molecular interactions between aquaporins and $\mathrm{Na}, \mathrm{K}$ ATPase. Neuroscience 168, 915-925. doi: 10.1016/j.neuroscience.2009.11.062

Imura, Y., Morizawa, Y., Komatsu, R., Shibata, K., Shinozaki, Y., Kasai, H., et al. (2013). Microglia release ATP by exocytosis. Glia 61, 1320-1330. doi: $10.1002 /$ glia.22517

Inoue, H., and Okada, Y. (2007). Roles of volume-sensitive chloride channel in excitotoxic neuronal injury. J. Neurosci. 27, 1445-1455. doi: 10.1523/jneurosci. 4694-06.2007

Itoh, T., Beesley, J., Itoh, A., Cohen, A. S., Kavanaugh, B., Coulter, D. A., et al. (2002). AMPA glutamate receptor-mediated calcium signaling is transiently enhanced during development of oligodendrocytes. J. Neurochem. 81, 390-402. doi: 10.1046/j.1471-4159.2002.00866.x

Jabaudon, D., Scanziani, M., Gahwiler, B. H., and Gerber, U. (2000). Acute decrease in net glutamate uptake during energy deprivation. 
Proc. Natl. Acad. Sci. U S A 97, 5610-5615. doi: 10.1073/pnas.97. 10.5610

Jayakumar, A. R., Taherian, M., Panickar, K. S., Shamaladevi, N., Rodriguez, M. E., Price, B. G., et al. (2018). Differential response of neural cells to trauma-induced swelling in vitro. Neurochem. Res. 43, 397-406. doi: 10.1007/s11064-0172434-2

Jha, R. M., Kochanek, P. M., and Simard, J. M. (2019). Pathophysiology and treatment of cerebral edema in traumatic brain injury. Neuropharmacology 145, 230-246. doi: 10.1016/j.neuropharm.2018.08.004

Jung, S., Wiest, R., Gralla, J., McKinley, R., Mattle, H., and Liebeskind, D. (2017). Relevance of the cerebral collateral circulation in ischaemic stroke: time is brain, but collaterals set the pace. Swiss Med. Wkly. 147:w14538. doi: 10.4414/smw.2017.14538

Juurlink, B. H., Thorburne, S. K., and Hertz, L. (1998). Peroxide-scavenging deficit underlies oligodendrocyte susceptibility to oxidative stress. Glia 22, 371-378. doi: 10.1002/(sici)1098-1136(199804)22:4<371::aid-glia6>3.0.co;2-6

Kahles, T., Luedike, P., Endres, M., Galla, H. J., Steinmetz, H., Busse, R., et al. (2007). NADPH oxidase plays a central role in blood-brain barrier damage in experimental stroke. Stroke 38, 3000-3006. doi: 10.1161/strokeaha.107.489765

Kalogeris, T., Bao, Y., and Korthuis, R. J. (2014). Mitochondrial reactive oxygen species: a double edged sword in ischemia/reperfusion vs. preconditioning. Redox Biol. 2, 702-714. doi: 10.1016/j.redox.2014.05.006

Kanai, Y., and Hediger, M. A. (2004). The glutamate/neutral amino acid transporter family SLC1: molecular, physiological and pharmacological aspects. Pflugers Arch. 447, 469-479. doi: 10.1007/s00424-003-1146-4

Kang, J., Kang, N., Lovatt, D., Torres, A., Zhao, Z., Lin, J., et al. (2008). Connexin 43 hemichannels are permeable to ATP. J. Neurosci. 28, 4702-4711. doi: 10.1523/jneurosci.5048-07.2008

Káradóttir, R., and Attwell, D. (2007). Neurotransmitter receptors in the life and death of oligodendrocytes. Neuroscience 145, 1426-1438. doi: 10.1016/j. neuroscience.2006.08.070

Káradóttir, R., Cavelier, P., Bergersen, L. H., and Attwell, D. (2005). NMDA receptors are expressed in oligodendrocytes and activated in ischaemia. Nature 438, 1162-1166. doi: 10.1038/nature04302

Karikó, K., Weissman, D., and Welsh, F. A. (2004). Inhibition of toll-like receptor and cytokine signaling-a unifying theme in ischemic tolerance. J. Cereb. Blood Flow Metab. 24, 1288-1304. doi: 10.1097/01.wcb.0000145666.68576.71

Katayama, Y., Kawamata, T., Tamura, T., Hovda, D. A., Becker, D. P., and Tsubokawa, T. (1991). Calcium-dependent glutamate release concomitant with massive potassium flux during cerebral ischemia in vivo. Brain Res. 558, 136-140. doi: 10.1016/0006-8993(91)90730-j

Kauppinen, T. M., and Swanson, R. A. (2007). The role of poly(ADP-ribose) polymerase-1 in CNS disease. Neuroscience 145, 1267-1272. doi: 10.1016/j. neuroscience.2006.09.034

Kawahara, K., Kosugi, T., Tanaka, M., Nakajima, T., and Yamada, T. (2005). Reversed operation of glutamate transporter GLT-1 is crucial to the development of preconditioning-induced ischemic tolerance of neurons in neuron/astrocyte co-cultures. Glia 49, 349-359. doi: 10.1002/glia.20114

Ketheeswaranathan, P., Turner, N. A., Spary, E. J., Batten, T. F., McColl, B. W., and Saha, S. (2011). Changes in glutamate transporter expression in mouse forebrain areas following focal ischemia. Brain Res. 1418, 93-103. doi: 10.1016/j.brainres.2011.08.029

Kim, H. J., and Chuang, D. M. (2014). HDAC inhibitors mitigate ischemiainduced oligodendrocyte damage: potential roles of oligodendrogenesis, VEGF, and anti-inflammation. Am. J. Transl. Res. 6, 206-223.

Kim, Y., Davidson, J. O., Green, C. R., Nicholson, L. F. B., O'Carroll, S. J., and Zhang, J. (2018). Connexins and pannexins in cerebral ischemia. Biochim. Biophys. Acta Biomembr. 1860, 224-236. doi: 10.1016/j.bbamem.2017. 03.018

Kim, T. K., Park, D., Ban, Y. H., Cha, Y., An, E. S., Choi, J., et al. (2018). Improvement by human oligodendrocyte progenitor cells of neurobehavioral disorders in an experimental model of neonatal periventricular leukomalacia. Cell Transplant 27, 1168-1177. doi: 10.1177/0963689718781330

Kimelberg, H. K. (2005). Astrocytic swelling in cerebral ischemia as a possible cause of injury and target for therapy. Glia 50, 389-397. doi: 10.1002/glia. 20174

Kimelberg, H. K., Goderie, S. K., Higman, S., Pang, S., and Waniewski, R. A. (1990). Swelling-induced release of glutamate, aspartate, and taurine from astrocyte cultures. J. Neurosci. 10, 1583-1591. doi: 10.1523/jneurosci.10-0501583.1990

Kirino, T., and Sano, K. (1984). Selective vulnerability in the gerbil hippocampus following transient ischemia. Acta Neuropathol. 62, 201-208. doi: 10.1007/bf00691853

Kitagawa, K., Matsumoto, M., Kuwabara, K., Tagaya, M., Ohtsuki, T., Hata, R., et al. (1991). 'Ischemic tolerance' phenomenon detected in various brain regions. Brain Res. 561, 203-211. doi: 10.1016/0006-8993(91)91596-s

Kitagawa, K., Matsumoto, M., Tagaya, M., Hata, R., Ueda, H., Niinobe, M., et al. (1990). 'Ischemic tolerance' phenomenon found in the brain. Brain Res. 528, 21-24. doi: 10.1016/0006-8993(90)90189-i

Krebs, C., Fernandes, H. B., Sheldon, C., Raymond, L. A., and Baimbridge, K. G. (2003). Functional NMDA receptor subtype $2 \mathrm{~B}$ is expressed in astrocytes after ischemia in vivo and anoxia in vitro. J. Neurosci. 23, 3364-3372. doi: 10.1523/jneurosci.23-08-03364.2003

Krzyżanowska, W., Pomierny, B., Filip, M., and Pera, J. (2014). Glutamate transporters in brain ischemia: to modulate or not? Acta Pharmacol. Sin. 35, 444-462. doi: 10.1038/aps.2014.1

Kudin, A. P., Augustynek, B., Lehmann, A. K., Kovacs, R., and Kunz, W. S. (2012). The contribution of thioredoxin-2 reductase and glutathione peroxidase to $\mathrm{H}_{2} \mathrm{O}_{2}$ detoxification of rat brain mitochondria. Biochim. Biophys. Acta 1817, 1901-1906. doi: 10.1016/j.bbabio.2012.02.023

Kugler, P., and Schleyer, V. (2004). Developmental expression of glutamate transporters and glutamate dehydrogenase in astrocytes of the postnatal rat hippocampus. Hippocampus 14, 975-985. doi: 10.1002/hipo.20015

Kumagai, A., Sasaki, T., Matsuoka, K., Abe, M., Tabata, T., Itoh, Y., et al. (2019). Monitoring of glutamate-induced excitotoxicity by mitochondrial oxygen consumption. Synapse 73:e22067. doi: 10.1002/syn.22067

Lai, T. W., Zhang, S., and Wang, Y. T. (2014). Excitotoxicity and stroke: identifying novel targets for neuroprotection. Prog. Neurobiol. 115, 157-188. doi: 10.1016/j. pneurobio.2013.11.006

Lalo, U., Palygin, O., Verkhratsky, A., Grant, S. G., and Pankratov, Y. (2016). ATP from synaptic terminals and astrocytes regulates NMDA receptors and synaptic plasticity through PSD-95 multi-protein complex. Sci. Rep. 6:33609. doi: 10.1038/srep33609

Lalo, U., Pankratov, Y., Kirchhoff, F., North, R. A., and Verkhratsky, A. (2006). NMDA receptors mediate neuron-to-glia signaling in mouse cortical astrocytes. J. Neurosci. 26, 2673-2683. doi: 10.1523/jneurosci.468905.2006

Lazarou, M., Sliter, D. A., Kane, L. A., Sarraf, S. A., Wang, C., Burman, J. L., et al. (2015). The ubiquitin kinase PINK1 recruits autophagy receptors to induce mitophagy. Nature 524, 309-314. doi: 10.1038/nature14893

Lee, J. M., Calkins, M. J., Chan, K., Kan, Y. W., and Johnson, J. A. (2003). Identification of the NF-E2-related factor-2-dependent genes conferring protection against oxidative stress in primary cortical astrocytes using oligonucleotide microarray analysis. J. Biol. Chem. 278, 12029-12038. doi: 10.1074/jbc.m211558200

Lee, S. Y., and Kim, J. H. (2015). Mechanisms underlying presynaptic $\mathrm{Ca}^{2+}$ transient and vesicular glutamate release at a CNS nerve terminal during in vitro ischaemia. J. Physiol. 593, 2793-2806. doi: 10.1113/jp270060

Lehre, K. P., and Danbolt, N. C. (1998). The number of glutamate transporter subtype molecules at glutamatergic synapses: chemical and stereological quantification in young adult rat brain. J. Neurosci. 18, 8751-8757. doi: 10.1523/jneurosci.18-21-08751.1998

Lehre, K. P., Davanger, S., and Danbolt, N. C. (1997). Localization of the glutamate transporter protein GLAST in rat retina. Brain Res. 744, 129-137. doi: 10.1016/s0006-8993(96)01022-0

Lewis, D. K., Thomas, K. T., Selvamani, A., and Sohrabji, F. (2012). Agerelated severity of focal ischemia in female rats is associated with impaired astrocyte function. Neurobiol. Aging 33, 1123.e1-1123.e16. doi: 10.1016/j. neurobiolaging.2011.11.007

Li, C., Guan, T., Chen, X., Li, W., Cai, Q., Niu, J., et al. (2013). BNIP3 mediates pre-myelinating oligodendrocyte cell death in hypoxia and ischemia. $J$. Neurochem. 127, 426-433. doi: 10.1111/jnc.12314

Li, S., Mealing, G. A., Morley, P., and Stys, P. K. (1999). Novel injury mechanism in anoxia and trauma of spinal cord white matter: glutamate release via reverse $\mathrm{Na}^{+}$-dependent glutamate transport. J. Neurosci. 19:RC16. doi: 10.1523/jneurosci.19-14-j0002.1999 
Li, S., and Stys, P. K. (2000). Mechanisms of ionotropic glutamate receptormediated excitotoxicity in isolated spinal cord white matter. J. Neurosci. 20, 1190-1198. doi: 10.1523/jneurosci.20-03-01190.2000

Li, X., Zhang, W., Xiao, M., Wang, F., Zhou, P., Yang, J., et al. (2019). MicroRNA146b-5p protects oligodendrocyte precursor cells from oxygen/glucose deprivation-induced injury through regulating Keap1/Nrf2 signaling via targeting bromodomain-containing protein 4. Biochem. Biophys. Res. Commun. 513, 875-882. doi: 10.1016/j.bbrc.2019.04.045

Li, K., Zhou, H., Zhan, L., Shi, Z., Sun, W., Liu, D., et al. (2018). Hypoxic preconditioning maintains GLT-1 against transient global cerebral ischemia through upregulating $\mathrm{Cx} 43$ and inhibiting c-src. Front. Mol. Neurosci. 11:344. doi: 10.3389/fnmol.2018.00344

Lin, C. H., Chen, P. S., and Gean, P. W. (2008). Glutamate preconditioning prevents neuronal death induced by combined oxygen-glucose deprivation in cultured cortical neurons. Eur. J. Pharmacol. 589, 85-93. doi: 10.1016/j.ejphar. 2008.05.047

Linying, Z., Wei, W., Minxia, W., Wenmin, Z., and Liangcheng, Z. (2014). Neuroprotective effects of neuregulin-1 $\beta$ on oligodendrocyte type 2 astrocyte progenitors following oxygen and glucose deprivation. Pediatr. Neurol. 50, 357-362. doi: 10.1016/j.pediatrneurol.2013.12.007

Lipton, S. A., and Rosenberg, P. A. (1994). Excitatory amino acids as a final common pathway for neurologic disorders. N. Engl. J. Med. 330, 613-622. doi: 10.1056/nejm199403033300907

Liu, F., Lu, J., Manaenko, A., Tang, J., and Hu, Q. (2018). Mitochondria in ischemic stroke: new insight and implications. Aging Dis. 9, 924-937. doi: 10.14336/ad. 2017.1126

Liu, X. B., Shen, Y., Plane, J. M., and Deng, W. (2013). Vulnerability of premyelinating oligodendrocytes to white-matter damage in neonatal brain injury. Neurosci. Bull. 29, 229-238. doi: 10.1007/s12264-013-1311-5

Liu, H. T., Tashmukhamedov, B. A., Inoue, H., Okada, Y., and Sabirov, R. Z. (2006). Roles of two types of anion channels in glutamate release from mouse astrocytes under ischemic or osmotic stress. Cryobiology 54, 343-357. doi: $10.1002 /$ glia. 20400

López-Redondo, F., Nakajima, K., Honda, S., and Kohsaka, S. (2000). Glutamate transporter GLT-1 is highly expressed in activated microglia following facial nerve axotomy. Mol. Brain Res. 76, 429-435. doi: 10.1016/s0169$328 \mathrm{x}(00) 00022-\mathrm{x}$

Luoma, J. I., Kelley, B. G., and Mermelstein, P. G. (2011). Progesterone inhibition of voltage-gated calcium channels is a potential neuroprotective mechanism against excitotoxicity. Steroids 76, 845-855. doi: 10.1016/j.steroids.2011.02.013

Lyons, S. A., and Kettenmann, H. (1998). Oligodendrocytes and microglia are selectively vulnerable to combined hypoxia and hypoglycemia injury in vitro. J. Cereb. Blood Flow Metab. 18, 521-530. doi: 10.1097/00004647-19980500000007

Ma, D., Feng, L., Cheng, Y., Xin, M., You, J., Yin, X., et al. (2018). Astrocytic gap junction inhibition by carbenoxolone enhances the protective effects of ischemic preconditioning following cerebral ischemia. J. Neuroinflammation 15:198. doi: 10.1186/s12974-018-1230-5

MacAulay, N., Gether, U., Klaerke, D. A., and Zeuthen, T. (2001). Water transport by the human $\mathrm{Na}^{+}$-coupled glutamate cotransporter expressed in Xenopus oocytes. J. Physiol. 530, 367-378. doi: 10.1111/j.1469-7793.2001.0367k.x

Manley, G. T., Fujimura, M., Ma, T., Noshita, N., Filiz, F., Bollen, A. W., et al. (2000). Aquaporin-4 deletion in mice reduces brain edema after acute water intoxication and ischemic stroke. Nat. Med. 6, 159-163. doi: 10.1038/72256

Marini, C., Totaro, R., and Carolei, A. (1999). Long-term prognosis of cerebral ischemia in young adults. National Research Council Study Group on Stroke in the Young. Stroke 30, 2320-2325. doi: 10.1161/01.str.30.11.2320

Mark, L. P., Prost, R. W., Ulmer, J. L., Smith, M. M., Daniels, D. L., Strottmann, J. M., et al. (2001). Pictorial review of glutamate excitotoxicity: fundamental concepts for neuroimaging. AJNR Am. J. Neuroradiol. 22, 1813-1824.

Marmiroli, P., and Cavaletti, G. (2012). The glutamatergic neurotransmission in the central nervous system. Curr. Med. Chem. 19, 1269-1276. doi: 10.2174/092986712799462711

Massie, A., Cnops, L., Smolders, I., McCullumsmith, R., Kooijman, R., Kwak, S., et al. (2008). High-affinity $\mathrm{Na}^{+} / \mathrm{K}^{+}$-dependent glutamate transporter EAAT4 is expressed throughout the rat fore- and midbrain. J. Comp. Neurol. 511, 155-172. doi: 10.1002/cne.21823
Matsumoto, M., Hatakeyama, T., Morimoto, K., and Yanagihara, T. (1990). Cerebral blood flow and neuronal damage during progressive cerebral ischemia in gerbils. Stroke 21, 1470-1477. doi: 10.1161/01.str.21.10.1470

Matthias, K., Kirchhoff, F., Seifert, G., Huttmann, K., Matyash, M., Kettenmann, H., et al. (2003). Segregated expression of AMPA-type glutamate receptors and glutamate transporters defines distinct astrocyte populations in the mouse hippocampus. J. Neurosci. 23, 1750-1758. doi: 10.1523/jneurosci. 23-05-01750.2003

Matute, C. (2008). P2X7 receptors in oligodendrocytes: a novel target for neuroprotection. Mol. Neurobiol. 38, 123-128. doi: 10.1007/s12035-008-8028-x

Matute, C. (2011). Glutamate and ATP signalling in white matter pathology. J. Anat. 219, 53-64. doi: 10.1111/j.1469-7580.2010.01339.x

Matute, C., Alberdi, E., Ibarretxe, G., and Sánchez-Gómez, M. V. (2002). Excitotoxicity in glial cells. Eur. J. Pharmacol. 447, 239-246. doi: 10.1016/s00142999(02)01847-2

Matute, C., Domercq, M., and Sanchez-Gomez, M. V. (2006). Glutamatemediated glial injury: mechanisms and clinical importance. Glia 53, 212-224. doi: 10.1002/glia.20275

Matute, C., and Ransom, B. R. (2012). Roles of white matter in central nervous system pathophysiologies. ASN Neuro 4:e00079. doi: 10.1042/an20110060

Matute, C., Torre, I., Perez-Cerda, F., Perez-Samartin, A., Alberdi, E., Etxebarria, E., et al. (2007). P2X(7) receptor blockade prevents ATP excitotoxicity in oligodendrocytes and ameliorates experimental autoimmune encephalomyelitis. J. Neurosci. 27, 9525-9533. doi: 10.1523/jneurosci.057907.2007

McDonald, J. W., Althomsons, S. P., Hyrc, K. L., Choi, D. W., and Goldberg, M. P. (1998). Oligodendrocytes from forebrain are highly vulnerable to AMPA/kainate receptor-mediated excitotoxicity. Nat. Med. 4, 291-297. doi: 10.1038/nm0398-291

Miao, B., Yin, X. H., Pei, D. S., Zhang, Q. G., and Zhang, G. Y. (2005). Neuroprotective effects of preconditioning ischemia on ischemic brain injury through down-regulating activation of JNK1/2 via N-methyl-Daspartate receptor-mediated Akt1 activation. J. Biol. Chem. 280, 21693-21699. doi: 10.1074/jbc.m500003200

Micu, I., Jiang, Q., Coderre, E., Ridsdale, A., Zhang, L., Woulfe, J., et al. (2006). NMDA receptors mediate calcium accumulation in myelin during chemical ischaemia. Nature 439, 988-992. doi: 10.1038/nature04474

Micu, I., Ridsdale, A., Zhang, L., Woulfe, J., McClintock, J., Brantner, C. A., et al. (2007). Real-time measurement of free $\mathrm{Ca}^{2+}$ changes in CNS myelin by two-photon microscopy. Nat. Med. 13, 874-879. doi: 10.1038/nm1568

Mifsud, G., Zammit, C., Muscat, R., Di Giovanni, G., and Valentino, M. (2014). Oligodendrocyte pathophysiology and treatment strategies in cerebral ischemia. CNS Neurosci. Ther. 20, 603-612. doi: 10.1111/cns.12263

Milewski, K., Bogacinska-Karas, M., Hilgier, W., Albrecht, J., and Zielinska, M. (2019). TNF $\alpha$ increases STAT3-mediated expression of glutaminase isoform KGA in cultured rat astrocytes. Cytokine 123:154774. doi: 10.1016/j.cyto.2019. 154774

Min, K. J., Yang, M. S., Kim, S. U., Jou, I., and Joe, E. H. (2006). Astrocytes induce hemeoxygenase-1 expression in microglia: a feasible mechanism for preventing excessive brain inflammation. J. Neurosci. 26, 1880-1887. doi: 10.1523/jneurosci.3696-05.2006

Mölders, A., Koch, A., Menke, R., and Klocker, N. (2018). Heterogeneity of the astrocytic AMPA-receptor transcriptome. Glia 66, 2604-2616. doi: $10.1002 /$ glia.23514

Mongin, A. A. (2016). Volume-regulated anion channel-a frenemy within the brain. Pflugers Arch. 468, 421-441. doi: 10.1007/s00424-015-1765-6

Montana, V., Ni, Y., Sunjara, V., Hua, X., and Parpura, V. (2004). Vesicular glutamate transporter-dependent glutamate release from astrocytes. J. Neurosci. 24, 2633-2642. doi: 10.1523/jneurosci.3770-03.2004

Montero, T. D., and Orellana, J. A. (2015). Hemichannels: new pathways for gliotransmitter release. Neuroscience 286, 45-59. doi: 10.1016/j.neuroscience. 2014.11.048

Moretto, M. B., Arteni, N. S., Lavinsky, D., Netto, C. A., Rocha, J. B., Souza, D. O., et al. (2005). Hypoxic-ischemic insult decreases glutamate uptake by hippocampal slices from neonatal rats: prevention by guanosine. Exp. Neurol. 195, 400-406. doi: 10.1016/j.expneurol.2005.06.005

Mori, T., Tateishi, N., Kagamiishi, Y., Shimoda, T., Satoh, S., Ono, S., et al. (2004). Attenuation of a delayed increase in the extracellular glutamate level in the 
peri-infarct area following focal cerebral ischemia by a novel agent ONO-2506. Neurochem. Int. 45, 381-387. doi: 10.1016/j.neuint.2003.06.001

Morioka, N., Abdin, M. J., Kitayama, T., Morita, K., Nakata, Y., and Dohi, T. (2008). P2X(7) receptor stimulation in primary cultures of rat spinal microglia induces downregulation of the activity for glutamate transport. Glia 56, 528-538. doi: 10.1002/glia.20634

Morita, M., Saruta, C., Kozuka, N., Okubo, Y., Itakura, M., Takahashi, M., et al. (2007). Dual regulation of astrocyte gap junction hemichannels by growth factors and a pro-inflammatory cytokine via the mitogen-activated protein kinase cascade. Glia 55, 508-515. doi: 10.1002/glia.20471

Murugan, M., Sivakumar, V., Lu, J., Ling, E. A., and Kaur, C. (2011). Expression of N-methyl D-aspartate receptor subunits in amoeboid microglia mediates production of nitric oxide via NF-kB signaling pathway and oligodendrocyte cell death in hypoxic postnatal rats. Glia 59, 521-539. doi: 10.1002/glia.21121

Nadarajan, V., Perry, R. J., Johnson, J., and Werring, D. J. (2014). Transient ischaemic attacks: mimics and chameleons. Pract. Neurol. 14, 23-31. doi: 10.1136/practneurol-2013-000782

Nedergaard, M., Takano, T., and Hansen, A. J. (2002). Beyond the role of glutamate as a neurotransmitter. Nat. Rev. Neurosci. 3, 748-755. doi: $10.1038 / \mathrm{nrn} 916$

Ni, Y., and Parpura, V. (2009). Dual regulation of $\mathrm{Ca}^{2+}$-dependent glutamate release from astrocytes: vesicular glutamate transporters and cytosolic glutamate levels. Glia 57, 1296-1305. doi: 10.1002/glia.20849

Niizuma, K., Yoshioka, H., Chen, H., Kim, G. S., Jung, J. E., Katsu, M., et al. (2010). Mitochondrial and apoptotic neuronal death signaling pathways in cerebral ischemia. Biochim. Biophys. Acta 1802, 92-99. doi: 10.1016/j.bbadis.2009. 09.002

Noda, M., Nakanishi, H., and Akaike, N. (1999). Glutamate release from microglia via glutamate transporter is enhanced by amyloid- $\beta$ peptide. Neuroscience 92 , 1465-1474. doi: 10.1016/s0306-4522(99)00036-6

Noda, M., Nakanishi, H., Nabekura, J., and Akaike, N. (2000). AMPA-kainate subtypes of glutamate receptor in rat cerebral microglia. J. Neurosci. 20, 251-258. doi: 10.1523/jneurosci.20-01-00251.2000

North, R. A. (2002). Molecular physiology of P2X receptors. Physiol. Rev. 82, 1013-1067. doi: 10.1152/physrev.00015.2002

O’Kane, R. L., Martinez-Lopez, I., DeJoseph, M. R., Vina, J. R., and Hawkins, R. A. (1999). $\mathrm{Na}^{+}$-dependent glutamate transporters (EAAT1, EAAT2 and EAAT3) of the blood-brain barrier. A mechanism for glutamate removal. J. Biol. Chem. 274, 31891-31895. doi: 10.1074/jbc.274.45.31891

Oliveira-Ferreira, A. I., Major, S., Przesdzing, I., Kang, E. J., and Dreier, J. P. (2019). Spreading depolarizations in the rat endothelin-1 model of focal cerebellar ischemia. J. Cereb. Blood Flow Metab. doi: 10.1177/0271678x19861604 [Epub ahead of print].

Olney, J. W. (1971). Glutamate-induced neuronal necrosis in the infant mouse hypothalamus. An electron microscopic study. J. Neuropathol. Exp. Neurol. 30, 75-90. doi: 10.1097/00005072-197101000-00008

Onténiente, B., Couriaud, C., Braudeau, J., Benchoua, A., and Guégan, C. (2003). The mechanisms of cell death in focal cerebral ischemia highlight neuroprotective perspectives by anti-caspase therapy. Biochem. Pharmacol. 66, 1643-1649. doi: 10.1016/s0006-2952(03)00538-0

Orlando, M., Lignani, G., Maragliano, L., Fassio, A., Onofri, F., Baldelli, P., et al. (2014). Functional role of ATP binding to synapsin I in synaptic vesicle trafficking and release dynamics. J. Neurosci. 34, 14752-14768. doi: 10.1523/jneurosci.1093-14.2014

Orrenius, S., Zhivotovsky, B., and Nicotera, P. (2003). Regulation of cell death: the calcium-apoptosis link. Nat. Rev. Mol. Cell Biol. 4, 552-565. doi: 10.1038/nrm1150

Osei-Owusu, J., Yang, J., Vitery, M. D. C., and Qiu, Z. (2018). Molecular biology and physiology of volume-regulated anion channel (VRAC). Curr. Top. Membr. 81, 177-203. doi: 10.1016/bs.ctm.2018.07.005

Ouyang, Y. B., Xu, L., Lu, Y., Sun, X., Yue, S., Xiong, X. X., et al. (2013). Astrocyte-enriched miR-29a targets PUMA and reduces neuronal vulnerability to forebrain ischemia. Glia 61, 1784-1794. doi: 10.1002/glia.22556

Pachernegg, S., Strutz-Seebohm, N., and Hollmann, M. (2012). GluN3 subunitcontaining NMDA receptors: not just one-trick ponies. Trends Neurosci. 35, 240-249. doi: 10.1016/j.tins.2011.11.010

Page, K. J., and Everitt, B. J. (1995). The distribution of neurons coexpressing immunoreactivity to AMPA-sensitive glutamate receptor subtypes (GluR1-4) and nerve growth factor receptor in the rat basal forebrain. Eur. J. Neurosci. 7, 1022-1033. doi: 10.1111/j.1460-9568.1995.tb01090.x

Pajarillo, E., Rizor, A., Lee, J., Aschner, M., and Lee, E. (2019). The role of astrocytic glutamate transporters GLT-1 and GLAST in neurological disorders: potential targets for neurotherapeutics. Neuropharmacology 161:107559. doi: 10.1016/j. neuropharm.2019.03.002

Palygin, O., Lalo, U., and Pankratov, Y. (2011). Distinct pharmacological and functional properties of NMDA receptors in mouse cortical astrocytes. $\mathrm{Br}$. J. Pharmacol. 163, 1755-1766. doi: 10.1111/j.1476-5381.2011.01374.x

Pang, Y., Campbell, L., Zheng, B., Fan, L., Cai, Z., and Rhodes, P. (2010). Lipopolysaccharide-activated microglia induce death of oligodendrocyte progenitor cells and impede their development. Neuroscience 166, 464-475. doi: 10.1016/j.neuroscience.2009.12.040

Panickar, K. S., Qin, B., and Anderson, R. A. (2015). Ischemia-induced endothelial cell swelling and mitochondrial dysfunction are attenuated by cinnamtannin D1, green tea extract and resveratrol in vitro. Nutr. Neurosci. 18, 297-306. doi: 10.1179/1476830514y.0000000127

Papazian, I., Kyrargyri, V., Evangelidou, M., Voulgari-Kokota, A., and Probert, L. (2018). Mesenchymal stem cell protection of neurons against glutamate excitotoxicity involves reduction of NMDA-triggered calcium responses and surface glurl and is partly mediated by TNF. Int. J. Mol. Sci. 19:E651. doi: 10.3390/ijms19030651

Park, E., Bell, J. D., and Baker, A. J. (2008). Traumatic brain injury: can the consequences be stopped? CMAJ 178, 1163-1170. doi: 10.1503/cmaj.080282

Pasantes-Morales, H., and Vázquez-Juarez, E. (2012). Transporters and channels in cytotoxic astrocyte swelling. Neurochem. Res. 37, 2379-2387. doi: 10.1007/s11064-012-0777-2

Pedata, F., Dettori, I., Coppi, E., Melani, A., Fusco, I., Corradetti, R., et al. (2016). Purinergic signalling in brain ischemia. Neuropharmacology 104, 105-130. doi: 10.1016/j.neuropharm.2015.11.007

Persson, M., and Rönnbäck, L. (2012). Microglial self-defence mediated through GLT-1 and glutathione. Amino Acids 42, 207-219. doi: 10.1007/s00726-0110865-7

Petr, G. T., Sun, Y., Frederick, N. M., Zhou, Y., Dhamne, S. C., Hameed, M. Q., et al. (2015). Conditional deletion of the glutamate transporter GLT-1 reveals that astrocytic GLT-1 protects against fatal epilepsy while neuronal GLT-1 contributes significantly to glutamate uptake into synaptosomes. J. Neurosci. 35, 5187-5201. doi: 10.1523/jneurosci.4255-14.2015

Pforte, C., Henrich-Noack, P., Baldauf, K., and Reymann, K. G. (2005). Increase in proliferation and gliogenesis but decrease of early neurogenesis in the rat forebrain shortly after transient global ischemia. Neuroscience 136, 1133-1146. doi: 10.1016/j.neuroscience.2005.08.043

Piccolini, V. M., Bottone, M. G., Bottiroli, G., De Pascali, S. A., Fanizzi, F. P., and Bernocchi, G. (2013). Platinum drugs and neurotoxicity: effects on intracellular calcium homeostasis. Cell Biol. Toxicol. 29, 339-353. doi: 10.1007/s10565-0139252-3

Pignataro, G., Gala, R., Cuomo, O., Tortiglione, A., Giaccio, L., Castaldo, P., et al. (2004). Two sodium/calcium exchanger gene products, NCX1 and NCX3, play a major role in the development of permanent focal cerebral ischemia. Stroke 35, 2566-2570. doi: 10.1161/01.str.0000143730.29964.93

Pin, J. P., and Duvoisin, R. (1995). The metabotropic glutamate receptors: structure and functions. Neuropharmacology 34, 1-26. doi: 10.1016/00283908(94)00129-g

Pinky, N. F., Wilkie, C. M., Barnes, J. R., and Parsons, M. P. (2018). Regionand activity-dependent regulation of extracellular glutamate. J. Neurosci. 38, 5351-5366. doi: 10.1523/JNEUROSCI.3213-17.2018

Pivonkova, H., and Anderova, M. (2017). Altered homeostatic functions in reactive astrocytes and their potential as a therapeutic target after brain ischemic injury. Curr. Pharm. Des. 23, 5056-5074. doi: 10.2174/1381612823666170710161858

Pivonkova, H., Benesova, J., Butenko, O., Chvatal, A., and Anderova, M. (2010). Impact of global cerebral ischemia on $\mathrm{K}^{+}$channel expression and membrane properties of glial cells in the rat hippocampus. Neurochem. Int. 57, 783-794. doi: 10.1016/j.neuint.2010.08.016

Pivovarova, N. B., Nguyen, H. V., Winters, C. A., Brantner, C. A., Smith, C. L., and Andrews, S. B. (2004). Excitotoxic calcium overload in a subpopulation of mitochondria triggers delayed death in hippocampal neurons. J. Neurosci. 24, 5611-5622. doi: 10.1523/jneurosci.0531-04.2004 
Pocock, J. M., and Kettenmann, H. (2007). Neurotransmitter receptors on microglia. Trends Neurosci. 30, 527-535. doi: 10.1016/j.tins.2007.07.007

Pregnolato, S., Chakkarapani, E., Isles, A. R., and Luyt, K. (2019). Glutamate transport and preterm brain injury. Front. Physiol. 10:417. doi: 10.3389/fphys. 2019.00417

Price, C. J., Karayannis, T., Pal, B. Z., and Capogna, M. (2005). Group II and III mGluRs-mediated presynaptic inhibition of EPSCs recorded from hippocampal interneurons of CA1 stratum lacunosum moleculare. Neuropharmacology 49, 45-56. doi: 10.1016/j.neuropharm.2005.05.009

Puig, B., Brenna, S., and Magnus, T. (2018). Molecular communication of a dying neuron in stroke. Int. J. Mol. Sci. 19:E2834. doi: 10.3390/ijms19092834

Radak, D., Katsiki, N., Resanovic, I., Jovanovic, A., SudarMilovanovic, E., Zafirovic, S., et al. (2017). Apoptosis and acute brain ischemia in ischemic stroke. Curr. Vasc. Pharmacol. 15, 115-122. doi: $10.2174 / 1570161115666161104095522$

Rakers, C., and Petzold, G. C. (2017). Astrocytic calcium release mediates peri-infarct depolarizations in a rodent stroke model. J. Clin. Invest. 127, 511-516. doi: 10.1172/jci89354

Rama, R., and García, J. C. (2016). "Excitotoxicity and oxidative stress in acute stroke," in Ischemic Stroke-Updates, ed. B. Schaller (London: InTech), 17-42.

Ransom, B. R., and Baltan, S. B. (2009). Axons get excited to death. Ann. Neurol. 65, 120-121. doi: 10.1002/ana.21659

Rao, V. L., Bowen, K. K., and Dempsey, R. J. (2001). Transient focal cerebral ischemia down-regulates glutamate transporters GLT-1 and EAAC1 expression in rat brain. Neurochem. Res. 26, 497-502. doi: 10.1023/a:10109567 11295

Rauen, T., Rothstein, J. D., and Wässle, H. (1996). Differential expression of three glutamate transporter subtypes in the rat retina. Cell Tissue Res. 286, 325-336. doi: $10.1007 /$ s004410050702

Rebai, O., and Amri, M. (2018). Chlorogenic acid prevents AMPA-mediated excitotoxicity in optic nerve oligodendrocytes through a PKC and caspasedependent pathways. Neurotox. Res. 34, 559-573. doi: 10.1007/s12640-0189911-5

Ribeiro, F. M., Paquet, M., Cregan, S. P., and Ferguson, S. S. (2010). Group I metabotropic glutamate receptor signalling and its implication in neurological disease. CNS Neurol. Disord. Drug Targets 9, 574-595. doi: $10.2174 / 187152710793361612$

Riddle, A., Luo, N. L., Manese, M., Beardsley, D. J., Green, L., Rorvik, D. A., et al. (2006). Spatial heterogeneity in oligodendrocyte lineage maturation and not cerebral blood flow predicts fetal ovine periventricular white matter injury. J. Neurosci. 26, 3045-3055. doi: 10.1523/jneurosci.5200-05.2006

Romera, C., Hurtado, O., Mallolas, J., Pereira, M. P., Morales, J. R., Romera, A., et al. (2007). Ischemic preconditioning reveals that GLT1/EAAT2 glutamate transporter is a novel PPAR $\gamma$ target gene involved in neuroprotection. J. Cereb. Blood Flow Metab. 27, 1327-1338. doi: 10.1038/sj.jcbfm.9600438

Rossi, D. J., Brady, J. D., and Mohr, C. (2007). Astrocyte metabolism and signaling during brain ischemia. Nat. Neurosci. 10, 1377-1386. doi: 10.1038/nn2004

Rossi, D. J., Oshima, T., and Attwell, D. (2000). Glutamate release in severe brain ischaemia is mainly by reversed uptake. Nature 403, 316-321. doi: $10.1038 / 35002090$

Rothman, S. (1984). Synaptic release of excitatory amino acid neurotransmitter mediates anoxic neuronal death. J. Neurosci. 4, 1884-1891. doi: 10.1523/jneurosci.04-07-01884.1984

Rowley, N. M., Madsen, K. K., Schousboe, A., and Steve White, H. (2012). Glutamate and GABA synthesis, release, transport and metabolism as targets for seizure control. Neurochem. Int. 61, 546-558. doi: 10.1016/j.neuint.2012. 02.013

Ryoo, K., and Park, J. Y. (2016). Two-pore domain potassium channels in astrocytes. Exp. Neurobiol. 25, 222-232. doi: 10.5607/en.2016.25.5.222

Sakoh, M., Ostergaard, L., Rohl, L., Smith, D. F., Simonsen, C. Z., Sorensen, J. C., et al. (2000). Relationship between residual cerebral blood flow and oxygen metabolism as predictive of ischemic tissue viability: sequential multitracer positron emission tomography scanning of middle cerebral artery occlusion during the critical first 6 hours after stroke in pigs. J. Neurosurg. 93, 647-657. doi: $10.3171 /$ jns.2000.93.4.0647

Salter, M. G., and Fern, R. (2005). NMDA receptors are expressed in developing oligodendrocyte processes and mediate injury. Nature 438, 1167-1171. doi: $10.1038 /$ nature 04301
Sánchez-Gómez, M. V., Alberdi, E., Pèrez-Navarro, E., Alberch, J., and Matute, C. (2011). Bax and calpain mediate excitotoxic oligodendrocyte death induced by activation of both AMPA and kainate receptors. J. Neurosci. 31, 2996-3006. doi: 10.1523/jneurosci.5578-10.2011

Sanchez-Olea, R., Moran, J., Martinez, A., and Pasantes-Morales, H. (1993a). Volume-activated $\mathrm{Rb}+$ transport in astrocytes in culture. Am. J. Physiol. 264, C836-C842. doi: 10.1152/ajpcell.1993.264.4.c836

Sanchez-Olea, R., Pena, C., Moran, J., and Pasantes-Morales, H. (1993b). Inhibition of volume regulation and efflux of osmoregulatory amino acids by blockers of Cl- transport in cultured astrocytes. Neurosci. Lett. 156, 141-144. doi: 10.1016/0304-3940(93)90458-w

Sanganalmath, S. K., Gopal, P., Parker, J. R., Downs, R. K., Parker, J. C. Jr., and Dawn, B. (2017). Global cerebral ischemia due to circulatory arrest: insights into cellular pathophysiology and diagnostic modalities. Mol. Cell. Biochem. 426, 111-127. doi: 10.1007/s11010-016-2885-9

Sattler, R., Xiong, Z., Lu, W. Y., Hafner, M., MacDonald, J. F., and Tymianski, M. (1999). Specific coupling of NMDA receptor activation to nitric oxide neurotoxicity by PSD-95 protein. Science 284, 1845-1848. doi: 10.1126/science. 284.5421 .1845

Savtchouk, I., and Volterra, A. (2018). Gliotransmission: beyond black-and-white. J. Neurosci. 38, 14-25. doi: 10.1523/jneurosci.0017-17.2017

Schneider, G. H., Baethmann, A., and Kempski, O. (1992). Mechanisms of glial swelling induced by glutamate. Can. J. Physiol. Pharmacol. 70, S334-S343. doi: $10.1139 / \mathrm{y} 92-280$

Schober, A. L., Wilson, C. S., and Mongin, A. A. (2017). Molecular composition and heterogeneity of the LRRC8-containing swelling-activated osmolyte channels in primary rat astrocytes. J. Physiol. 595, 6939-6951. doi: 10.1113/jp275053

Schwarz, Y., Zhao, N., Kirchhoff, F., and Bruns, D. (2017). Astrocytes control synaptic strength by two distinct v-SNARE-dependent release pathways. Nat. Neurosci. 20, 1529-1539. doi: 10.1038/nn.4647

Segovia, K. N., McClure, M., Moravec, M., Luo, N. L., Wan, Y., Gong, X., et al. (2008). Arrested oligodendrocyte lineage maturation in chronic perinatal white matter injury. Ann. Neurol. 63, 520-530. doi: 10.1002/ana.21359

Serrano, A., Robitaille, R., and Lacaille, J. C. (2008). Differential NMDA-dependent activation of glial cells in mouse hippocampus. Glia 56, 1648-1663. doi: 10.1002/glia.20717

Seshadri, S., Beiser, A., Kelly-Hayes, M., Kase, C. S., Au, R., Kannel, W. B., et al. (2006). The lifetime risk of stroke: estimates from the Framingham Study. Stroke 37, 345-350. doi: 10.1161/01.str.0000199613.38911.b2

Seyama, T., Kamei, Y., Iriyama, T., Imada, S., Ichinose, M., Toshimitsu, M., et al. (2018). Pretreatment with magnesium sulfate attenuates white matter damage by preventing cell death of developing oligodendrocytes. J. Obstet. Gynaecol. Res. 44, 601-607. doi: 10.1111/jog.13568

Shashidharan, P., Huntley, G. W., Murray, J. M., Buku, A., Moran, T., Walsh, M. J., et al. (1997). Immunohistochemical localization of the neuronspecific glutamate transporter EAAC1 (EAAT3) in rat brain and spinal cord revealed by a novel monoclonal antibody. Brain Res. 773, 139-148. doi: 10.1016/s0006-8993(97)00921-9

Sheldon, A. L., and Robinson, M. B. (2007). The role of glutamate transporters in neurodegenerative diseases and potential opportunities for intervention. Neurochem. Int. 51, 333-355. doi: 10.1016/j.neuint.2007. 03.012

Shelton, M. K., and McCarthy, K. D. (1999). Mature hippocampal astrocytes exhibit functional metabotropic and ionotropic glutamate receptors in situ. Glia 26, 1-11. doi: 10.1002/(sici)1098-1136(199903)26:1<1::aid-glia1>3.0. co;2-z

Shibata, M., Hisahara, S., Hara, H., Yamawaki, T., Fukuuchi, Y., Yuan, J., et al. (2000). Caspases determine the vulnerability of oligodendrocytes in the ischemic brain. J. Clin. Invest. 106, 643-653. doi: 10.1172/jci10203

Shibata, T., Yamada, K., Watanabe, M., Ikenaka, K., Wada, K., Tanaka, K., et al. (1997). Glutamate transporter GLAST is expressed in the radial glia-astrocyte lineage of developing mouse spinal cord. J. Neurosci. 17, 9212-9219. doi: 10.1523/jneurosci.17-23-09212.1997

Shih, A. Y., Johnson, D. A., Wong, G., Kraft, A. D., Jiang, L., Erb, H., et al. (2003). Coordinate regulation of glutathione biosynthesis and release by Nrf2-expressing glia potently protects neurons from oxidative stress. J. Neurosci. 23, 3394-3406. doi: 10.1523/jneurosci.23-08-03394.2003 
Simard, J. M., Chen, M., Tarasov, K. V., Bhatta, S., Ivanova, S., Melnitchenko, L., et al. (2006). Newly expressed SUR1-regulated NC(Ca-ATP) channel mediates cerebral edema after ischemic stroke. Nat. Med. 12, 433-440. doi: $10.1038 / \mathrm{nm} 1390$

Simões, A. P., Silva, C. G., Marques, J. M., Pochmann, D., Porciuncula, L. O., Ferreira, S., et al. (2018). Glutamate-induced and NMDA receptor-mediated neurodegeneration entails P2Y1 receptor activation. Cell Death Dis. 9:297. doi: 10.1038/s41419-018-0351-1

Sivakumar, V., Ling, E. A., Lu, J., and Kaur, C. (2010). Role of glutamate and its receptors and insulin-like growth factors in hypoxia induced periventricular white matter injury. Glia 58, 507-523. doi: 10.1002/glia.20940

Socodato, R., Portugal, C. C., Rodrigues, A., Henriques, J., Rodrigues, C., Figueira, C., et al. (2018). Redox tuning of $\mathrm{Ca}^{2+}$ signaling in microglia drives glutamate release during hypoxia. Free Radic. Biol. Med. 118, 137-149. doi: 10.1016/j.freeradbiomed.2018.02.036

Somjen, G. G. (2001). Mechanisms of spreading depression and hypoxic spreading depression-like depolarization. Physiol. Rev. 81, 1065-1096. doi: 10.1152/physrev.2001.81.3.1065

Song, Y., Li, Z., He, T., Qu, M., Jiang, L., Li, W., et al. (2019). M2 microgliaderived exosomes protect the mouse brain from ischemia-reperfusion injury via exosomal miR-124. Theranostics 9, 2910-2923. doi: 10.7150/thno.30879

Soria, F. N., Pèrez-Samartin, A., Martin, A., Gona, K. B., Llop, J., Szczupak, B., et al. (2014). Extrasynaptic glutamate release through cystine/glutamate antiporter contributes to ischemic damage. J. Clin. Invest. 124, 3645-3655. doi: $10.1172 /$ jci71886

Soriano, F. X., Papadia, S., Hofmann, F., Hardingham, N. R., Bading, H., and Hardingham, G. E. (2006). Preconditioning doses of NMDA promote neuroprotection by enhancing neuronal excitability. J. Neurosci. 26, 4509-4518. doi: 10.1523/JNEUROSCI.0455-06.2006

Stellwagen, D., Beattie, E. C., Seo, J. Y., and Malenka, R. C. (2005). Differential regulation of AMPA receptor and GABA receptor trafficking by tumor necrosis factor- $\alpha$. J. Neurosci. 25, 3219-3228. doi: 10.1523/jneurosci.4486-04.2005

Stokum, J. A., Kurland, D. B., Gerzanich, V., and Simard, J. M. (2015). Mechanisms of astrocyte-mediated cerebral edema. Neurochem. Res. 40, 317-328. doi: 10.1007/s11064-014-1374-3

Stokum, J. A., Kwon, M. S., Woo, S. K., Tsymbalyuk, O., Vennekens, R., Gerzanich, V., et al. (2018). SUR1-TRPM4 and AQP4 form a heteromultimeric complex that amplifies ion/water osmotic coupling and drives astrocyte swelling. Glia 66, 108-125. doi: 10.1002/glia.23231

Strong, A. J., Anderson, P. J., Watts, H. R., Virley, D. J., Lloyd, A., Irving, E. A., et al. (2007). Peri-infarct depolarizations lead to loss of perfusion in ischaemic gyrencephalic cerebral cortex. Brain 130, 995-1008. doi: 10.1093/brain/awl392

Su, G., Kintner, D. B., Flagella, M., Shull, G. E., and Sun, D. (2002a). Astrocytes from $\mathrm{Na}^{+}-\mathrm{K}^{+}-\mathrm{Cl}^{-}$cotransporter-null mice exhibit absence of swelling and decrease in EAA release. Am. J. Physiol. Cell Physiol. 282, C1147-C1160. doi: 10.1152/ajpcell.00538.2001

Su, G., Kintner, D. B., and Sun, D. (2002b). Contribution of $\mathrm{Na}^{+}-\mathrm{K}^{+}-\mathrm{Cl}^{-}$ cotransporter to high- $\left[\mathrm{K}^{+}\right]_{\mathrm{o}}$ - induced swelling and EAA release in astrocytes. Am. J. Physiol. Cell Physiol. 282, C1136-C1146. doi: 10.1152/ajpcell.00478.2001

Sugawara, T., Noshita, N., Lewen, A., Gasche, Y., Ferrand-Drake, M., Fujimura, M., et al. (2002). Overexpression of copper/zinc superoxide dismutase in transgenic rats protects vulnerable neurons against ischemic damage by blocking the mitochondrial pathway of caspase activation. J. Neurosci. 22, 209-217. doi: 10.1523/jneurosci.22-01-00 209.2002

Sun, X., Shih, A. Y., Johannssen, H. C., Erb, H., Li, P., and Murphy, T. H. (2006). Two-photon imaging of glutathione levels in intact brain indicates enhanced redox buffering in developing neurons and cells at the cerebrospinal fluid and blood-brain interface. J. Biol. Chem. 281, 17420-17431. doi: 10.1074/jbc. m601567200

Takano, T., Oberheim, N., Cotrina, M. L., and Nedergaard, M. (2009). Astrocytes and ischemic injury. Stroke 40, S8-S12. doi: 10.1161/STROKEAHA.108.533166

Takeuchi, H., Jin, S., Wang, J., Zhang, G., Kawanokuchi, J., Kuno, R., et al. (2006). Tumor necrosis factor- $\alpha$ induces neurotoxicity via glutamate release from hemichannels of activated microglia in an autocrine manner. J. Biol. Chem. 281, 21362-21368. doi: 10.1074/jbc.m600504200

Takumi, Y., Matsubara, A., Danbolt, N. C., Laake, J. H., Storm-Mathisen, J., Usami, S., et al. (1997). Discrete cellular and subcellular localization of glutamine synthetase and the glutamate transporter GLAST in the rat vestibular end organ. Neuroscience 79, 1137-1144. doi: 10.1016/s0306-4522(97)00025-0

Talos, D. M., Fishman, R. E., Park, H., Folkerth, R. D., Follett, P. L., Volpe, J. J., et al. (2006). Developmental regulation of $\alpha$-amino-3-hydroxy-5-methyl4-isoxazole-propionic acid receptor subunit expression in forebrain and relationship to regional susceptibility to hypoxic/ischemic injury: I. Rodent cerebral white matter and cortex. J. Comp. Neurol. 497, 42-60. doi: 10.1002/cne. 20972

Tanaka, H., Calderone, A., Jover, T., Grooms, S. Y., Yokota, H., Zukin, R. S., et al. (2002). Ischemic preconditioning acts upstream of GluR2 down-regulation to afford neuroprotection in the hippocampal CA1. Proc. Natl. Acad. Sci. U S A 99, 2362-2367. doi: 10.1073/pnas.261713299

Tannenberg, R. K., Scott, H. L., Westphalen, R. I., and Dodd, P. R. (2004). The identification and characterization of excitotoxic nerve-endings in Alzheimer disease. Curr. Alzheimer Res. 1, 11-25. doi: 10.2174/1567205043480591

Thompson, B. J., and Ronaldson, P. T. (2014). Drug delivery to the ischemic brain. Adv. Pharmacol. 71, 165-202. doi: 10.1016/bs.apha.2014.06.013

Thrane, A. S., Rangroo Thrane, V., and Nedergaard, M. (2014). Drowning stars: reassessing the role of astrocytes in brain edema. Trends Neurosci. 37, 620-628. doi: 10.1016/j.tins.2014.08.010

Thushara Vijayakumar, N., Sangwan, A., Sharma, B., Majid, A., and Rajanikant, G. K. (2016). Cerebral ischemic preconditioning: the road so far. Mol. Neurobiol. 53, 2579-2593. doi: 10.1007/s12035-015-9278-z

Torp, R., Hoover, F., Danbolt, N. C., Storm-Mathisen, J., and Ottersen, O. P. (1997). Differential distribution of the glutamate transporters GLT1 and rEAAC1 in rat cerebral cortex and thalamus: an in situ hybridization analysis. Anat. Embryol. 195, 317-326. doi: 10.1007/s004290050051

Torralba, D., Baixauli, F., and Sánchez-Madrid, F. (2016). Mitochondria know no boundaries: mechanisms and functions of intercellular mitochondrial transfer. Front. Cell Dev. Biol. 4:107. doi: 10.3389/fcell.2016.00107

Trendelenburg, G., Prass, K., Priller, J., Kapinya, K., Polley, A., Muselmann, C., et al. (2002). Serial analysis of gene expression identifies metallothionein-II as major neuroprotective gene in mouse focal cerebral ischemia. J. Neurosci. 22, 5879-5888. doi: 10.1523/jneurosci.22-14-05879.2002

Tretter, L., and Adam-Vizi, V. (2002). Glutamate release by an $\mathrm{Na}^{+}$load and oxidative stress in nerve terminals: relevance to ischemia/reperfusion. J. Neurochem. 83, 855-862. doi: 10.1046/j.1471-4159.2002.01191.x

Umebayashi, D., Natsume, A., Takeuchi, H., Hara, M., Nishimura, Y., Fukuyama, R., et al. (2014). Blockade of gap junction hemichannel protects secondary spinal cord injury from activated microglia-mediated glutamate exitoneurotoxicity. J. Neurotrauma 31, 1967-1974. doi: 10.1089/neu.2013.3223

Unal-Cevik, I., Kilinc, M., Can, A., Gursoy-Ozdemir, Y., and Dalkara, T. (2004). Apoptotic and necrotic death mechanisms are concomitantly activated in the same cell after cerebral ischemia. Stroke 35, 2189-2194. doi: 10.1161/01.str. 0000136149.81831.c5

Uzdensky, A. B. (2019). Apoptosis regulation in the penumbra after ischemic stroke: expression of pro- and antiapoptotic proteins. Apoptosis 24, 687-702. doi: 10.1007/s10495-019-01556-6

Van Damme, P., Bogaert, E., Dewil, M., Hersmus, N., Kiraly, D., Scheveneels, W., et al. (2007). Astrocytes regulate GluR2 expression in motor neurons and their vulnerability to excitotoxicity. Proc. Natl. Acad. Sci. U S A 104, 14825-14830. doi: 10.1073/pnas.0705046104

VanGilder, R. L., Huber, J. D., Rosen, C. L., and Barr, T. L. (2012). The transcriptome of cerebral ischemia. Brain Res. Bull. 88, 313-319. doi: 10.1016/j. brainresbull.2012.02.002

Verma, M., Wills, Z., and Chu, C. T. (2018). Excitatory dendritic mitochondrial calcium toxicity: implications for Parkinson's and other neurodegenerative diseases. Front. Neurosci. 12:523. doi: 10.3389/fnins.2018.00523

Vitarella, D., DiRisio, D. J., Kimelberg, H. K., and Aschner, M. (1994). Potassium and taurine release are highly correlated with regulatory volume decrease in neonatal primary rat astrocyte cultures. J. Neurochem. 63, 1143-1149. doi: 10.1046/j.1471-4159.1994.63031143.x

Volpe, J. J., Kinney, H. C., Jensen, F. E., and Rosenberg, P. A. (2011). The developing oligodendrocyte: key cellular target in brain injury in the premature infant. Int. J. Dev. Neurosci. 29, 423-440. doi: 10.1016/j.ijdevneu.2011.02.012

Volterra, A., Trotti, D., and Racagni, G. (1994). Glutamate uptake is inhibited by arachidonic acid and oxygen radicals via two distinct and additive mechanisms. Mol. Pharmacol. 46, 986-992. 
Voss, F. K., Ullrich, F., Munch, J., Lazarow, K., Lutter, D., Mah, N., et al. (2014). Identification of LRRC8 heteromers as an essential component of the volumeregulated anion channel VRAC. Science 344, 634-638. doi: 10.1126/science. 1252826

Wadiche, J. I., Amara, S. G., and Kavanaugh, M. P. (1995). Ion fluxes associated with excitatory amino acid transport. Neuron 15, 721-728. doi: 10.1016/08966273(95)90159-0

Waller, R., Murphy, M., Garwood, C. J., Jennings, L., Heath, P. R., Chambers, A., et al. (2018). Metallothionein-I/II expression associates with the astrocyte DNA damage response and not Alzheimer-type pathology in the aging brain. Glia 66, 2316-2323. doi: 10.1002/glia.23465

Wang, M., Song, J., Xiao, W., Yang, L., Yuan, J., Wang, W., et al. (2012). Changes in lipid-sensitive two-pore domain potassium channel TREK-1 expression and its involvement in astrogliosis following cerebral ischemia in rats. J. Mol. Neurosci. 46, 384-392. doi: 10.1007/s12031-011-9598-z

Warby, S. C., Doty, C. N., Graham, R. K., Carroll, J. B., Yang, Y. Z., Singaraja, R. R., et al. (2008). Activated caspase-6 and caspase-6-cleaved fragments of huntingtin specifically colocalize in the nucleus. Hum. Mol. Genet. 17, 2390-2404. doi: 10.1093/hmg/ddn139

Weller, M. L., Stone, I. M., Goss, A., Rau, T., Rova, C., and Poulsen, D. J. (2008). Selective overexpression of excitatory amino acid transporter 2 (EAAT2) in astrocytes enhances neuroprotection from moderate but not severe hypoxiaischemia. Neuroscience 155, 1204-1211. doi: 10.1016/j.neuroscience.2008. 05.059

Wetterling, F., Chatzikonstantinou, E., Tritschler, L., Meairs, S., Fatar, M., Schad, L. R., et al. (2016). Investigating potentially salvageable penumbra tissue in an in vivo model of transient ischemic stroke using sodium, diffusion, and perfusion magnetic resonance imaging. BMC Neurosci. 17:82. doi: 10.1186/s12868-016-0316-1

Wilson, C. S., and Mongin, A. A. (2018). Cell volume control in healthy brain and neuropathologies. Curr. Top. Membr. 81, 385-455. doi: 10.1016/bs.ctm.2018. 07.006

Wilson-Costello, D., Friedman, H., Minich, N., Siner, B., Taylor, G., Schluchter, M., et al. (2007). Improved neurodevelopmental outcomes for extremely low birth weight infants in 2000-2002. Pediatrics 119, 37-45. doi: 10.1542/peds.2006-1416

Winkler, E. A., Minter, D., Yue, J. K., and Manley, G. T. (2016). Cerebral edema in traumatic brain injury: pathophysiology and prospective therapeutic targets. Neurosurg. Clin. N. Am. 27, 473-488. doi: 10.1016/j.nec.2016.05.008

Woo, D. H., Han, K. S., Shim, J. W., Yoon, B. E., Kim, E., Bae, J. Y., et al. (2012). TREK-1 and Bestl channels mediate fast and slow glutamate release in astrocytes upon GPCR activation. Cell 151, 25-40. doi: 10.1016/j.cell.2012. 09.005

Wu, X., Liu, Y., Chen, X., Sun, Q., Tang, R., Wang, W., et al. (2013). Involvement of TREK-1 activity in astrocyte function and neuroprotection under simulated ischemia conditions. J. Mol. Neurosci. 49, 499-506. doi: 10.1007/s12031-0129875-5

Wu, X. M., Liu, Y., Qian, Z. M., Luo, Q. Q., and Ke, Y. (2016). CX3CL1/CX3CR1 axis plays a key role in ischemia-induced oligodendrocyte injury via p38MAPK signaling pathway. Mol. Neurobiol. 53, 4010-4018. doi: 10.1007/s12035-015-9339-3

Xiao, Y., Geng, F., Wang, G., Li, X., Zhu, J., and Zhu, W. (2018). Bone marrowderived mesenchymal stem cells-derived exosomes prevent oligodendrocyte apoptosis through exosomal miR-134 by targeting caspase-8. J. Cell. Biochem. doi: $10.1002 /$ jcb.27519 [Epub ahead of print].

Xin, W. J., Weng, H. R., and Dougherty, P. M. (2009). Plasticity in expression of the glutamate transporters GLT-1 and GLAST in spinal dorsal horn glial cells following partial sciatic nerve ligation. Mol. Pain 5:15. doi: 10.1186/1744-80 69-5-15

Yan, Z., Khadra, A., Li, S., Tomic, M., Sherman, A., and Stojilkovic, S. S. (2010). Experimental characterization and mathematical modeling of $\mathrm{P} 2 \mathrm{X} 7$ receptor channel gating. J. Neurosci. 30, 14213-14224. doi: 10.1523/jneurosci.239010.2010

Yang, J.-L., Mukda, S., and Chen, S.-D. (2018). Diverse roles of mitochondria in ischemic stroke. Redox Biol. 16, 263-275. doi: 10.1016/j.redox.2018. 03.002
Yang, J., Vitery, M. D. C., Chen, J., Osei-Owusu, J., Chu, J., and Qiu, Z. (2019). Glutamate-releasing SWELL1 channel in astrocytes modulates synaptic transmission and promotes brain damage in stroke. Neuron 102, 813.e6-827.e6. doi: 10.1016/j.neuron.2019.03.029

Yao, G. Y., Zhu, Q., Xia, J., Chen, F. J., Huang, M., Liu, J., et al. (2018). Ischemic postconditioning confers cerebroprotection by stabilizing VDACs after brain ischemia. Cell Death Dis. 9:1033. doi: 10.1038/s41419-018-1089-5

Yuan, F., and Wang, T. (1996). Glutamate-induced swelling of cultured astrocytes is mediated by metabotropic glutamate receptor. Sci. China C Life Sci. 39, 517-522.

Yung, L. M., Wei, Y., Qin, T., Wang, Y., Smith, C. D., and Waeber, C. (2012). Sphingosine kinase 2 mediates cerebral preconditioning and protects the mouse brain against ischemic injury. Stroke 43, 199-204. doi: 10.1161/strokeaha.111.626911

Zeng, W., Tong, Y., Li, H., Luo, R., and Mao, M. (2012). P2X7 receptor modulation of the viability of radial glial clone L2.3 cells during hypoxic-ischemic brain injury. Mol. Med. Rep. 5, 1357-1361. doi: 10.3892/mmr.2012.816

Zhang, H., Cao, H. J., Kimelberg, H. K., and Zhou, M. (2011). Volume regulated anion channel currents of rat hippocampal neurons and their contribution to oxygen-and-glucose deprivation induced neuronal death. PLoS One 6:e16803. doi: 10.1371/journal.pone.0016803

Zhang, L., Dong, L. Y., Li, Y. J., Hong, Z., and Wei, W. S. (2012). miR-21 represses FasL in microglia and protects against microglia-mediated neuronal cell death following hypoxia/ischemia. Glia 60, 1888-1895. doi: 10.1002/glia.22404

Zhang, M., Gong, J. X., Wang, J. L., Jiang, M. Y., Li, L., Hu, Y. Y., et al. (2017). p38 MAPK participates in the mediation of GLT-1 up-regulation during the induction of brain ischemic tolerance by cerebral ischemic preconditioning. Mol. Neurobiol. 54, 58-71. doi: 10.1007/s12035-015-9652-x

Zhang, L. N., Hao, L., Guo, Y. S., Wang, H. Y., Li, L. L., Liu, L. Z., et al. (2019). Are glutamate transporters neuroprotective or neurodegenerative during cerebral ischemia? J. Mol. Med. 97, 281-289. doi: 10.1007/s00109-019-01745-5

Zhang, M., Li, W. B., Geng, J. X., Li, Q. J., Sun, X. C., Xian, X. H., et al. (2007). The upregulation of glial glutamate transporter-1 participates in the induction of brain ischemic tolerance in rats. J. Cereb. Blood Flow Metab. 27, 1352-1368. doi: 10.1038/sj.jcbfm.9600441

Zhang, J. M., Wang, H. K., Ye, C. Q., Ge, W., Chen, Y., Jiang, Z. L., et al. (2003). ATP released by astrocytes mediates glutamatergic activity-dependent heterosynaptic suppression. Neuron 40, 971-982. doi: 10.1016/s08966273(03)00717-7

Zhang, J., Zhang, Y., Xing, S., Liang, Z., and Zeng, J. (2012). Secondary neurodegeneration in remote regions after focal cerebral infarction: a new target for stroke management? Stroke 43, 1700-1705. doi: 10.1161/STROKEAHA.111.632448

Zhao, W., Belayev, L., and Ginsberg, M. D. (1997). Transient middle cerebral artery occlusion by intraluminal suture: II. Neurological deficits and pixel-based correlation of histopathology with local blood flow and glucose utilization. J. Cereb. Blood Flow Metab. 17, 1281-1290. doi: 10.1097/00004647-19971200000003

Zhao, S. C., Ma, L. S., Chu, Z. H., Xu, H., Wu, W. Q., and Liu, F. (2017). Regulation of microglial activation in stroke. Acta Pharmacol. Sin. 38, 445-458. doi: 10.1038/aps.2016.162

Zhao, F., Qu, Y., Wang, H., Huang, L., Zhu, J., Li, S., et al. (2017). The effect of miR-30d on apoptosis and autophagy in cultured astrocytes under oxygenglucose deprivation. Brain Res. 1671, 67-76. doi: 10.1016/j.brainres.2017.06.011

Conflict of Interest: The authors declare that the research was conducted in the absence of any commercial or financial relationships that could be construed as a potential conflict of interest.

Copyright (c) 2020 Belov Kirdajova, Kriska, Tureckova and Anderova. This is an open-access article distributed under the terms of the Creative Commons Attribution License (CC BY). The use, distribution or reproduction in other forums is permitted, provided the original author(s) and the copyright owner(s) are credited and that the original publication in this journal is cited, in accordance with accepted academic practice. No use, distribution or reproduction is permitted which does not comply with these terms. 